Portland State University

PDXScholar

\title{
Development and Analysis of a Model for Change in the Workplace, Using Quasi-Experimentation with Computer Professionals in Northwestern Investor Owned Utilities
}

John Ronald Thompson

Portland State University

Follow this and additional works at: https://pdxscholar.library.pdx.edu/open_access_etds Let us know how access to this document benefits you.

\section{Recommended Citation}

Thompson, John Ronald, "Development and Analysis of a Model for Change in the Workplace, Using Quasi-Experimentation with Computer Professionals in Northwestern Investor Owned Utilities" (1991). Dissertations and Theses. Paper 1248.

https://doi.org/10.15760/etd.1247

This Dissertation is brought to you for free and open access. It has been accepted for inclusion in Dissertations and Theses by an authorized administrator of PDXScholar. Please contact us if we can make this document more accessible: pdxscholar@pdx.edu. 
AN ABSTRACT OF THE DISSERTATION OF John Ronald Thompson for the Doctor of Philosophy in systems science: Business Administration presented March 7, 1991.

Title: Development and Analysis of A Model for Change in the Workplace, Using Quasi-Experimentation with Computer Professionals in Northwestern Investor owned Utilities.

APPROVED BY THE MEMBERS OF THE DISSERTATION COMMITTEE:

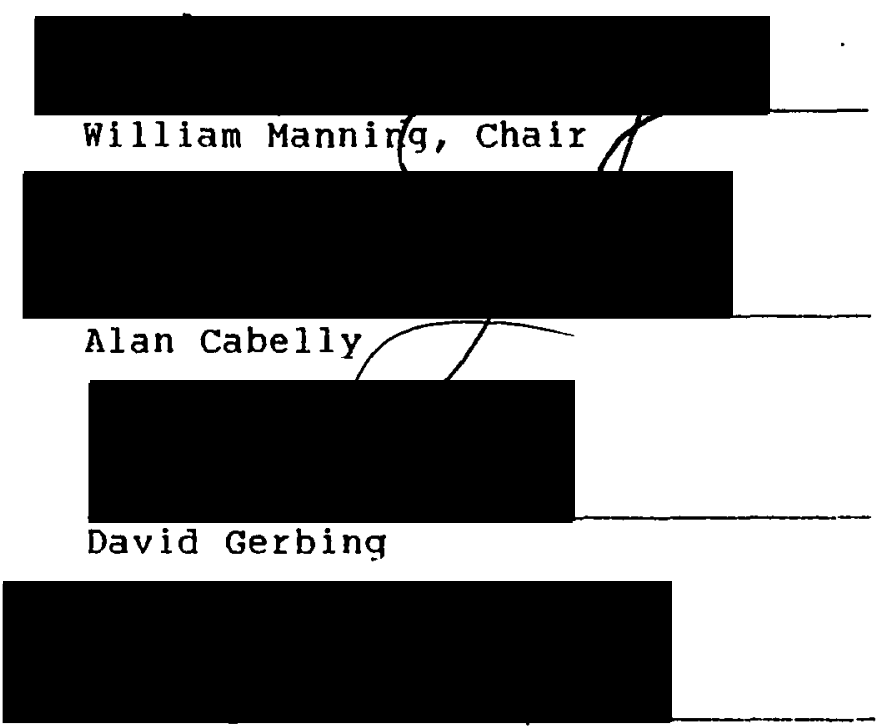

Kish Sharma

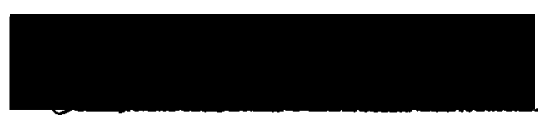

Loyde Hales

Computer professionals have been agents of change in many organizations. In some cases the role inadvertently 
became theirs as they were the ones at the vanquard of implementing the new information processing technoloqy in orqanizations. While in other cases they were the catalysts for change, to force new methods/procedures onto letharqic orqanizations. While introducing change on others in the organization and adapting to new technological changes themselves, the computer professionals have not: really had to face a siqnificant change in their status, power, or importance to the orqanization.

The introduction of the personal computer has brouqht about siqnificant change in the way the job of the computer protessional is perceived by many in the business world. While this change is personally affecting the way they do their job, there has not been a noticeable attempt by those manaqing computer professionals to deal with the human emotions enqendered by such a chanqe. Part of the reason for this lack of attention may be due to the lack of a model as to how computer professionals react to chanqe. Such a model would provide a system whereby it would be possible to recognize where efforts could be made to measure, predict, and modify situations so that a smooth transition can be made to the chanqe.

Toward this end a model was developed which presents a system as to how computer professionals react to chanqe. Ihis dissertation presents the model, surveys a population 
of computer professionals, and analyzes the model using data gathered from the population.

The data was qathered in the form of a self administered survey which was given to computer professionals working for six investor owned electric and gas utilities in the Northwestern United States. They answered questions on a scale of from one to five as to their emotions and perceptions about the introduction of personal computers into their organizations. These questions spanned the timeframe as the organizations migrated from the early beginnings of personal computer introduction, to a situation where the use of personal computers was widespread in the company. In the case of three of the companies the personal computer had not yet achieved widespread use at the time of the survey. The data gathered from the computer professionals was statistically analyzed to see if relationships exist between the model and the data.

Additionally, interesting demographic data was analyzed to see if certain other factors affected the computer professional's perception as to the impact of the personal computer on their quality of worklife. 


\title{
DEVELOPMENT AND ANALYSIS OF A MODEL FOR CHANGE IN THE WORKPLACE, USING QUASI-EXPERIMENTATION WITH COMPUTER PROFESSIONALS IN NORTHWESTERN INVESTOR OWNED UTILITIES
}

\author{
by \\ JOHN RONALD THOMPSON
}
A dissertation submitted in partial fulfillment of the requirements for the degree of

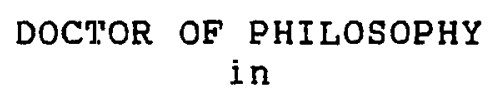

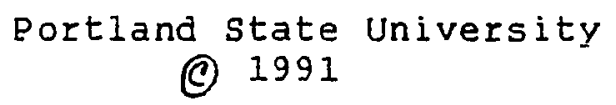


TO THE OFFICE OF GRADUATE STUDIES:

The members of the Committee approve the dissertation of John Ronald Thompson presented March 7, 1991.

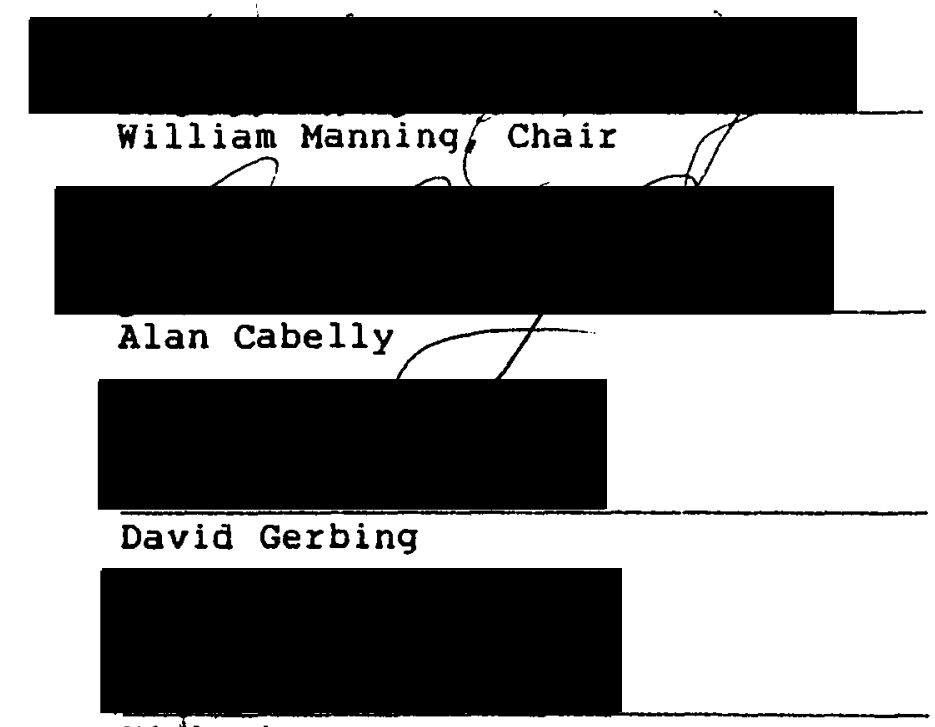

Kish Sharma

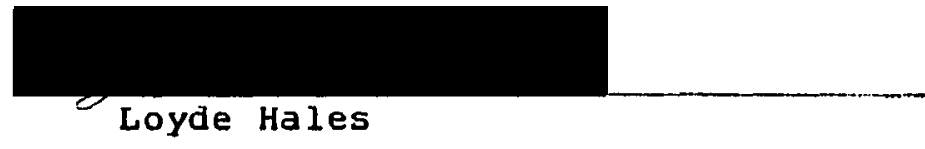

APPROVED :

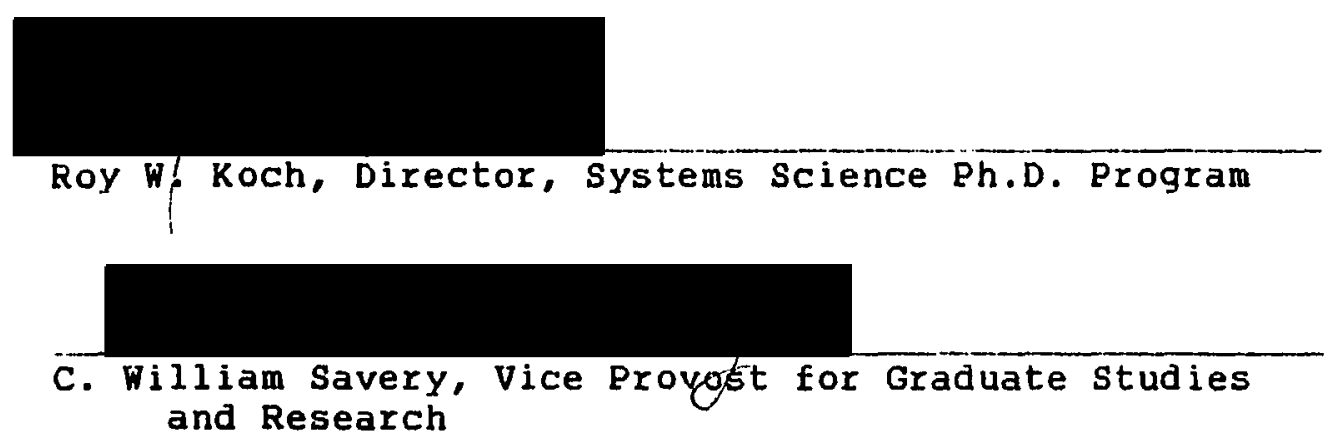


PREFACE

This dissertation is the end product of many years of work experience in the information systems field. It is my attempt at applying a systems science approach to the problem of people accepting change in the workplace, by developing and verifying a model as to how people move through various stages of appraisals and psychological responses when change is introduced into the workplace.

As a bright, eager youth of twenty-one, I entered the professional ranks of the workforce as a scientific programmer, after receiving my degree in mathematics. I had much the same attitude as Robert McNamara and his "Whiz Kids" regarding a scientific approach to problems. I believed that most problems could be solved using a logical, scientific approach, and that those people who tended to arrive at decisions with little effort at analysis were either too lazy or too ignorant to do the necessary work. I worked my way into management and in 1974 started managing an information systems department for a major company, and have since managed such departments for three different companies. As I progressed in my career, I began to encounter problems which defied logic, and it seemed all of them were people related problems. 
Eventualiy, I too gave up trying to analyze many people oriented problems and like many others resorted to hunches. I came to realize that most of these people related problems involved getting people to accept change in the workplace. I got better at using my hunches and intuition to handle people problems, but still found myself in lose/lose situations too often.

Frequently, good technical decisions would result in products which did not yield as high a level of return as was anticipated, nor did the execution of these decisions flow as smoothly as it seemed they should have. Much pondering of these types of situations seemed to always lead to people oriented problems, and Erequently it seemed the root cause was the degree of acceptance of change. I became more humanistic in my approach to problem solving and began to recognize the human element in problems.

The worst (for my career) types of situations I faced were the cases when my department would develop a new system. Naturally, we involved the end users of the system in the development and implementation process. Then, after many months of work, many good technical decisions having been made, many hours spent on communications, many dollars having been spent, and much effort and attention being expended, the new system is implemented. All too often, the first week of new system implementation, a high 
level manaqer or vice president would descend from their abode and enthusiastically ask the overworked and confused clerk in front of the video display terminal how he or she liked the new system. In spite of efforts at involvement, training, and familiarization to prepare the clerk for the new system, operating it in the crush and pressures of the real life work environment proved to be overwhelming, and the clerk blurted out something to the effect: "This new system is so confusing (complicated, hard to understand, difficult to work with, not user friendly - you can substitute any number of phrases in here), I wish we were doing things the old way." Then if I were lucky, I would receive an agitated phone call from the high level person and be told that my department had failed in providing what was needed, with the implication that I had personally failed and had wasted hundreds of thousands (or even millions) of dollars of the company's money. If I were unlucky, the high level person would not tell me directly but would go behind my back telling everyone who would listen the same story. A few months later I would go and visit that same clerk, and give them a "flinch test," by saying that the system did not seem to be reaping the benefits we had hoped for, and we were going to shut down the new system, and go back to the old way of doing business. Whereupon, the clerk would immediately defend 
the system, and say something to the effect that without the system there was no way the current workload could be met, and they could not do their job without the system. Somehow the people involved in the change had moved from non-acceptance to acceptance. I wondered how we could have done things differently so we could have avoided the non-acceptance phase, or at least have shortened the time duration leading to acceptance. Using a non-scientific sampling method, I determined for every system we installed that impacted a large number of people, we would always have some who readily embraced the new system, some who did not care whether we had a new system or not, and some who saw the new system as something bad. Those who saw the coming of a new system as something bad, sometimes rose to the occasion and became enthusiastic supporters of the system even before it was implemented, others took some time to finally accept the system, and even a very few seemed to never feel at ease with the system.

I sampled other work environments whenever I had the chance and asked people using video display devices how they liked the system when it was first installed, and what they thought of it now. I received the same sort of replies with the same breakout of assessments as I did at my workplace. For example, I asked a woman at a travel agency, a man behind the counter at an autowrecking yard, a 
teller at a bank, a women auditing me at the IRS, a man taking my order at sears, and employees at companies I visited. It was a universal problem, in as much as there were always a certain number of people who had trouble accepting the change, but eventually most of them had come to love the change, and could not imagine having to do the job the old way.

While taking a systems science class on information systems at Portland State University, Dr. George Lendaris presented us with a general model of an information system. His model represents a systems scientist's attempt to lay out the elements making up a complete information system and the relationships between the elements. His model was fairly simple, but was general enough in nature to be applicable to every type of information system we brought up in the class. As a term project in the class, I analyzed an information system which was the most poorly developed and implemented project I ever had the misfortune to be involved with in a company.

The system was developed by consultants who were experts in their field, ended up about two million dollars over budget, one year over schedule, missing some vital features which were in the original specifications, and was poorly received by the end users and my staff. Over the next two years my "maintenance programmers" spent their 
time creating the capabilities the system was supposed to have in the first place. In spite of the problems, the new system did perform better than what was being done before, so it was not considered a failure by management, but for those who lived through the experience it would be hard to call it a success.

For Dr. Lendaris's class I went back to the beginning of the project and applied his model to the system. I looked for the points at which critical relationships between the elements of the model had been overlooked, and I came up with what I believe would have been a better approach to the whole project. A large part of the problem was not recognizing the importance of the context, environment, and users of the new system. The consultants, being technical experts in their field, had used their technical expertise and had developed something along the lines of a system which was being successfully used by two other companies in the same business as ours. Yet at our company, the great technical solution presented did not result in a great system.

Since Dr. Lendaris had a model to use for analyzing information systems, then a model for how people might react to changes in the workplace would be useful for analyzing resistance to change. 
Toward this end I became interested in what had been done in the field of change analysis. I found that in spite of much research in the field of adjusting to change, there was not a good model which I found that had been verified through research. There was much in the way of empirical evidence as to what minimized resistance to change, and a lot of "armchair philosophizing" as to how people reacted to change, but I was unable to find anything researched which was along the lines of what I was seeking. I have put together from a synthesis of other researchers' work what I believe to be a model which shows the elements involved in people adjusting to change in the workplace, along with the relationships those elements exhibit among themselves. This model represents a system which can be used to analyze worker's adjusting to change. I have verified this model for a certain class of worker which I believe represents a worst case since they have never before had to adjust to such a major change in the workplace which could impact their status, role, pay grade, importance, or worklife. I likewise picked an industry which is noted for being resistant to change and having a history of stogy management. I feel if the model can be verified for this situation then it is very likely to be verifiable in almost all situations. 
I have come to recognize that even the best technical solutions, with great promises of benefits to be reaped, are no good if they are not accepted by the people who need to use them. 
TABLE OF CONTENTS

PAGE

PREFACE . . . . . . . . . . . . . . . . . . . $i i i$

LIST OF TABLES • . . . . . . . . . . . . . . . . . XV

LIST OF FIGURES . . . . . . . . . . . . . . . . . . . xVi

CHAPTER

I BACKGROUND AND INTRODUCTION . . . . . . . . 1

Introduction . . . . . . . . . . . . 1

Computer Technology Has Been a Center

of Rapid Change . . . . . . . . . . 1

Computer Professionals as Agents

of Change ............ 3

Computer Professionals Familiar With

Technological Change.. . . . . . 4

What Happens when Computer Professionals

Face Change in Their Jobs? . . . . 4

Job Related Stress . . . . . . . . 5

The Investor-owned Public Utility Business (Gas \& Electric Specifically) • . . 7

Gas \& Electric IOUs in the Northwestern United States . . . . . . . . 12

Rationale for a study . . . . . . . . 13

I I LITERATURE ABOUT CHANGE AND A MODEL FOR CHANGE 17 Introduction . . . . . . . . . 17

Literature and Statements Ebout Change 17

A Spectrum of Change Implementations . . 21 
Where the Change on Computer professionals Brought About by the Introduction of

PCs Fits in the spectrum.... . 25

The Chanqe Model . . . . . . . . 27

The Change Model is A System . . . . . 31

Statement of Analysis Postulates . . . . 33

III RESEARCH DESIGN AND METHODOLOGY . . . . . . 36

Introduction . . . . . . . . . . 36

The Environment and Research Subjects . . 36

Research Desiqn . . . . . . . . . . 39

Data Collection Method . . . . . . . 41

Orqanization of Data . . . . . . . . 42

Data Analysis Methodology . . . . . . 42

The Instrument . . . . . . . . . . . 44

Nature of the Instrument. . . . . . . 44

First Level of Appraisals (A) . . . 45

Second Level of Appraisals (B). . . 48

Third Level of Appraisals (C) . . . . 49

Demographic Data . . . . . . . . 53

The Completed Pilot Instrument . . 53

Results of the Pilot Instrument. . . 54

Further Field Testing . . . . . . 66

IV ANALYSIS AND CONCLUSIONS . . . . . . . . . 70

Introduction . . . . . . . . . . 70

Response Rate. . . . . . . . . . 70

Scale Reliability and Cronbach's Alpha . 72

Level A Analysis . . . . . . . . 73

Distribution of Responses . . . . . 73

Correlations of Responses . . . . . 81

Level B Analysis . . . . . . . 88

Level C Analysis . . . . . . . . . 91 
Correlations Consistent with the Model . 93 Demographic Data . . . . . . . . 94

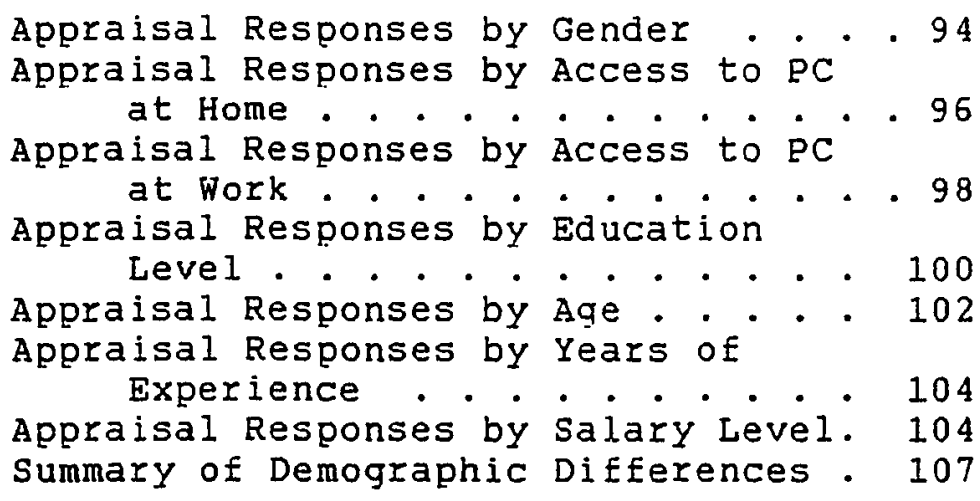


APPENDICES

A ORIGINAL SET OF SCALES AND ITEMS FROM

WHICH QUESTIONNAIRE WAS MADE . . 139

B PILOT QUESTIONNAIRE . . . . . . . . . . 154

C REVISED ITEMS FOR FINAL QUESTIONNAIRE • 164

D REVISED ITEMS FOR FINAL QUESTIONNAIRE

CROSS REFERENCED WITH THE NUMBERS

FOR THE ITEMS ON THE PILOT

INSTRUMENT . . . . . . . . . . . . 174

E FINAL QUESTIONNAIRE . . . . . . . . 181 
I Sources of Pilot Instrument scales and Items Level A. . . . . . . . . . . . 47

I Sources of Pilot Instrument scales and Items Level B.............. . . 50

II Sources of Pilot Instrument scales and Items Level C............... . 52

IV Results of Pilot Instrument - Level A. . . 61

$\mathrm{V}$ Results of Pilot Instrument - Level B . . . 63

VI Results of Pilot Instrument - Level C . . . 65

VII Response Rate Data . . . . . . . . 71

VIII Scales and Associated Cronbach's Alpha . . 74

IX Level A Distribution of Appraisals . . . . 77

X Scale Correlates for Level A . . . . . 83

XI Scale Correlates for Level A, for Companies

Still at Level A (Company one) . . . . 85

XI Scale Correlates for Level A, for Companies Still at Level B (Companies Two \& Three) . 86

XIII Scale Correlates for Level A, for Companies at Level C (Companies Four, Five \& Six) . 87 XIV Scale Correlates for Level B......... 90 XV Scale correlates for Level C........ . 92 


$\begin{aligned} \text { XVI } & \text { ADDraisal Responses by Gender . . . . . . . . } 95 \\ \text { XVII } & \text { ADDraisal Responses by Access to PC at Home . } 97 \\ \text { XVIII } & \text { ADpraisal Responses by Access to PC at Work . } 99 \\ \text { XIX } & \text { ADDraisal Responses by Education Level . . . } 101 \\ \text { XX } & \text { Appraisal Responses by Aqe . . . . . . . } 103 \\ \text { XXI } & \text { ADpraisal Responses by Years of Experience. . } 105 \\ \text { XXII } & \text { Appraisal Responses by Salary Level . . . . } 106 \\ \text { XXIII } & \text { Demographic Summary . . . . . . . . . . . } 108\end{aligned}$




\section{LIST OF FIGURES}

F I GURE

PAGE

1. Spectrum of Strategies for Deliberate Changing . . . . . . . . . . . 23

2. Proposed Change Model . . . . . . . . . 29

3. Proposed Change Model with Levels Indicated. . 38

4. The Model . . . . . . . . . . . . 111 
CHAPTER I

\section{BACKGROUND AND INTRODUCTION}

\section{INTRODUCTION}

Computers have brought about rapid change in our society. The computer professional has been at the heart of this change, but have been able to maintain their status throughout all the changes that have taken place. The advent of personal computers has changed their status more than other changes. Job related change can lead to stress on the job, yet a good model for how workers react to change has not been developed and analyzed. This paper proposes a model for change, and using a quas1-experiment analyzes the model for the case of changes faced by computer professionals associated with the introduction of personal computers.

COMPUTER TECHNOLOGY HAS BEEN A CENTER OF RAPID CHANGE

Within the past four decades, the computer has gone from a rare item of mystery and awe, to a commonplace tool for the American business, and to an almost commonplace ornament in the American household. With an unprecedented rapidity, the computer has become pervasive in American 
society and has touched the lives of literally every citizen.

During these four decades there has been one constant factor which the computer (and associated information processing technology) has manifested to the observer: change in the lives of the computer users and in society in general. Scanlong (1987) has reported that several years ago, researchers at the University of Minnesota asked companies how long they could survive if their data processing operations were destroyed. The survey, known as the "belly-up study," indicated that many companies felt they could only last for a matter of days. Part of the reason for the rapid change in our society is the rapidly emerging technology which we have all seen. But, the main reason for the change which people have experienced is because this technology is readily accepted and adapted as soon as it is available. Without the widespread adaptation rapidly changing technology would have little impact on the lives of the people in a society. Feeding on widespread adaptation, and subsequent rewards to be earned by seling the technology, growth in new technology has been continuous and has lead to a cycle of 1 . introduction of new technology (hardware and software), 2. acceptance, 3 . adaptation, 4. success in the marketplace, and 5. search for additional new technology to sell in the marketplace (which leads back to the introduction of new technology). 
COMPUTER PROFESSIONALS AS AGENTS OF CHANGE

\begin{abstract}
During this time of rapid introduction of computer technology, the computer professionals who work for the organizations that buy and use computers (as opposed to
\end{abstract} employees of IBM or Apple who make computers) have been used as agents of change, both to introduce the new technology into organizations and as catalysts for change to force new methods/procedures onto lethargic organizations (Forcht, Kulonda, and Moates, 1987). The computer types are quite familiar with walking into a department of their company and turning all the other employees upside down by requiring new techniques, procedures, lingo, skills, and even mind sets. Frequently, the computer professionals cannot understand why the other employees are so resistant to change, especially when the change is obviously so beneficial to the company and to the employee (Morrison 1988). It should be obvious that one is better off using a keyboard rather than a pencil! or, looking at a CRT rather than leafing through paper. Often there is no recognition of the trauma associated with learning to use a keyboard, or of interfacing with a machine instead of real people, or of reading a video tube while its whirring fan deadens the audio senses, or reading dot matrix characters and white letters on a black background which is the opposite of black ink letters on 
white paper. The computer professionals seem to enjoy their role as superior individuals bringing modernization to the more backward people of their company.

COMPUTER PROFESSIONALS FAMILIAR WITH TECHNOLOGICAL CHANGE

Because of the rapidly changing technology, computer technicians are accustomed to keeping abreast of the technology and learning the newest capabilities which are being introduced by the vendors of both hardware and software. It would seem that change is a part of their life. They not only change the worklife of others, but they must keep current with the latest changes as well. One professional said that he reads an average of over a hundred IBM change notices a month about modifications to operating system software and standard languages such as COBOL and FORTRAN. The one constant factor has been change. However, the change that the computer professionals have experienced the most is technological change, not change in their status, power, rank, and importance.

\section{WHAT HAPPENS WHEN COMPUTER PROFESSIONALS} FACE CHANGE IN THEIR JOBS?

An examination will be made as to the personal impact some of the newest technology has had on the people who have been past masters at imposing change on others, namely 
the computer professionals themselves. The impact of the microcomputer (and associated software and peripheral hardware) has probably affected the information processing specialist more than any other change in the technology (Winkler 1986). It has freed the computer users from being totally dependent upon the "computer gurus" and has allowed the computer users a certain degree of liberty and new creativity in the use of information processing technology. One department head of a major corporation, whose department had totally embraced the use of microcomputers (hereafter referred to as PCs for Personal Computers), stated that there was something entrepreneurial about the use of PCs, in that they gave each of his staff the chance to take the risk of creative use of the computer and have the opportunity to reap the reward if successful. With more and more of their formerly locked-in customers becoming their own entrepreneurs of computer usage, the computer professionals are seeing the largest change ever in the way they do their work, the way they work with their users, the power they had in the company, and the status they enjoyed with their previously inapproachable, technological priesthood (Leinfuss 1989).

JOB RELATED STRESS

One of the common psychological responses to change is stress. Yet, Schar, Reeder and Dirken (1973) point out, 
although the concept of stress is utilized with considerable frequency, there is not a complete consensus on the meaning of the term. Thus, it is necessary for the author to define what this study will mean by the term stress. Folkman, Lazarus, Gruen, and Delongis (1986) describe stress as being transactional in that the person and the environment are viewed as being in a dynamic, mutually reciprocal, bidirectional relationship. Stress is conceptualized as a relationship between the person and the environment that is appraised by the person as taxing or exceeding his or her resources and as endangering well-being. This is the definition which will be used for stress.

To an individual, the stress which he or she is experiencing is a summation of all relationships with the environment, and thus it may be impossible to isolate the stress which the individual experiences in the job environment from that which the individual experiences from the rest of the environment. However, it is possible to identify those sources of stress which are coming from the work environment. Job related stress is defined as stress which is being caused by an individual's relationships with the work environment. This definition of stress could include stress caused by physical threats as well as emotional threats. In the context of the study, the subjects do not have jobs which are commonly thought of as 
being physically dangerous such as police officers, coal miners, or steeple jacks. Thus, the subjects' job related stress will be analysed at the psychological level as emotional distress, although physical and somatic symptoms may appear as a result of the stress.

THE INVESTOR-OWNED PUBLIC UTILITY BUSINESS

(GAS AND ELECTRIC SPECIFICALLY)

This study will utilize the environment of Investor-owned Public Utilities (IOUs) for the examination of change upon the information processing specialist brought about by the introduction of PCs.

IOUs are a fairly homogeneous group of companies for a variety of reasons. They are in a very mature industry which has been selling the same product since the turn of the century. Each is a government authorized monopoly within a certain geographical area. That is, no one else can offer or sell the same product as the IOU within a legally set geographical area. Thus, within that territory an IOU has no direct competitor. In exchange for this exclusive monopoly, the IOU must submit to government regulation to assure that the IOU does not use the monopoly to abuse the people it serves. All fifty states have some form of public utility commissioner(s), and these fifty commissions share ideas, meet as part of regional and national committees, and adopt one another's ideas. While 
there are individual differences in commissions' rulings from state to state, these commissions have a lot in common, and the differences are minor when compared to the things they do and share in common. Hence, one has companies, without competition, selling the same product, being regulated with similar government bodies, in a very mature industry.

Additionally, the noncompetitiveness has led the IOUs to share good ideas among themselves, and they have formed the American Gas Association (AGA), and the Edison Electric Institute (EEI) as vehicles for sharing management and operational ideas. There are committees which meet regularly for these purposes on almost all aspects of the running of IOUs. There are committees for Information Systems, Accounting, Auditing, Power Transmission, Gas Transmission, Power Generation, Risk Management, Procurement, Regulatory Affairs, Marketing \& Sales, Engineering, Public Affairs, Legal Affairs, and even one for the running of a Library. Many utilities, such as Pacific Gas and Electric (PG\&E) and Sierra Pacific, have both gas and electric and as a result the AGA and EEI have combined committees for many areas. For example, the author was a member of the $A G A / E E I$ Information systems Committee for eleven years. This committee consists of 70 members who represent MIS management from IOUs in Canada and the United states. There were two meetings a year 
where the 70 members met for three days to discuss common situations, shared solutions, and even gave away free software packages as a part of solutions. Additionally, once a year there was a one week meeting, with seminars and vendor exhibits, which was attended by around 600 information specialist from IoUs. The author discovered during the eleven years, that both gas and electric utilities faced much the same problems and had much the same management responses, even though the end product being sold was different. The problems of mass distribution, large customer base with small average billings, being government authorized monopolies, with the same regulatory bodies, and other factors, tended to make gas and electric utilities more alike than different.

There are two other significant items which helped to make the IOUs homogeneous. First, because all gas companies sell the same product and all electric companies sell the same product, they are interconnected in their respective channels of distribution (called T\&D for Transmission and Distribution). For example, all electric utilities must have the same frequency, cycle, and quality of product because of the interconnection. If one utility on the arid goes down, it will impact the neighboring utilities. In reality customers of Portland General Electric Company (PGE) do not know if the electrons entering their home through the wire were actually 
generated in a PGE plant or if the electricity came from Bonneville power, or PG\&E. Even PGE cannot tell where the electrons came from, nor do they really care. In fact the IoUs are merely responsible for keeping the pressure (for gas) or potential (for electricity) up to some minimal level on the system, and the customers essentially let the product flow out the end when desired. Because of the interconnectedness, all the Ious with the same product must cooperate and operate their systems in fairly similar manners.

The second reason is an outgrowth of the fact that they are selling the same product. Because the customer does not view anything unique about the product from one gas or electric IOU as being any different from another, and in fact the customer is not really interested in buying gas or electricity, but rather what that source of energy provides, such as warmich, light, hot water, etc., the Ious have polled their research dollars and do not do much in the way of individual scientific research. For example, the electric IOUs have created the Electric Power Research Institute (EPRI), and jointly fund research which all share equally. PGE contributes around two million dollars a year to ERRI, gains a voice in the direction of the research performed, and shares equally with all other EPRI members in the findings. With pooled research dollars, and common sharing of new scientific discovers, all electric IOUs 
migrate along the same path into the future.

Indicative of the homogeneous nature of the IoUs are some of the problems the industry faces. They all face pressure in the form of trying to hold their rates down. Utility commissions accoss the nation are at odds with the IOUs over their rates, and the commissions have been getting more aggressive in keeping rates down by rejecting some expenses as not being part of good, prudent operation and management. They also face problems of having long term supply problems. They both see a finite supply of natural gas (the electric utilities are concerned with gas also and see natural gas as the most trouble free, pollution free, thermal generation source of electricity). The electric IoUs can not find further rivers to dam, new nuclear power is not feasible today, and coal and oil burning pollutes the atmosphere in several ways. All Ious are seen by the investment community as cash cows, and hence they are trying to minimize the amount of new investment being made (besides, the utility commissions nowadays tend to not allow much of the cost of new construction anyway).

It is not surprising that, because of the factors given in the above discussion, these homogeneous businesses are known for having developed a very conservative, stodgy, risk averse management style. Ious are not known as the innovators of American industry. 
GAS AND ELECTRIC IOUS IN THE NORTHWESTERN UNITED STATES

While the IOUs are fairly homogeneous, there are still some unique features about the rous in the Northwestern United states. What stands out the most is the existence of the federal government's involvement in the marketplace for electricity. Just as the Tennessee Valley Authority has provided government subsidized electricity to the populations in and around the Tennessee Valley, the Bonneville Power Authority has provided government subsidized electricity to the populations west of the continental divide in Montana, Idaho, Washington and Oregon. This has had the effect of lowering the rates paid by the customers of the IoUs in a couple of ways. First, the Northwestern electric IOUs can buy cheap, surplus electricity from Bonneville, thereby lowering the average cost of their product. Second, any Northwestern city, county, or municipality can establish their own public utility department (PUD) and buy cheap electricity from Bonneville and distribute it to their residents. If the electric IOUs' price is too far out of line with the PUDs around it, then their customers are liable to be motivated to form their own PUD. In fact this has happened to Pacific Power and Light Company (PP\&L) several times in places like Tillamook, Hood River, and Lane county. This has had a similar effect on the gas IoUs because they try 
to keep their rates on somewhat of a parity with electricity for comparable uses in the form of heating. As a result of this, the Northwestern United states has some of the lowest rates in the nation.

The actual operation of the IOUs is much the same as the other Ious in the nation. There are some minor differences. The Northwest does not have much in the way of its own supply of natural gas nor does it have petroleum, so the electric Ious do not generate much with gas or oil; and the gas IOUs are dependent upon long pipelines for their supply. Also, the electric IOUs have made use of the rivers for hydro generated electricity. However, there are many Ious across the nation with similar situations, so the Northwestern IOUs has some aspects which are atypical, but are not really very unique.

RATIONALE FOR A STUDY

The information processing professionals are change agents, and have readily accepted technological change where that change has not really impacted their own personal value system or status. Indeed, in almost all other cases, the technological change has increased their status and worth. They also do not hesitate to implement change where it will impact the quality of work life of their customers and co-workers; the end-users of application oriented information systems. From the 
viewpoint of most managers, they see the computer technician as being constantly involved in change, and so they should readily accept change themselves. Of course, computer professionals are not the dispassionate creatures which some people perceive them to be; they are also human with all the same problems of ego, hopes, aspirations, phobias, and neuroses as other humans. If anything, perhaps computer professionals are a bit more logical and rational than the average person in the workforce, but that logic does not do away with the emotions and entirely human feelings that rest in the hearts of all mankind.

The author personally knows managers of information systems departments from over seventy IOUs in Canada and the United states, and does not know of a single case where a really overt effort was made to help the computer technicians adjust to the human aspects of the introduction of PCs into their organizations. Every one of the Ious provided technical training on the use, care, and feeding of PCs, but no attention was given to the human impact of the changes which would occur in the quality of work 1 ife for the computer professionals. Frequently, attention was even given to training computer professionals on how to handle the human aspects of their customers, the computer end-users, who would now be doing their jobs using the PCs, but no training for change, for the agents of change themselves. 
Part of the lack of attention can also be attributed to the lack of a good model for understanding the change process which a computer professional goes through when their status, power, importance, and value to the organization are challenged.

This study proposes and analysis a model as to the process which the computer professionals go through in adapting to such dramatic change. A model is presented which represents the change process, and analysis postulates are formulated to be used for analyzing the model. Measures and scales are developed to give a degree of measure and quantification towards explaining behavior and studying of relationships. A quasi-experiment is designed, performed, and evaluated to analyze the postulates.

While this model is general in nature, and could be applicable to change situations in many environments, it is outside of the scope of this study to validate the model for all situations and in all environments.

IOUs are selected to be the target environment for three primary reasons. The first is the author's familiarity with the industry, having spent over a decade as the MIS Director of the largest IOU in the Northwestern United states, and his familiarity with many other MIS departments in IOUs. Second, the IOU is an interesting 
environment in which to study change, because the Iou as a whole is more resistant to change than most for-profit organizations. Thus, it provides a better controlled setting where other change factors are minimized. Third, because of the author's personal familiarity with the managers in IOUs, greater cooperation in conducting the study is possible.

The study presented in this research examines how computer professionals, working in certain Northwestern IoUs, react to the change brought about by the introduction of PCs into their organizations. This change has the possibility of impacting them in their concept of what their job entails, and threatens their quality of work life. A model is presented, and measurement scales are developed for the model. The scales are necessary in order to give a degree of measure and quantification to the model so that analysis may be performed which will go toward explaining behavior of people involved in occupational situations. A quasi-experiment is performed to analyze the model and investigate relationships between elements of the model. The model represents a process as to how these computer professionals react to change in the workplace. 
CHAPTER II

LITERATURE ABOUT CHANGE AND A MODEL FOR CHANGE

INTRODUCTION

There has been much literature about change, and much comment on how to implement change, but little has been developed about models for change. With a model the systems science approach can be used to analyze change. A statement of analysis postulates will be made which will be the basis of a model for change.

\section{LITERATURE AND STATEMENTS ABOUT CHANGE}

"Men are disturbed not by things, but by the views which they take of things." The Roman philosopher Epictetus made this observation two thousand years ago (Ivancevich, et al. 1987), and in spite of all the changes that have occurred in, with, and because of the human race, this statement still reflects how people respond to change. Each person brings their own propensity, temperament, background, experiences, education, fears, and phobias into the evaluation of change. Almost from their birth, people start making judgments as to cause and effects. It is necessary in order to survive and prosper. When one sees a 
change, then one prejudges what the effect will be. Over the years a bias builds as to what types of changes have brought about desirable or neutral effects, and the types of changes which bring about undesirable effects. So people are predetermined to judge certain classes of change when they have experienced similar events before.

Much has been stated in the popular press lately about CEOs being needed who can be "Changemasters" (Kanter 1983) and about the need for change in order for the American business world to continue with a competitive edge (McLaughlin 1989). Before the current rash of publications and articles, there was a popular movement which was concerned about individuals undergoing "future shock" which was brought about by too much change (Toffler 1970). Regardless of whether one feels there has been too nuch change, or too little of the right kind of change, the human race has had to adapt to continual change in the way it reacts with its environment. One primary reason for this is because the human race has the ability and the propensity to continually change its environment. Unlike other animals inhabiting the planet, mankind has the tool making ability to improve (or damage) their surroundings. The human species is unique in rapidly causing change, and hence in causing the rapid need to adjust to change.

A means of measuring "Social Desirability" (SD) has been proposed as a means to gain the approval of others 
when implementing change (Crowne and Marlowe 1954).

Golembiewski (1983) suggest that SD be built into a program of organizational change to modify expectations about results and to guide their interpretation.

The human species continually feels a need to try to improve its environment, and to make for a more bountiful and pleasurable iife. It cuts down the forest to build homes, and to make room for fields to plant its own choice of domesticated crops. It supplants the native animals and replaces them with its own choice of domesticated animals. In so doing, it frequently must make further adjustments in order for these crops and animals to flourish. Mankind is the cause of the need to change, and also the one with the most need to be able to adabt to the chanqe. The ability to create change, and to adapt to the change, has allowed mankind to span the globe and to live from the arctic to the equator.

Yet in spite of all the ability at creating change, there still is the problem of individuals being able to accept change, and being able to work well together in times of change.

There have been studies as to the impact of change on workers brought about by the introduction of new technology. For example, Majchrazak and Cotton (1988) made a longitudinal study of adjustment to technological change which involved a manufacturing company that switched from 
mass production to computer-automated batch production. They point out that longitudinal studies of workers changing technologies have been few and have yielded equivocal results. They believe that individual adjustment is a function of individual's perceived fit between their own abilities and values, and the abilities and values demanded by the work environment. Gutek (1982) studied the adjustment of a secretary and manager to a computerized managerial work-station and found that the implementation of the work-station positively changed the secretary's evaluation of her work but not that of the manager. Argote, Goodman and Schkade (1983) studied workers involved in the implementation of a batch production robot and found that the implementation of the computer driven robot increased the stress experienced on the job. Doan and Tziner (1988) studied computer-based automation in the office. They observed that to date little attempt has been made to empirically ascertain just how technological changes relate to experienced stress associated with different occupational and organizational aspects. They also discovered that even those workers who had prior experience using the technology still experienced considerable stress when a different form of the technology was introduced. Martin and wall (1989) state that research has implicated attentional demand and responsibility as two sources of stress among blue collar workers, and that 
attentional demand and responsibility will become increasingly significant in shopfloor work with the increasing use of computer-based technology. These studies are informative but lack a good model for how people react to change. If a good model as to how people react to change in the workplace existed and could be substantiated, then it would demonstrate that the way people react to change is a system with interrelations between the different elements of the model. As a system it would be possible to examine the interrelations and interpret, predict, measure, and evaluate the effects of change in the workplace. These previous studies also did not involve studying the agents of change (the computer professionals) who brought about the change in people's worklife. Thus, there are some studies which have looked at the change brought about by computerization on workers, but nothing that has looked at the adjustment to change which computer professionals have had to make as the PC has changed their rank, status, power, and coworker relationships.

\section{A SPECTRUM OF CHANGE IMPLEMENTATIONS}

A spectrum of general strategies for deliberately effecting changes in human systems has been developed by Chin and Benne (1969), utilizing some of the earlier work of Etzioni (1961). These strategies are schemes or plans for achieving the purpose of successfully implementing 
change. The spectrum is depicted in Figure 1 and can be grouped into three general categories: A. Rational-Empirical, B. Normative-Reeducative, and C. Power-Coercive.

The Rational-Empirical group of strategies are what is normally used by educated people of European backgrounds. A fundamental assumption underlying these strategies is that people are rational. Also, that people will follow their rational self-interest, once they have an understanding of what it is. Basically it consists of having the proposed change presented to a group of people, along with an explanation or demonstration as to the desirability of that change, how it is in the group's best interest to change, and explaining or demonstrating how the change can be carried out to gain the benefit. Because the group is assumed to be rational and moved by self-interest, it is assumed that they will adopt the proposed change if the effort is worth the reward. This is the whole basis for the free enterprise system and is at the heart of Adam Smith's "invisible hand" which guides society in securing the best possible mix of goods and services which maximizes the benefit to society. Many of the believers in this type of approach advocate the universal education of people and a totally free exchange of ideas, so that people will have the best opportunity to judge what is in their best 
A. Ratlonal-Emplrical

Viaws of the Enlightenment and Classical Liberalism

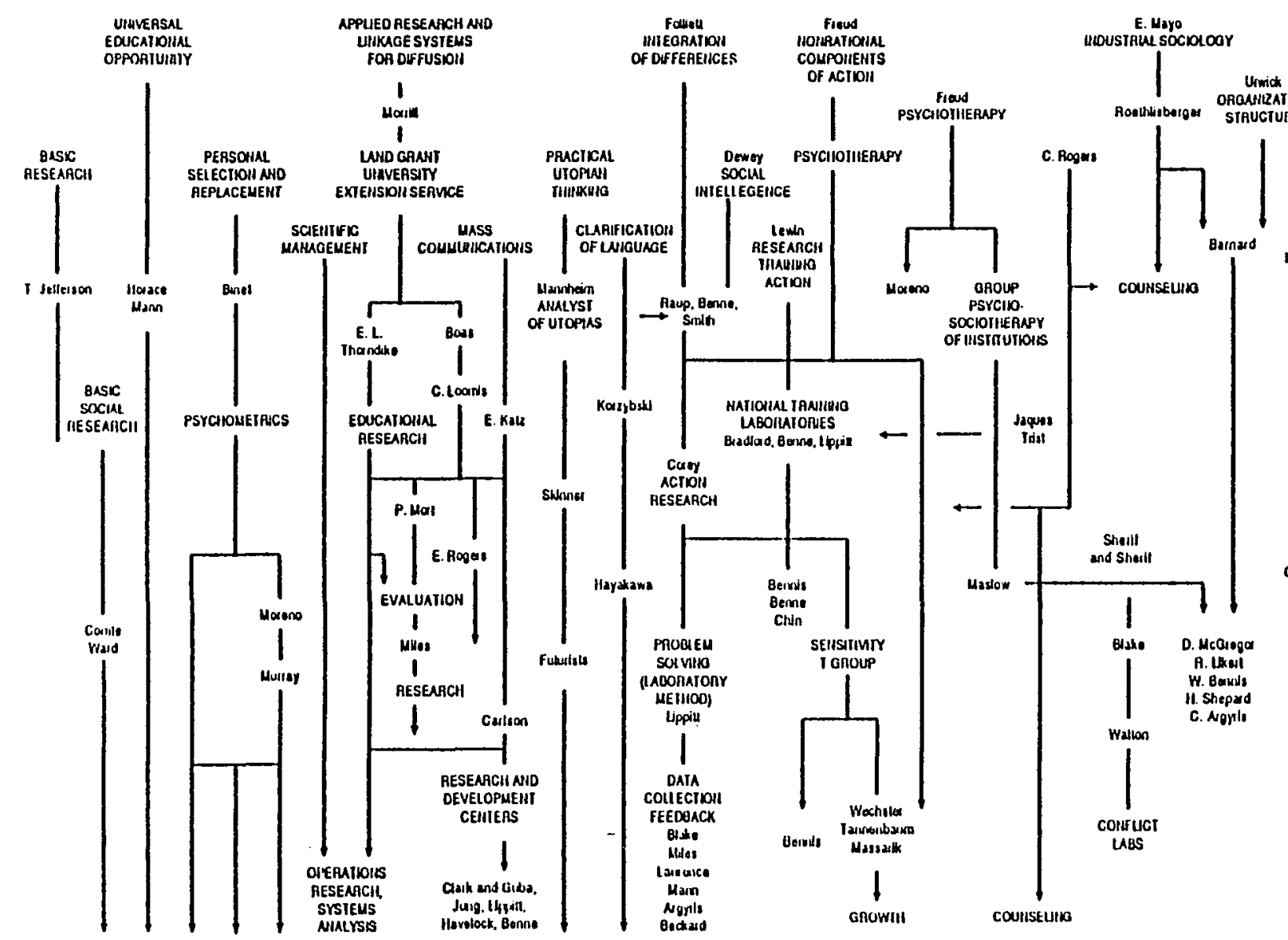

Figure 1. Spectrum ol stralegies lor deliberate changing. (Chin and Benne 1969)
C. Power-Coercive

USE of
POIIICAL

POUICAL
IISInUTIORS

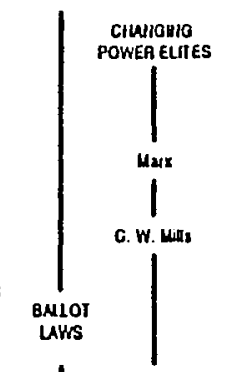

sr. Doms | F. Hurest

couphouise

NECOIuIOIS |

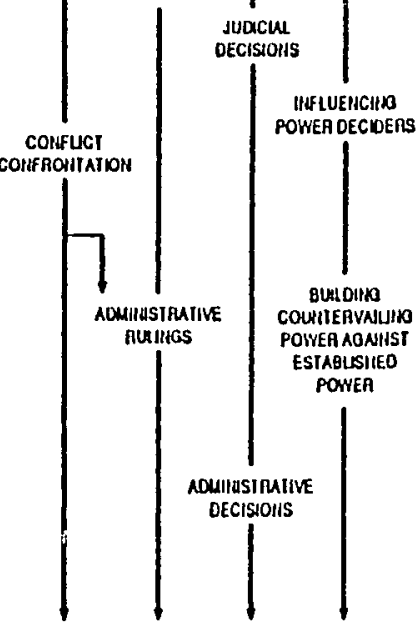


rational self-interest and which changes are able to fulfill those self interests.

The Normative-Reeducative group of strategies believe in the rationality and intelligence of people also, but that patterns of action and practice are supported by sociocultural norms and by commitments on the part of individuals to these norms. Sociocultural norms are supported by the attitude and value systems of individuals' normative outlooks which underlay their commitments. Change in a pattern of action will occur only as the persons involved are brought to change their normative orientations to old patterns and develop commitments to new ones. Hence, changes in normative orientations involve changes in attitudes, values, skills, and significant relationships, not just changes in knowledge, information or intellectual rationales. Freud and his development of psychotherapy followed this group of strategies. The modern organizational behaviorist such as McGregor (1968), Likert (1967), and Argyris (1962) are disciples of this group of strategies.

The Power-Coercive is what one thinks of as the traditional way in which change has historically been brought about. It is based on the use of power in some form to force those with lesser power to accept the will, plans, direction, philosophy, or leadership of the stronger. Often the power to be applied is the legitimate 
power or authority of law. People such as Lenin used the power to make their own laws, and had no hesitation to use physical force to gain acceptance of change. Such quotes as "power comes from the barrel of a gun," or "if you want to make an omelet, you have to break some eggs" are typical of this type of use of power to effect change. Gandhi put a new twist on this category of power by not using physical force, but instead the power of a stronger will applied against those who had a weaker resolve (or a weaker commitment for not changing).

All of the methods shown in the spectrum in Figure 1 have been used at one time or another, and to varying degrees of success. All of them have their place (somewhere and sometimes) in the practice of bringing about change, and all of them have places where they would not be effective in bringing about proposed change. Based on the available evidence there does not appear to be one right way to always bring about change.

\section{WHERE THE CHANGE ON COMPUTER PROFESSIONALS BROUGHT ABOUT BY THE INTRODUCTION OF PCS FITS IN THE SPECTRUM}

In the several Investor owned Utilities (IOUs) in the U.S. and Canada which the author is aware of, there has not been a single effort to consciously try to develop a plan or scheme for gaining the acceptance of the computer professionals to changes which affect their jobs and 
positions. An unconscious belief that computer professionals are very rational beings, and that it is in their self-interest to utilized the best automation tools available in order to make their job easier, has lead to an unconscious use of the Rational-Empirical approach to change. However, it can hardly be called a plan. The MIS Directors put forth deliberate plans along the lines of the Normative-Reeducative group in order to bring end-users to accept the use of computers, be they micros, minis, or maxis, but they left their own staffs without any deliberate plans for acceptance of change because of their belief in the rationality of their staff and the supposed obvious benefits from PCs.

Part of this lack of attention can also be attributed to the lack of a good model for understanding the change process which a computer professional goes through when their status, power, importance, and value to the organization are challenged. Furthermore, the MIS Directors are conditioned to seeing their staffs readily accept and adopt technological changes, and hence they tend to believe that the Rational-Empirical strategy is sufficient. However, it is one thing to adopt a new technology which does not threaten your power base and change your status, and quite another to accept a new technology which changes the way you do your job and the way your job is perceived. While the computer 
professionals have been masters at changing other's jobs, they may not be as ready to accept change in their own position. It is always easier to accept the need for change in someone else's job and power base than in your own .

THE CHANGE MODEL

Lazarus and Folkman (1985) discuss a triad of responses which people make to events which occur. First, there is the Irrelevant Appraisal, which is that they perceive the event has no impact on them, and hence they have indifferent feelings and emotions about the event. Second, is the stressful Appraisal in which they perceive that the event has the potential to cause them mental, emotional, physical, or some other type of harm. Third, is the Benign-positive Appraisal in which they perceive that the event will be beneficial to them. Ivancevich, Schweiger, and Power (1987) have identified a triad of response appraisals when an individual is faced with the changes associated with a merger of two companies. First, there is a Harm/Loss Appraisal which indicates that there has been some damage to a person such as financial loss, loss of self-esteem or a sense of powerlessness. Second, is a Threat Appraisal when the individual perceives of a harm or loss that has not yet occurred but is anticipated. There are three 
factors that influence the intensity of a Threat Appraisal and its ensuing effect on an individual's response. 1. The Uncertainty of the event, both the not knowing whether the event will occur or what its consequences will be. 2 . The Duration of the event, which is how long the stress event will last if it does occur. 3. The Imminence of the event, which is the amount of time before the actual event occurs. Third and lastly, is a Challenge Appraisal when the individual feels a need to arise to the challenge and sees it as an opportunity with the potential for gain or growth. synthesizing these two concepts of triads of responses, and adding further ideas, a model was developed which is represented in Figure 2. This model starts with an impending change being identified by an individual. That individual appraises the change based upon all the special characteristics which make up the individual. The result of the appraisal leads to one of three appraisals being made by the individual. Either the change is appraised as being irrelevant, a threat, or benign-positive. If it is irrelevant, then the individual has indifferent feelings and emotions about the impending change. If it is benign-positive, then the individual has pleasurable and comfortable feelings and emotions. If it is appraised as being a threat, the individual brings his or her own perceptions of the nature of the threat into play, as well as the three factors of uncertainty, duration and 


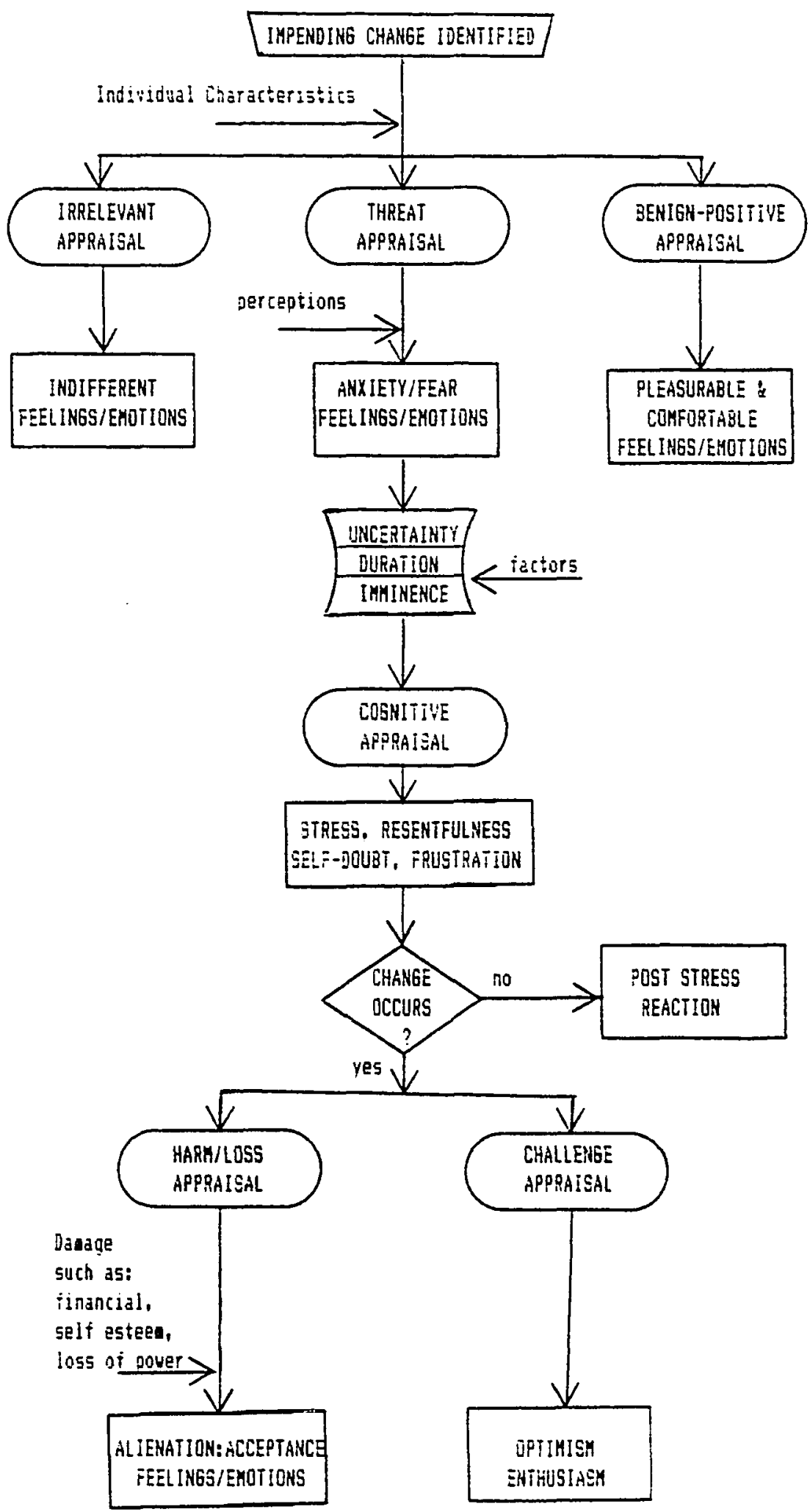

Figure 2. Proposed thange zocei. 
imminence. At this point the individual does a cognitive appraisal of the change based upon the perceptions and factors, and during the time of imminence of the change has emotional reactions of anxiety, self-doubt, fear, frustration, resentfulness, etc. There is a debate in the academic community if the cognitive appraisal takes place before the emotions and hence leads to the emotions, or if the emotions take place first and then lead to a cognitive appraisal which supports the emotions, or if the two are part of an iterative process which cycles until a convergence of emotions and cognition occur. This model does not try to resolve the order of the process, merely that the two go together, and that as a result there are emotions which the individual develops, and that these types of emotions will stay with the individual all through the imminence period of the change. These emotions, or psychological responses, are what are commonly associated with workplace stress. The longer the imminence period, the longer the individual will undergo the stress associated with the threat appraisal. This part of the model differs from the Ivancevich, Schweiger, and Power (1987) triad of responses in that rather than having a triad of responses (harm/loss, threat, or challenge), they proposed first a threat appraisal with the imminence factor playing the key role as to whether there is an immediate harm/loss or challenge appraisal, or if the threat hangs on 
for a longer time period. In the proposed model if the imminence is immediate, then the threat appraisal passes quite quickly, and the individual goes immediately into the other two appraisals, but still the individual does a threat appraisal even though it may be momentary.

The end result of the threat appraisal is that either the change occurs, or it does not occur. If it does not occur, then the individual is relieved of the emotions associated with the threat, and goes into a post stress reaction and a return to normalcy.

If the change does occur, then the individual either does a harm/loss appraisal, or a challenge appraisal. If a challenge appraisal is the result, then the individual feels optimism or enthusiasm as a result of the change. If a harm/loss appraisal results, then the individual makes an assessment of the damage, and eventualiy either feels alienation or acceptance.

\section{THE CHANGE MODEL IS A SYSTEM}

Frequently, the notion of a system is loosely used, and often in its use there is not even reference to a definition of what constitutes a system. This has led to misunderstandings, and what appears to be conflicts in various researchers' results. For the purpose of this research the author feels a definition is needed 
and uses the following from an article by George Lendaris $(1986):$

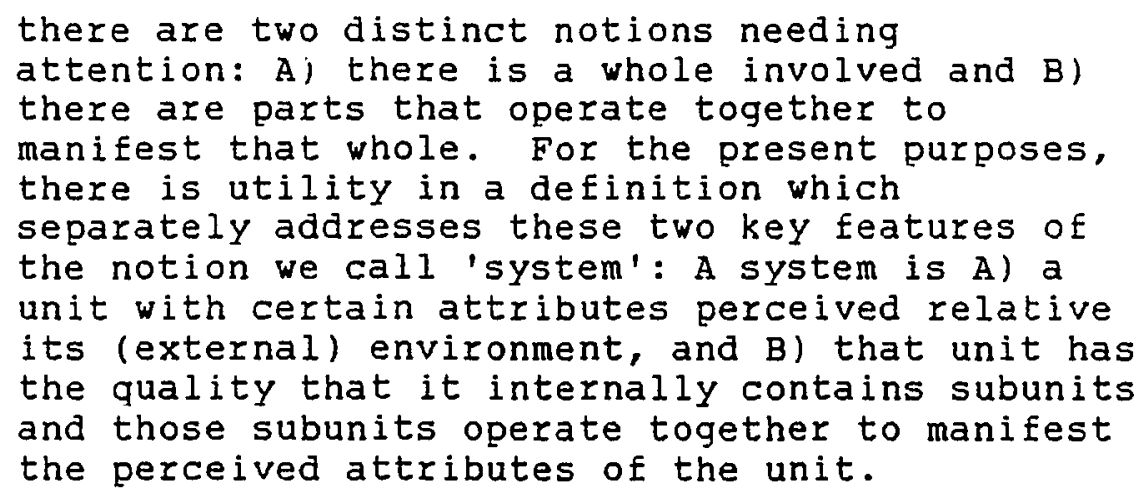

Imbedded in this definition is the role of an observer who does the perceiving, as well as that of an environment in which the system exists. For our purposes the observer will be the author, but could just as easily be the MIS manager who is overseeing the implementation of change in the MIS department. The environment is that of an MIS department in an IOU. This environment includes the discussion of Ious and their environment contained in Chapter I, but goes further since the MIS department is a service organization in the IOU, and is a department which deals with implementing and operating the technology associated with information systems.

The model represented by Figure 2 fits the above definition of a system. The model is a unit within an environment which has certain perceived attributes consisting of relationships, and it internally contains subunits which operate together manifesting the attributes 
of the unit, such as the three appraisals:

Benign-positive, Threat, and Irrelevant which each have their own components yet still relate to one another. With the change model functioning as a system it will enable observers to measure, analyze, predict, interpret, and evaluate the relationships between the system and its environment as well as the relationships between the units within the system.

\section{STATEMENT OF ANALYSIS POSTULATES}

Wher programmers and systems analysts are faced with the job changes associated with the use of PCs in their organizations, they follow the processes represented by the model in Figure 2 in developing psychological responses.

specifically this means, they first go through a triad of either an Irrelevant Appraisal, Threat Appraisal, or a Benign-Positive Appraisal. With the Irrelevant Appraisal they have indifferent feelings/emotions. With the Benign-Positive Appraisal they have pleasurable and comfortable feelings/emotions. With the Threat Appraisal they go through a cognitive process involving individual characteristics, perceptions, and factors associated with the change, which result in emotions causing stress during the duration of the threat. If the change does not occur then they return to normal situations. If the change does 
occur, then either they will have a Harm/Loss Appraisal or a Challenge Appraisal.

This is represented by the following statements of analysis postulates which will be demonstrated:

P1: When faced with a change event the subject computer professionals go through a triad of appraisals and make either an Irrelevant Appraisal, Threat Appraisal, or a Benign-positive Appraisal.

Q2: With the Irrelevant Appraisal the subject computer professionals have indifferent feelings/emotions.

P3: With the Benign-Positive Appraisal the subject computer professionals have pleasurable and comfortable feelings/emotions.

Q4: With the Threat Appraisal the subject computer professionals go through a cognitive process which produces psychological responses resulting from stress, such as loss of self esteem, anxiety, fear, and performance difficulty.

P5: With the Threat Appraisal, after the change event has transpired, the subject computer professionals will have a Harm/Loss Appraisal or a Challenge Appraisal.

Data from the instrument will be used to determine if the various respondents to the survey can be categorized into groups which correspond to the Level A appraisals, and thus help collaborate P1.

The instrument has scales which will be used to register the various emotions and feelings which the 
respondents experienced while going through the change event associated with the introduction of the PC into the organizations for which they worked. These scales will be checked for correlations to determine if relationships exist between the various emotions and feelings which the model forecasts and are indicated by the analysis postulates. The correlations of the scales will be used as an analysis tool for the analysis postulates. 
CHAPTER III

RESEARCH DESIGN AND METHODOLOGY

INTRODUCTION

In order to verify or reject the model, the research desian and methodoloqy must define the environment and research subjects, the nature of the instrument for measuring results, the data collection method, the data orqanization, the data analysis methodology, and how the instrument is developed and tested.

THE ENVIRONMENT AND RESEARCH SUBJECTS

The orqanizational environment is that of IOUs in the Northwestern United States. The Information Systems departments of $\mathbf{s i x}$ IOUs have aqreed to allow their systems analysts and programmers to participate in the research as the subject computer professionals (there are a total of seven such IOUs). The systems analysts and programmers who are the subjects of the research are those people who support the end users with application programs, such as: accounts payable, general ledger, material and inventory management, engineering calculations, and human resource systems. These are the computer professionals who have had 
the most impact on the quality of their work life due to the PC. It does not include the systems programmers, who maintain the operating systems and telecommunication software packages, and have minimal contact with the end users and thus their work has not been impacted as much. This yields a total population of around 300 people. If even a $50 \%$ response rate is achieved, this will yield a sample of around 150 people.

It needs to be recognized that different organizations will be at different stages of introduction of the PCs into the organization, so the computer professionals from company to company will be experiencing different aspects of the model at any one time. For the purpose of being able to identify the levels of PC penetration into organizations, the model is divided into three levels of PC penetration (see Figure 3 ). At Level A the organization is considering implementation of PCs, but has not yet done so. At Level $B$ the organization has starting using PCs, but has not matured in the use PCs. At Level $C$ the $P C$ is pervasive throughout the company and is an accepted part of the way of doing business. 


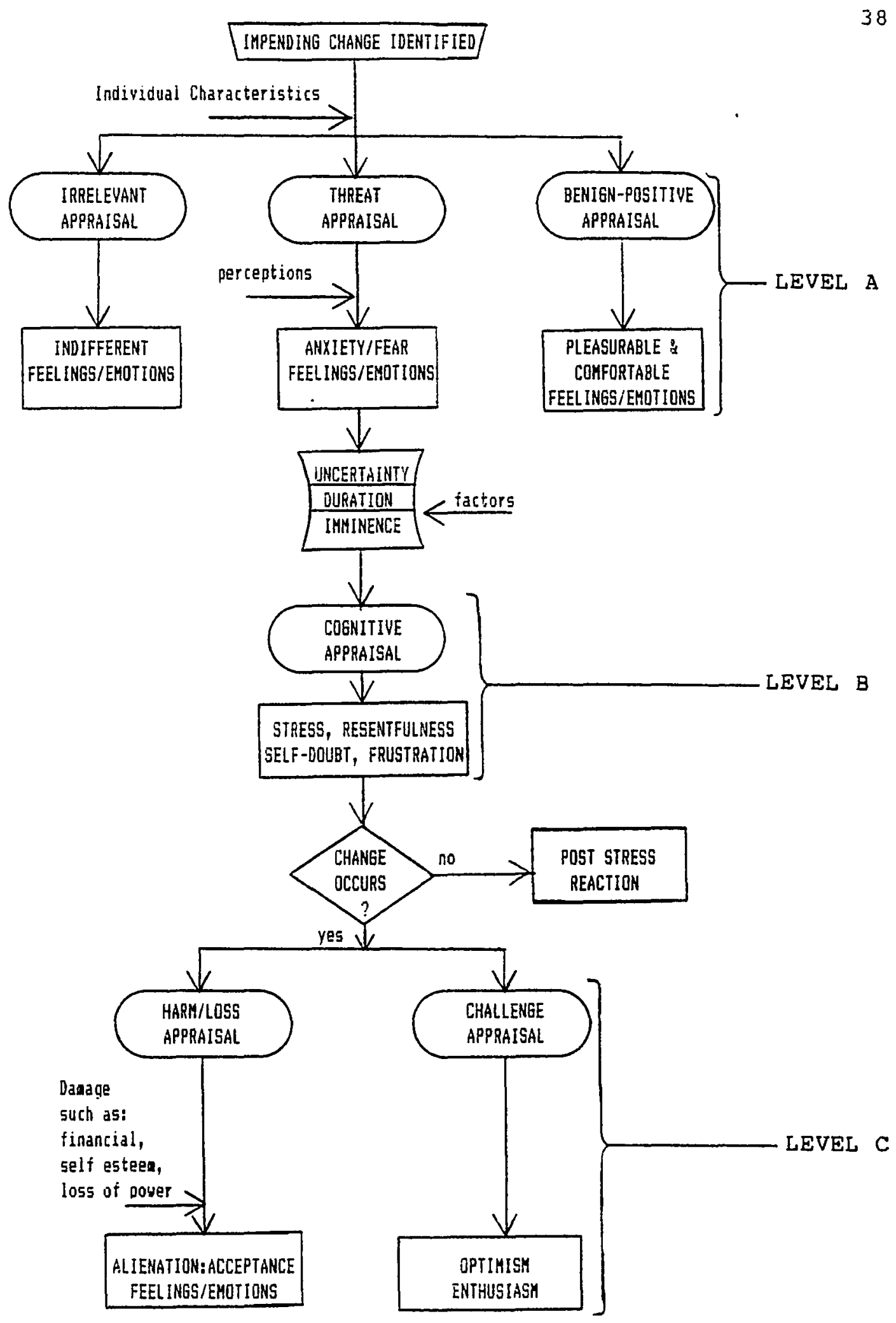

Figure 3. Proposed change aodel uith levels indicated. 


\section{RESEARCH DESIGN}

The research is a cross sectional evaluation of psychological responses of the computer professionals as they now feel about the changes brought about by the PC. For those organizations which have progressed further in the introduction of the PC into the organization, and maybe have even matured in the use of PCs, the computer professionals will be asked to recall their psychological responses at the time that they went through the various appraisals of the model.

The instrument is in the form of a survey. Surveys are an accepted method of measuring psychological responses. For example, in measuring stress there is a differentiation between objective and subjective forms. objective stress is measured independently of a person's environmental perceptions, whereas subjective stress relies on self-reports (i.e. surveys). From previous research we know that subjectively measured stress caused by role conflict, compared to objectively measured conflict, was a better predictor of job-related tension (Kraut 1965). Also, in a study of the relationship between quantitative work load and cardiovascular response, it was shown that subjective ratings of work load, compared to objective tallies by observers of each person's phone calls, office 
visits, and meetings, were better predictors of heart rate (French and Caplan 1972).

The instrument is a self-administered questionnaire which will contain demographic questions as well as questions relating to the model.

The author borrows heavily from existing instruments and the questions and measures which they contain. There are many instruments used by previous researchers which could apply in the measurement of various psychological responses to stress in the workplace. For example, in the area of job satisfaction there is an instrument developed by Brayfield and Rothe (1951) to measure overall job satisfaction, and satisfaction with the work itself can be measured by Johnson \& Graen (1973) in the Role orientation Index.

Measures of stress caused by role conflict and role ambiguity can be measured using a 30 item instrument developed by Rizzo, House, and Lirtzman (1970). Also, along the lines of stress caused by role conflict and organizational stress there is an instrument developed by Caplan (1971).

Relating to stress in general there are the General Health Questionnaire by Goldberg (1972 and 1978), the Symptom Distress Checklist by Parloff, Kelman, and Frank (1954), and the Subjective stress scale, used by the American Heart Association (1968) in the Los Angeles Heart 
study. Warr's model of mental health (1979 and 1987) measured: enthusiasm, contentment, satisfaction, and anxiety.

DATA COLLECTION METHOD

The questionnaires are self-administered to the computer professionals. The setting and method of administration varies from company to company since it is at the discretion of the MIS manager as to the actual giving of the instrument. The author is available to conduct a meeting in which the computer professionals are assembled. In such a meeting, the author provides instructions as to the instrument, and informs the subjects that the study does not identify individuals, nor does the study make evaluations about the wisdom or judgment of the computer professionals as they make the various appraisals. However, in most cases these instructions are written on the first page of the instrument because the author was not allowed to personally oversee the administration of the instrument. Almost all MIS managers expressed a desire to merely have the instrument mailed to their site, and they distributed them to their staff.

The resulting data from the instrument is entered into an IBM PC and is thus available for analysis. 


\section{ORGANIZATION OF DATA}

The data is organized by company, and within a company by salary level of the respondent. It is assumed that organizations are somewhat logical, and that salary correlates with value to the organization of the individual, and that in turn also correlates to the expertise and experience of the individual. There are also data fields for such items as: education, age, sex, and years in the computer field.

\section{DATA ANALYSIS METHODOLOGY}

The data analysis methodology relies heavily on statistical analyses of the data received from the surveys. First, the items in the survey are clustered into common traits which are used as scales. For example, there are scales for anxiety, job satisfaction, somatic symptoms, performance difficulty, resentment, depression, or instability of occupational self-esteem. These scales are developed and tested with the aid of statistical analysis to select those items which demonstrate the highest contribution to scale reliability, and Cronbach's alpha will be used as a measure of reliability. Other analyses are performed as appropriate.

Correlations between scales are computed, using Pearson's coefficient correlation to determine the relation 
between each pair of variables. This is displayed, using a correlation matrix which shows correlations which can vary from 1.0 (perfect correlation), to 0.0 (no correlation), to -1.0 (perfect negative correlation).

The distribution is noted as to how many of the computer professionals fall into the various categories of the different psychological responses. For example, it would not surprise the author if few of the computer technicians feel an Irrelevant Appraisal to the PC. Also, the author does not believe that those IOUs which have fully implemented PCs into the organization, have computer professionals who experienced the Threat Appraisal and yet fall into the category of not believing the change occurred (and thus fall into the post stress reaction category).

The scales' correlations will demonstrate if there is a correspondence to the relations which would be expected if the computer professionals make the same appraisals as forecast by the model. For example, those computer professionals who make a threat appraisal should show high correlation with the traits of anxiety, fear, frustration, and resentfulness. Those with a benign-positive appraisal should show high correlation with the traits of comfort, ease, and satisfaction.

Additional analysis will be performed to determine if there are some additional factors which might be moderators 
such as age, sex, expertise, or years in the computer field.

\section{THE INSTRUMENT}

An instrument is needed to be able to measure the psychological responses of the computer professionals to the change in their workplace brought about by the use of PCs. For this purpose a pilot instrument was developed for administration to a test population of computer professionals, which are different from the target population of computer professionals. Two organizations different from the six target IOUs were used, one an IoU and the other a quasi-government organization. With the seventh IOU being used as a pilot location, the author has used all of the rous in the Nothwestern United states in the research. The purpose of the pilot instrument is to develop, verify, and refine a questionnaire which may be given as the final instrument to the target population.

\section{Nature of the Instrument}

The pilot instrument needs to have the capability of verifying or negating the proposed model, using the ability to measure the psychological responses of the computer professionals to the change in their workplace brought about by the use of PCs. For this purpose, a self-report instrument was developed which consists of a series of 
multiple choice questions asking computer professionals to rank their responses on a scale of from one to five. The numerical responses indicated: 1. Always True, 2 . Often True, 3. Sometimes true, 4. Seldom True, 5. Never True.

It was felt that the pilot questionnaire should be tested for scale reliability, and to determine what number of items are sufficient to gain acceptable levels of reliability, yet avoid having too many items which makes the questionnaire too lengthy. Two companies were used for the pilot application of the instrument. The first was an IOU with a 100 computer professionals, and the second was a quasi-qovernment aqency with 24 computer professionals. Both companies had installed PCs some time ago and were considered to be at the $c$ Level of the model in their computer usage, that is, at the level when PCs have become an established tool at the organization.

First Level of Appraisals (A)

Accordingly, for the A Level of appraisals (namely: Benign-Positive, Irrelevant, and Threat) appropriate measures of typical psychological responses were developed. Benign-Positive Appraisal. For Benign-Positive four typical psychological responses were measured: 1 . Enthusiasm, 2. Pleasure, 3. Job Satisfaction, and 4. Technology Specific Self Gratification. (In Appendix A all categories and items for the instrument are shown.) 
Table I presents the sources and nature of the items in the scales which measure Enthusiasm, Pleasure, Job Satisfaction and Technology Specific self Gratification. There are several cases in the use of scales, which were borrowed from other researchers, that the author did not feel there were sufficient enough items in the scale to be assured that a high alpha would result from the administration of the instrument. The author generated additional items frequently using the form and format of the previous researchers' items. For example, Martin and Wall (1989) used a three item Enthusiasm Scale which consisted of:

1. This week my job made me feel keen.

2. This week my job made me feel lively.

3. This week my job made me feel enthusiastic.

In order to get more items in the Enthusiasm scale the author used Roget's Thesaurus to find synonyms for enthusiasm, and generated additional items using the synonyms: stimulated, excited, invigorated, energetic. specifically, four additional items were added to this scale:

4. This week my job made me feel stimulated.

5. This week my job made me feel excited.

6. This week my job made me feel invigorated.

7. This week my job made me feel energetic. 
TABILE I

SOURCES OF PILOT INSTRUMART SCALES AND I'TEAS - LEVET A

\begin{tabular}{|c|c|c|c|c|}
\hline Variable & $\begin{array}{l}\text { H of } \\
\text { Itenis }\end{array}$ & Solurce & $\begin{array}{l}\text { Cross Reference Scale Iten Munber } \\
\text { With Pilot Instrument Number }\end{array}$ & Connents \\
\hline \multicolumn{5}{|c|}{ Benign-Positive Appraisal } \\
\hline Bullusiasm & 7 & $\begin{array}{l}\text { 1,2,3 Martin \& Wall } 1989 \\
4,5,6,7 \text { Author }\end{array}$ & $\begin{array}{l}1-\Lambda 1 ; 2-\Lambda 8 ; 3-\Lambda 21 ; 4-A 2 B ; 5-A 35 ; 6-\Lambda 36 ; \\
7-A 43 .\end{array}$ & $\begin{array}{l}\text { Itenis } 4 \text { through } 7 \text { were creatod using a } \\
\text { thesaurus to match synonys for enthusiasm. }\end{array}$ \\
\hline Contentment & 9 & $\begin{array}{l}1,2,3 \text { Martin \& Wall } 1989 \\
4,5,6,7,8,9 \text { Author }\end{array}$ & 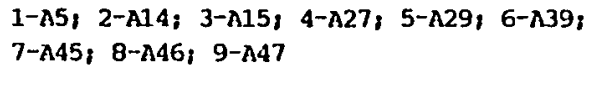 & $\begin{array}{l}\text { Items } 4 \text { through } 9 \text { were created using a } \\
\text { thesaurus to match synonyns for contentment. }\end{array}$ \\
\hline Job Satisfaction & 7 & $\begin{array}{l}\text { 1,2,3,4 Martin \& Wall } 1989 \\
5,6,7 \text { Author }\end{array}$ & $\begin{array}{l}\text { 1-A7; 2-A10; 3-A2O; 4-A23; 5-A33; 6-A37, } \\
\text { 7-A41. }\end{array}$ & $\begin{array}{l}\text { Itens } 5 \text { through } 7 \text { were created using a } \\
\text { thesaurus to match synonyms for satisfaction. }\end{array}$ \\
\hline $\begin{array}{l}\text { Teriunoloxyy Self } \\
\text { Gratification }\end{array}$ & 6 & $1,2,3,4,5,6$ Author & $1-A 3 ; 2-\Lambda 13 ; 3-\Lambda 17 ; 4-\Lambda 24 ; 5-\Lambda 32,6-A 40$ & $\begin{array}{l}\text { Measures self gratification wich subjects } \\
\text { receive from working with PCs. }\end{array}$ \\
\hline \multicolumn{5}{|c|}{ Irrelevant Appraisal } \\
\hline Indi f ference & 7 & $1,2,3,4,5,6,7$ nuthor & $\begin{array}{l}1-A 6 ; 2-A 12 ; 3-\Lambda 19 ; 4-A 22 ; 5-A 31 ; 6-\lambda 4 B ; \\
7-\Lambda 44 .\end{array}$ & $\begin{array}{l}\text { Measures indifference with which subjects } \\
\text { view the inyact of PCs upon their jobs. }\end{array}$ \\
\hline \multicolumn{5}{|c|}{ Threat Appraisal } \\
\hline liear & 7 & $1,2,3,4,5,6,7$ Author & $\begin{array}{l}1-\Lambda 2 ; 2-\AA 9 ; 3-A 18 ; 4-A 25 ; 5-A 30 ; 6-A 38 ; \\
7-A 42 .\end{array}$ & $\begin{array}{l}\text { Neasures how threatened, fearful or uncertain } \\
\text { subjects feel PCs were to them or their } \\
\text { profession. }\end{array}$ \\
\hline Anxicty & 5 & $\begin{array}{l}1,2,3 \text { Martin \& Wall } 1989 \\
4,5 \text { Author }\end{array}$ & $1-A 4 ; 2-A 11 ; 3-A 16 ; 4-\Lambda 26 ; 5-A 34$. & $\begin{array}{l}\text { Items } 4 \& 5 \text { were created using a thesaurus } \\
\text { to match synonyms for anxious. }\end{array}$ \\
\hline
\end{tabular}


The author would rather have too many items and have the luxury of reducing excessive items from the pilot instrument, rather than find out that an insufficient number of items were used and that the resulting Cronbach's alpha was below the acceptable level.

Irrelevant Appraisal. The Irrelevant Appraisal consisted of a single, seven item scale (labeled Indifference) which measures a computer professional's belief that the PC will not have much of an effect on their job. Table I presents the sources and nature of the items in this scale which measures indifference.

Threat Appraisal. For the Threat Appraisal two typical psychological responses were measured: Fear and Anxiety. Table I presents the sources and nature of the items in this scale which measures the fear, uncertainty, anxiety, or threat which computer professionals may feel toward PCs.

\section{Second Level of Appraisals (B)}

For those subjects exhibiting the Threat Appraisal, there is a second level (labeled the B Level) of appraisal which they undergo due to the uncertainty, duration, and imminence of the threat. This $B$ Level is called the Threat/Cognitive Appraisal.

Threat/Cognitive Appraisal. They undergo this Threat/Cognitive appraisal until the change either occurs 
or else is determined not to occur. To determine if the those computer professionals who perceive the Threat Appraisal also experience the Threat/Cognitive Appraisal, six cateqories of typical psycholoqical responses to threat will be measured: 1. Self Esteem, 2. Subjective Stress, 3. Mastery, 4. Interpersonal Trust, 5. Somatic symptoms, and 6. Performance Difficulty.

Table II presents the sources and nature of the items in the scales which measure self Esteem, subjective stress, Mastery, Interpersonal Trust, somatic symptoms, and Performance Difficulty.

Third Level of Apprạisals__(C)

For those computer professionals who experience the Threat Appraisal, and going through the Cognitive Appraisal, finally either the change does or does not occur, which leads to the $C$ Level of the model. For our case the PC does exist and all the target IOUs have moved, or plan on moving, ahead with the implementation of PCs in the organization. Hence, there is not a measure to determine if post stress reaction occurred in the case when no change occurs (i.e. PCs are not implemented in the company). Our model indicates that when the change does occur, those who felt threatened by the prospect of PC usage within their companies will either have a Harm/Loss Appraisal or a Challenge Appraisal. 
I'MIILE I.I

SOURCES OF PIIGY INSIRUMDNI SCALFS AND I'IDMS - LEVEI, B

\begin{tabular}{|c|c|c|c|c|}
\hline Variable. & $\begin{array}{l}\text { Hof } \\
\text { Itoms }\end{array}$ & Source & 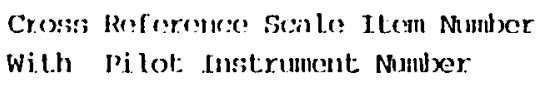 & Conmenta \\
\hline Solf Fiteen & 10 & 1-10 Rosenbury 1965 & 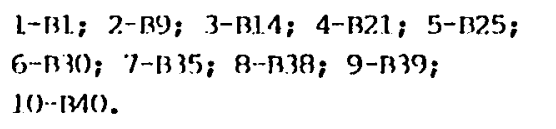 & Referrexl to as Rosenburcy's Self Esteen Scale. \\
\hline Subjective Stress & 84 & $\begin{array}{l}\text { 1-4 Shar, Reeder, \& } \\
\text { Dirken } 1973\end{array}$ & $1-\mathrm{B} 3 ; 2-\mathrm{B} 1.0 ; 3-\mathrm{B} 15 ; 4-1319$ & $\begin{array}{l}\text { Original ly developer by the American Heart } \\
\text { Association } 1968 \text {. }\end{array}$ \\
\hline Mastery & 7 & $\begin{array}{l}\text { 1-7 Folkman, Lazarus, } \\
\text { Gruen, \& DeLongis } 1986\end{array}$ & $\begin{array}{l}1-\mathrm{B} 2 ; 2-\mathrm{B} 7 ; 3-\mathrm{B} 16 ; 4-\mathrm{B} 23 ; 5-1326 ; \\
6-\mathrm{B} 32 ; 7-\mathrm{B} 36 .\end{array}$ & $\begin{array}{l}\text { Originally developed by pearlin schooler, } \\
\text { 1978. Assesses the extent to which one regards } \\
\text { one's life as being under one's control, in } \\
\text { contrast to being fatalistically determiner. }\end{array}$ \\
\hline $\begin{array}{l}\text { Interpersonal } \\
\text { Trust }\end{array}$ & 7 & $\begin{array}{l}\text { 1-7 Folkman, Iazarus, } \\
\text { Gruen, \& Delongis } 1986\end{array}$ & $\begin{array}{l}1-\mathrm{BA} ; 2-\mathrm{B} 11 ; 3-\mathrm{B} 17 ; 4-\mathrm{B} 2 \mathrm{O} ; \\
5-\mathrm{B} 29 ; 6-\mathrm{B} 33 ; 7-\mathrm{B} 37\end{array}$ & $\begin{array}{l}\text { Derived from a substantially shortened version } \\
\text { of Rotter's Scales } 1980 \text {. }\end{array}$ \\
\hline $\begin{array}{l}\text { Somatic } \\
\text { Symptans }\end{array}$ & 6 & $\begin{array}{l}\text { 1-6 Synptom Distress } \\
\text { Checklist by Parloff, } \\
\text { Kelman \& Frank } 1954\end{array}$ & $\begin{array}{l}\text { 1-B6; 2-B8; 3-B.18; 4-B22; 5-B27; } \\
\text { 6-B34. }\end{array}$ & $\begin{array}{l}\text { Also used by Lipman, Kickles, Covi, Derogatis, } \\
\text { and Uhlenhuth } 1969 .\end{array}$ \\
\hline $\begin{array}{l}\text { Perfonnance } \\
\text { Difficulty }\end{array}$ & 6 & $\begin{array}{l}\text { 1-6 Symptom Distress } \\
\text { Checklist by Parloff, } \\
\text { Kelman \& Frank } 1954\end{array}$ & $\begin{array}{l}1-\mathrm{B} 5 ; 2-\mathrm{B} 12 ; 3-\mathrm{B} 13 ; 4-\mathrm{B} 24 ; \\
5-\mathrm{B} 28 ; 6-\mathrm{B} 31 .\end{array}$ & $\begin{array}{l}\text { Both Somatic Symptans \& Performance Difficulty } \\
\text { are subsets of the Symptom Distress Checklist. }\end{array}$ \\
\hline
\end{tabular}


Harm/Loss Appraisal. The Harm/Loss Appraisal is measured by four typical psychological responses, namely: 1. Depression and 2. Resentment for the alienation outcome; and 3. Satisfaction with company and 4. Acceptance for the acceptance outcome. Table II presents the sources and nature of the items in the scales which measure Depression, Resentment, Satisfaction with Company, and Acceptance of the new technology.

Challenge Appraisal. The Challenge Appraisal is measured by three typical psychological responses to personal challenge, namely: 1. Challenge, 2. Enthusiasm, and 3 . Pleasure.

Table III presents the sources and nature of the items in the scales which measure Challenge, Enthusiasm, and Pleasure.

Appendix A contains the original set of scales and items which are used in the pilot questionnaire. Appendix B contains a copy of the pilot questionnaire which was administered to those companies which are presently at Level $C$ in their use of PCs.

The scales represent the means for being able to measure the emotions and feelings that the computer professionals experience as they go through the change event associated with the introduction of PCs into their workplace. 
TABLE III

SOURCSS OE PILOT INSTRUMTEN SCALES AND ITENS - LEVEL, C

\begin{tabular}{|c|c|c|c|c|}
\hline Variable & $\begin{array}{l}\text { \# of } \\
\text { Items }\end{array}$ & Source & $\begin{array}{l}\text { Cross Reference Scale Item Muniber } \\
\text { With pilot Instrument }\end{array}$ & Commenes \\
\hline \multicolumn{5}{|c|}{ Harm/Loss Appraisal } \\
\hline Depression & 10 & $\begin{array}{l}1,2,3 \text { Martin \& Wall } 1989 \\
4,5,5 \text {, Author } \\
7,8,9,10 \text { Sympton Distress } \\
\text { checklist, Parloff et al.1954 }\end{array}$ & $\begin{array}{l}1-C 1 ; 2-C B ; 3-C 17 ; 4-C 23 ; 5-C 32 ; \\
6-C 36 ; 7-C 42 ; 8-C 47 ; 9-C 51 ; \\
10-C 53 .\end{array}$ & $\begin{array}{l}\text { The author combined two well known scales for puposes } \\
\text { of the pilor instrument to measure depression. Itens } \\
4,5,6 \text { were created using the form of the Martin } 8 \text { wall } \\
\text { items and a thesaurus to match smonyms for depresion. }\end{array}$ \\
\hline Resentment & 5 & $\begin{array}{l}\text { 1,2,3 Sympton Distress } \\
\text { Checklist, Parloff ut } \\
\text { al. 1954; 4,5 Author }\end{array}$ & $1-C_{3} ; 2-C_{12} ; 3-c_{1} ; 4-c_{2} 5 ; 5-c_{3} ;$ & $\begin{array}{l}\text { The author added two additional itens in order to have } \\
\text { more than just three itens. The author's items dealt } \\
\text { with feeliny bitter or aggrevated about what has happened. }\end{array}$ \\
\hline $\begin{array}{l}\text { Satisfaction } \\
\text { with comsany }\end{array}$ & 6 & $1,2,3,4,5,6$ Author & $\begin{array}{l}1-C_{4} ; 2-C_{1} 4 ; 3-C_{15} ; 4-C_{2} ; 5-C_{3} ; \\
6-C_{3} .\end{array}$ & $\begin{array}{l}\text { The author created six items to measure the level of } \\
\text { satisfaction the computer professionals feit with the } \\
\text { organization as another measure of resentment. }\end{array}$ \\
\hline Acceptance & $\mathbf{8}$ & $1,2,3,4,5,6,7,8$ Author & $\begin{array}{l}1-C_{3} 2-C_{1} 1 ; 3-C_{2} 0 ; 4-C_{2} 7,5-C_{2} 9 ; \\
6-C_{3} ; 7-C_{4} ; 8-C_{4} 8 .\end{array}$ & $\begin{array}{l}\text { These questions are oriented toward the computer } \\
\text { professional's accaptance of PCs. }\end{array}$ \\
\hline
\end{tabular}

Challenge Appraisal

\begin{tabular}{|c|c|c|c|c|}
\hline quallenge & 8 & $1,2,3,4,5,6,7,8$ Author & $\begin{array}{l}1-C 7 ; 2-C 9 ; 3-C 19 ; 4-C 24 ; 5-C 35, \\
6-C 39 ; 7-C 43 ; 8-C 49 .\end{array}$ & $\begin{array}{l}\text { The author creaced eight items to measure the extent } \\
\text { of challenge presented by the new technologies. }\end{array}$ \\
\hline Enchusiasm & 7 & $\begin{array}{l}\text { 1,2,3 sartin \& Wall } 1989 \\
4,5,6,7 \text { Author }\end{array}$ & $\begin{array}{l}1-C 2 ; 2-C 13 ; 3-C 21 ; 4-C 26 ; 5-C 31 ; \\
6-C 40 ; 7-C 46 .\end{array}$ & $\begin{array}{l}\text { Itens } 4 \text { through } 7 \text { were created using a thesaurus } \\
\text { to match synonyms for enthusiasm. }\end{array}$ \\
\hline Contentment & 9 & $\begin{array}{l}1,2,3 \text { Martin \& wall } 1989 \\
4,5,6,7,8,9 \text { Author }\end{array}$ & $\begin{array}{l}1-C \sigma ; 2-C 10 ; 3-C 16 ; 4-C 28 ; S-C 30 \\
6-C 41 ; 7-C 45 ; 8-C 50 ; 9-C 52 \text {. }\end{array}$ & $\begin{array}{l}\text { Itens } 4 \text { through } 9 \text { were created using a thesaunus } \\
\text { to match symanyms for contentment. }\end{array}$ \\
\hline
\end{tabular}


Demographic Data

Demographic data is also included to determine the computer professionals: sex, age, salary level, years of experience, education level, and current access to PCs.

The Completed Pilot Instrument

The pilot instrument then consists of five parts (see Appendix B for sample). The first part is a general section with demographic information about the individual computer professional who is answering the questionnaire. The second part is a series of 48 multiple choice questions which are designed to measure responses to Level $A$ of the model. The third part is a series of 38 multiple choice questions which are designed to measure responses to Level $B$ of the model. The fourth part is a series of 53 multiple choice questions which are designed to measure responses to Level $C$ of the model. The fifth part is a comments page in which the respondents are free to make any comments which they believe might help the author improve the instrument. The total number of multiple choice questions totalled 146 , which makes for a fairly long questionnaire.

The above instrument was tested on the previously mentioned two companies and for the various categories of psychological responses. The answers to the associated items were tested using Cronbach's alpha which is a generally accepted measure of scale reliability. Alpha 
can range from a value of one on down to minus infinity, with a value of one indicating that the items in a scale have perfect reliability, and negative values are treated as "zero" with zero as an indication of no reliability. Most researchers are very pleased if the ir various measures have alphas greater than .70, with even an occasional .60 being acceptable. The author has set a standard that any alpha less than .70 will be unacceptable for this research.

\section{Results of the Rilot Instrument}

A total of 124 questionnaires were submitted to the two pilot companies. A total of 51 questionnaires were received back by the author for a response rate of 41 percert.

The IOU which has a hundred computer professionals has their staff physically located at two geographically separate locations. One of the locations is close by the author's location, and the other is several hundred miles away. From the nearby location the response rate was over 60 percent, but from the remote location the response rate was very poor. One of the managers from the nearby location indicated that this was to be expected as the remote people seldom received much communication from the local people, and as a result gave very little back. Mechanics of analysis. The responses from the 51 questionnaires were entered into a hard drive on an IBM PC. 
The PC software packages called SYSTAT, SYGRAPH, and TESTAT were used to perform the data collection and analys is. SYSTAT and SYGRAPH were purchased through Portland state University's Computer Services Department, and a copy of TESTAT was purchased directly from SYSTAT, Inc. in Evanston, Illinois.

SYSTAT contains commands which will enter data, manipulate data, and perform various statistical analysis. SYGRAPH has various plotting and graphic capabilities. TESTAT has routines for the testing the validity and reliability of questionnaire data which includes the computation of Cronbach's alpha based upon the raw data entered from the questionnaires.

One of the author's goals is to make a more compact questionnaire. This desire was borne out by several of the comments received from respondents to the pilot questionnaire. There were several comments both written and oral given to the author that the questionnaire was too lengthy, and advise was given that if the author really wanted to get people to fill it out and have an acceptable response rate, then it needed to be reduced in length. There were two criteria used for the evaluation of deleting, modifying, or adding items to a particular scale. The first deals with Cronbach's alpha. The alpha must be above .70 , and if alpha is below that level then the items on the scale must be examined and a determination made as 
to which items are causing a low alpha. Then, the items must be modified, deleted, or new items added, in an attempt to increase alpha above the .70 level.

The second deals with the desire to shorten the questionnaire. The author decided that no less than four items would be acceptable for any scale, even though some other researchers from whom the author had borrowed scales had scales with as little as three items, the author felt that since he only had one chance to administer the final questionnaire he would rather go forward with a slight cushion. Additionally, there was a practical matter that the SYSTAT and TESTAT software packages would not accept any less than four items per scale. However, even though there was a desire to limit the number of items per scale, if in the process of computing Cronbach's alpha it was determined that by eliminating an item from the scale, it would adversely lower alpha by more than .010, then that item would be retained.

For each of the various scales associated with each of the psychological responses, Cronbach's alpha was computed for the items associated with that particular scale. The TESTAT package not only computes Cronbach's alpha, but also displays for each item what the Cronbach alpha would have been for that scale if that particular item was not included. 
For example, the Challenge scale has eight items:

1. I feel that the new technology will provide exciting challenges.

2. I am really challenged by the new technology we have.

3. I feel the challenge of the new technology will provide opportunities.

4. The new technologies we have are making this a more interesting place to work.

5. The new technologies are like a breath of fresh air and invigorate me.

6. With the new technology my job is every bit as important as it has ever been.

7. With the new technology I will be able to show how important I am to this organization.

8. With the new technology this company will not be able to get along without me, or people like me. Computing Cronbach's alpha on the pilot data for the $C$ Level for Challenge an alpha $=.809$ was computed. This is an acceptable alpha, and since one of the goals is to reduce the length of the questionnaire, and to avoid unnecessary redundancy, then it is possible to eliminate one or more of the items. As was mentioned, TESTAT also gives the information as to what the alpha would have been if each one of the items had been omitted. The print out from TESTAT gave the following information: 
"Value for Alpha excluding this item:

$\begin{array}{llllllllll}\text { Item \# } & 1 & 2 & 3 & 4 & 5 & 6 & 7 & 8\end{array}$

Alpha $\quad .771 \quad .765 \quad .760 \quad .753 \quad .750 \quad .791 \quad .835 \quad .855^{\prime \prime}$

As can be seen from the above numbers, since the alpha for all eight items is .809 , then by omitting item eight the total alpha is not adversely effected, and in this case it is even slightly improved by .046 to .855 .

The data was rerun with item 8 being omitted and an alpha $=.855$ was computed as predicted, along with the following:

"Value for Alpha excluding this item:

$\begin{array}{lrrrrrrc}\text { Item \# } & 1 & 2 & 3 & 4 & 5 & 6 & 7 \\ \text { Alpha } & .831 & .824 & .819 & .803 & .810 & .852 & .889 \\ \text { Once again, it is observed that an item can be dropped }\end{array}$
without hurting (and in fact helping) the alpha, namely item seven can be dropped.

The data was rerun with item seven omitted and an alpha $=.889$ was computed, along with the following: "Value for Alpha excluding this item.

$\begin{array}{lrrrrrr}\text { Item \# } & 1 & 2 & 3 & 4 & 5 & 6 \\ \text { Alpha } & .871 & .873 & .859 & .854 & .857 & .903 " \\ \text { Once again, it is observed that an item can be dropped }\end{array}$
without hurting (and in fact increasing) the alpha, namely item six can be dropped.

The data was rerun with item six being omitted and an alpha $=.903$ was computed along with the following: 
"Value for Alpha excluaing this item.

$\begin{array}{llllll}\text { Item \# } & 1 & 2 & 3 & 4 & 5\end{array}$

Alpha $\quad .884 \quad .889 \quad .869 \quad .885 \quad .878^{\prime \prime}$

At this point any further reduction of items, namely Item 2, would cause a decrease in the value of Alpha, although admittedly a small reduction of .014 . Thus, the Challenge scale used in the final instrument consisted of the above five items.

Some scales were used in both the A Level of the model and in the $\mathrm{C}$ Level of the model. It is interesting to note what happened when Cronbach's alpha was computed and the above criteria for analyzing the items in the scale was applied. In all the cases, the same items were eliminated, and the final alpha for the reduced set of items was similar. For example, the Enthusiasm scale was used in both the A Level and the C Level. For Level A the Enthusiasm scale resulted in items 1,2 , and 3 being omitted because they had the least effect on alpha, with a final alpha of .936 being computed.. For Level $c$ of the model, the same first three items were omitted, and the resulting items $4,5,6$, and 7 yielded an alpha of .959 . Final outcome of pilot questionnaire. Values of Cronbach's alpha for the various scales run from .70 to .96, with the exception of one particular scale which only had an alpha of .58 (which will be discussed later). This 
is a good set of alphas, with the one noted exception, and gives an indication of good scale reliability.

Table IV gives the results of Cronbach's alpha for the various scales at the A Level of appraisals, namely: Benign-Positive, Irrelevant, and Threat.

Within the Threat Appraisal, a problem of scale reliability occurred for the Anxiety scale which required some corrective action. Originally, there were seven items in the scale, some of which had very poor reliability indexes. After eliminating 3 of the 7 items the alpha was only .58 which is considerably below the minimum target of .70 which the author had set. If four out of seven items were dropped, leaving only three items, then the alpha was raised above the .70 level, but the author had set another target of having at least four items for each scale, so this was unacceptable. After detailed investigation of the 51 individual responses to the seven items in the scale, the author determined a pattern as to what caused the inconsistent responses to the anxiety scale. Accordingly, the author decided to drop two of the items, reword another two items, and to add an additional item. Thus, Anxiety ended up as a six item scale. It did not seem to be practical to retest this one item on the pilot companies, so the modified scale was used in the final questionnaire and its Cronbach alpha was recomputed after the six target 
TABLE IV

RESULTS OF PILOT INSTRUMETT - LEVEL A

\begin{tabular}{|c|c|c|c|c|}
\hline Variable & $\begin{array}{l}\text { of Initial } \\
\text { Items }\end{array}$ & $\begin{array}{l}\text { \# of Final } \\
\text { Items }\end{array}$ & $\begin{array}{l}\text { Alpha For } \\
\text { Einal Iterns }\end{array}$ & $\begin{array}{l}\text { Cross Reference Scale Item Number } \\
\text { With Pilot Instrument Number }\end{array}$ \\
\hline & & & Benign-Positive & Appraisal \\
\hline Enthusiasm & 7 & 4 & .94 & $1-A 1 ; 2-A 8 ; 3-A 21 ; 4-A 28 ; 5-A 35 ; 6-.36 ; 7-A 43$ \\
\hline Contentment & 9 & 5 & .95 & $1-A 5 ; 2-A 14 ; 3-A 15 ; 4-A 27 ; 5-A 29 ; 6-A 39 ; 7-A 45 ; 8-A 46 ; 9-A 47$. \\
\hline Job Satisfaction & 7 & 5 & .89 & $1-A 7 ; 2-A 10 ; 3-A_{2} 0 ; 4-A_{2} 3 ; 5-A 33 ; 6-A .37 ; 7-A 41$ \\
\hline \multicolumn{5}{|l|}{ Technology } \\
\hline Self Gratification & 6 & 4 & .86 & $1-A 3 ; 2-A_{13} ; 3-A 17 ; 4-Z_{2} 4 ; 5-A_{3} ; 6-A 40$ \\
\hline
\end{tabular}

Irrelevant Appraisal

Indifference $\quad 7 \quad 4 \quad .86 \quad 1-A 6 ; 2-A 12 ; 3-A 19 ; 4-A 22 ; 5-A 31 ; 6-A 48 ; 7-A 44$.

Threat Appraisal

$\begin{array}{lllll}\text { Fear * } & 7 & 6 & .58 & 1-\mathrm{A} 2 ; 2-\mathrm{A} 9 ; 3-\mathrm{A} 18 ; 4-\mathrm{A} 25 ; 5-\mathrm{A} 30 ; 6-\mathrm{A} 38,7-\mathrm{A} 42 . \\ \text { Anxiety } & 5 & 5 & .85 & 1-\mathrm{A} 4 ; 2-\mathrm{A} 11 ; 3-\mathrm{A} 16 ; 4-\mathrm{A} 26 ; 5-\mathrm{A} 34 .\end{array}$

* Some itens in this scale were modified because of the low alpha. rtems five and six were dropped, and

a new item added. Iten four was modified to more clearly indicate fear of PCs. 
companies had completed the questionnaire. The author believes the resulting alpha will be acceptable.

Table $V$ gives the pilot instrument results of scale reliability for the $B$ Level of appraisal. Specifically, the Cognitive Appraisal which follows the Threat Appraisal. There are six categories of typical psychological responses to threat for which measurement scales were developed: 1 . Self Esteem, 2. Subjective Stress, 3. Mastery, 4. Interpersonal Trust, 5. Somatic symptoms, and 6 . Performance Difficulty.

One of the scales experienced scale reliability difficulties. For Subjective stress, an alpha of .71 was achieved when dropping one item of a four item scale and only using the three remaining items. When all four items were used the alpha was only .66 for the scale. This left a conflict with two of the original targets which the author set, namely that no alpha would be below .70 and that no less than four items per scale would be used. The first item in the scale was the cause of the alpha being below .70, and when it was omitted the alpha rose to an acceptable range. The author examined the detailed responses of the 51 individuals to the questionnaire and determined a pattern of inconsistent responses which had to do with interpretation of the meaning of the first item. 
TABLE V

RESULTS OF PILOT IRSTRUMENT - LEVEL B

\begin{tabular}{|c|c|c|c|c|}
\hline Variable & $\begin{array}{l}\text { of Initial } \\
\text { Items }\end{array}$ & $\begin{array}{l}\text { \# of Final } \\
\text { Items }\end{array}$ & $\begin{array}{l}\text { Alpha for } \\
\text { Final Items }\end{array}$ & $\begin{array}{l}\text { Cross Reference Scale Iten Number } \\
\text { With Pilot Instrunent Number }\end{array}$ \\
\hline Self Esteem & 10 & 5 & .85 & $\begin{array}{l}1-\mathrm{B} 1 ; 2-\mathrm{B} 9 ; 3-\mathrm{B} 14 ; 4-\mathrm{B} 21 ; 5-\mathrm{B} 25 ; 6-\mathrm{B} 30 ; 7-\mathrm{B} 35 ; \\
8-\mathrm{B} 38 ; 9-\mathrm{B} 39 ; 10-\mathrm{B} 40 .\end{array}$ \\
\hline Subjective Stress * & * 4 & 5 & .66 & $1-\mathrm{B} 3 ; 2-\mathrm{B} 10 ; 3-\mathrm{B} 15 ; 4-\mathrm{B} 19$. \\
\hline Mastery & 7 & 5 & .75 & $1-\mathrm{B} 2 ; 2-\mathrm{B} 7 ; 3-\mathrm{B} 16 ; 4-\mathrm{B} 23 ; 5-\mathrm{B} 26 ; 6-\mathrm{B} 32 ; 7-\mathrm{B} 36$. \\
\hline $\begin{array}{l}\text { Interpersonal } \\
\text { 'I'rust }\end{array}$ & 7 & 5 & .70 & $\begin{array}{l}\text { 1-B4; 2-B11; 3-B17; 4-B20; 5-B29; 6-B33; } \\
\text { 7-B37. }\end{array}$ \\
\hline Somatic Symptoms & 6 & 5 & .81 & $1-\mathrm{B} 6 ; 2-\mathrm{B} 8 ; 3-\mathrm{B} 18 ; 4-\mathrm{B} 22 ; 5-\mathrm{B} 27 ; 6-\mathrm{B} 34$ \\
\hline Performance & 6 & 5 & .75 & $1-\mathrm{B} 5 ; 2-\mathrm{B} 12 ; 3-\mathrm{B} 13 ; 4-\mathrm{B} 24 ; 5-\mathrm{B} 28 ; 6-\mathrm{B} 31$ \\
\hline
\end{tabular}

* Without item \# 1 the alpha for Subjective Stress would be . 71 , but this would only leave three questions which is below the acceptable level of at least four itens. A determination was made by the author to rewrite question \# 1 and to add a fifth question for the final questionaire in an effort to increase the alpha when the final questionaire is administered to the computer professionals in the six IOUs. 
Consequently, the first item was reworded, and the author added a fifth item, the net effect of which should be to raise the alpha to be within an acceptable range.

For Performance Difficulty all six items yielded an alpha of .75 . An alpha of .75 was retained when dropping one item of the six item scale. While an alpha of .75 is within the authors acceptable range, it is a lower alpha than the other scales, and the author opted to modify the scale in order to achieve a higher alpha for the final instrument. One of the retained items was slightly reworded to be more consistent with the other items, which should raise the final alpha higher.

Table VI gives the pilot instrument results of scale reliability for the $\mathrm{C}$ Level of appraisal. Which consists of either a Harm/Loss Appraisal or a Challenge Appraisal. specifically, there are a total of seven categories of typical psychological responses which had scales developed for them.

For the Harm/Loss Appraisal there are two prevalent outcomes: alienation or acceptance. Accordingly, the typical psychological responses represent those two types of outcomes. For the alienation outcome the two categories of typical psychological responses are: 1. Depression and 2. Resentment. For the acceptance outcome the two categories of typical psychological responses are: 1. Satisfaction with Company, and 2. Acceptance. 
TABLE VI

RESULTS OF PILOI INSTRUIIENT - L,EVEL C

\begin{tabular}{|c|c|c|c|c|}
\hline Variable & $\begin{array}{l}\text { \# of Initial } \\
\text { Items }\end{array}$ & $\begin{array}{l}\text { \# of Final } \\
\text { Items }\end{array}$ & $\begin{array}{l}\text { Alpha For } \\
\text { Final Itenss }\end{array}$ & $\begin{array}{l}\text { Cross Reference Scale Item Number } \\
\text { With Pilot Instrument Nunber }\end{array}$ \\
\hline
\end{tabular}

Hann/Loss Appraisal

$\begin{array}{lllll}\begin{array}{l}\text { Repression } \\ \text { Resentunt }\end{array} & 10 & 5 & .85 & \begin{array}{l}1-\mathrm{C} 1 ; 2-\mathrm{C} 8 ; 3-\mathrm{C} 17 ; 4-\mathrm{C} 23 ; 5-\mathrm{C} 32 ; 6-\mathrm{C} 36 ; 7-\mathrm{C} 42 ; \\ 8-\mathrm{C} 47 ; 9-\mathrm{C} 51 ; 10-\mathrm{C} 53 .\end{array} \\ \begin{array}{l}\text { Satisfaction } \\ \text { With Cornuany }\end{array} & 5 & 4 & .87 & 1-\mathrm{C} 3 ; 2-\mathrm{C} 12 ; 3-\mathrm{C} 18 ; 4-\mathrm{C} 25 ; 5-\mathrm{C} 33 . \\ \text { Acceptance } & 6 & 4 & .80 & 1-\mathrm{C} 4 ; 2-\mathrm{C} 14 ; 3-\mathrm{C} 15 ; 4-\mathrm{C} 22 ; 5-\mathrm{C} 34 ; 6-\mathrm{C} 38 . \\ & 8 & 4 & .89 & 1-\mathrm{C} 5 ; 2-\mathrm{C} 11 ; 3-\mathrm{C} 20 ; 4-\mathrm{C} 27 ; 5-\mathrm{C} 29 ; 6-\mathrm{C} 37 ; 7-\mathrm{C} 44 ; 8-\mathrm{C} 48 .\end{array}$

Challenge Apprai.sal

$\begin{array}{lllll}\text { Challenge } & 8 & 5 & .90 & 1-\mathrm{C} 7 ; 2-\mathrm{C} 9 ; 3-\mathrm{C} 19 ; 4-\mathrm{C} 24 ; 5-\mathrm{C} 35 ; 6-\mathrm{C} 39 ; 7-\mathrm{C} 43 ; 8-\mathrm{C} 49 . \\ \text { Enthusiasm } & 7 & 4 & .96 & 1-\mathrm{C} 2 ; 2-\mathrm{C} 13 ; 3-\mathrm{C} 21 ; 4-\mathrm{C} 26 ; 5-\mathrm{C} 31 ; 6-\mathrm{C} 40 ; 7-\mathrm{C} 46 . \\ \text { Contentanent } & 9 & 5 & .89 & \begin{array}{l}1-\mathrm{C} 6 ; 2-\mathrm{C} 10 ; 3-\mathrm{C} 16 ; 4-\mathrm{C} 28 ; 5-\mathrm{C} 30 ; 6-\mathrm{C} 41 ; 7-\mathrm{C} 45 ; \\ 8-\mathrm{C} 50 ; 9-\mathrm{C} 52 .\end{array}\end{array}$


For the Challenge Appraisal the three categories of typlcal psychological responses were: 1. Challenge,

2. Enthusiasm, and 3. Pleasure.

For the $C$ Level of appraisal there were no problems of scale reliability encountered with the pilot instrument. The values for Cronbach's alpha ranged from a low of .80 for Satisfaction with Company, to a high of .96 for Enthusiasm. Also, the number of items per scale are reduced to either four or five.

As can be judged from the Tables IV, V, and VI, a significant number of unnecessary items (40) have been eliminated without sacrificing the scale reliability. Thus, one of the goals of reducing the number of questions in the questionnaire has been accomplished by reducing from 142 to $102(-28 \%)$ the total number of responses required. Based on the written comments in the pilot questionnaire (as well as oral comments from several of the participants), it is believed that the response rate will increase because of the shortening of the number of the questions. This has been achieved while still maintaining the goal set for values of Cronbach's alpha.

\section{Further Field Testing}

It is always desirable to perform further field testing after a questionnaire is modified, however there is also the practical limit as to how many MIS managers from 
companies will continue to participate in what they view as merely an academic exercise. The author felt that the effort and courtesy extended to him by the participants was sufficient and that to ask them to do more would be excessive. For the other remaining IoUs in the Northwestern United States, they were the target companies and the author desired to leave them undisturbed until the final questionnaire was administered.

Rather than try to extend the territory for testing to IOUs outside of the Northwest, or to try and get participation from similar organizations, such as public utility departments, where the author had no contacts, another approach was used. The author utilized personal interviews with twelve computer professionals who had taken the original pilot questionnaire. First, they were interviewed after they had completed the questionnaire and their impressions were noted. Mostly they complained about the length of the questionnaire, with the second most common complaint being of the redundancy of many of the questions. These were also the most frequent of the written complaints turned in with the questionnaire.

Their third most common complaint was that they did not see the relevancy of the questionnaire as to how it is going to help computer professionals adjust to change. This type of comment was also noted in some of the written comments on the questionnaire. The author did not indicate 
to anyone what the real purpose of the questionnaire was other than to make a vague reference to it being "an attempt to measure the responses of computer professionals to the introduction and use of personal computers (PCs) in the workplace." The author did not want to bias the respondents by giving them too much information about it being an instrument to analyze a model, and of course they were never shown the model. It is interesting to note that many people still arrived at their own conclusions as to what the real purpose was, and did an evaluation as to whether or not the instrument would be effective for the purpose which they had imagined for it.

After the questionnaire had been redesigned, the same twelve computer professionals were shown the revised instrument and then interviewed for their comments again. Their comments were duly noted, and then they were shown the model which was to be analyzed, were told the purpose of the questionnaire and how it was to help in the analysis of the model. Further comments were solicited at this point and then noted. These comments were utilized in making further revisions to the questionnaire. Appendix $\mathrm{C}$ contains the revised items for the final questionnaire. Appendix $D$ contains the revised items for the final questionnaire cross referenced with the numbers for the items as shown on the pilot instrument. 
Thus, further field testing of the revised questionnaire was made in person using a one-on-one situation with computer professionals who had already taken the questionnaire, and who eventually were given full knowledge of the purpose of the questionnaire. Having completed all this testing, the author decided it was appropriate to risk the issuance of the questionnaire to the six target companies. There is always an element of risk that something has been overlooked, and when the completed questionnaires are received and Cronbach's alpha recomputed that the questionnaire may be found lacking.

Appendix $E$ contains a copy of the final questionnaire which was issued to the target Ious. 
CHAPTER IV

ANALYSIS AND CONCLUSIONS

INTRODUCTION

The response rates of the companies are over fifty percent for all companies. The scale reliability and Cronbach's alpha are presented and discussed. The various distribution of responses and the correlations of responses are presented and discussed. Based on the findings of the quasi-experiment the analysis postulates are confirmed. The demographic results are presented and tested for statistical independence.

\section{RESPONSE RATE}

A total of 294 questionnaires were submitted to the six target companies. In Table VII a summary of basic data, about the target companies and the associated responses, is given. A total of 201 questionnaires were received back by the author for a response rate of 68 percent. Of those questionnaires received back, there were a total of five which were not usable by the author for purposes of this research because they were not completely filled out. 
TABLE VII

RESPONSE RATE DATA

\begin{tabular}{lcccccc}
\hline $\begin{array}{l}\text { Company } \\
\text { Number }\end{array}$ & Sent & Returned $(\%)$ & Usable $(\%)$ & $\begin{array}{c}\text { Level PC } \\
\text { Penetration }\end{array}$ \\
\hline 1. & 27 & 21 & $78 \%$ & 21 & $78 \%$ & A \\
2. & 56 & 38 & $68 \%$ & 37 & $66 \%$ & B \\
3. & 30 & 22 & $73 \%$ & 21 & $70 \%$ & B \\
4. & 66 & 49 & $74 \%$ & 49 & $74 \%$ & C \\
5. & 45 & 33 & $73 \%$ & 31 & $69 \%$ & C \\
6. & 70 & 38 & 548 & 37 & $53 \%$ & C \\
\hline
\end{tabular}


In one case the respondent filled out about a third of the questionnaire and wrote that he felt the questionnaire was redundant and too lengthy to deserve his further attention. In the other four cases the respondents filled out the initial personal information and the portions relating to Levels $B$ or $C$, but did not fill out the portions relating to Level $A$. In one case a respondent indicated that she did not join the company until after the company had already progressed past Level A. The author believes the same situation probably accounted for the other three similar responses.

\section{SCALE RELIABILITY AND CRONBACH'S ALPHA}

The analysis of scale reliability which was conducted upon the responses from the pilot companies led the author to modify some of the items associated with certain scales, and to reduce the number of items for most of the scales. Hence, it is appropriate to recompute Cronbach's alpha for the responses received from the target companies. Table VIII gives the summary of the alpha computations, with all of the values being greater than or equal to .80 which are good results and exceeds the author's goal of not having an alpha below the value of .70 .

Those scales which had marginal alphas on the pilot instrument, and required modification to the items, all have considerably higher alphas well within the acceptable 
range which was established as a criteria as can be seen in Table VIII.

\section{LEVEL A ANALYGIG}

For Level A of the model, there are two key aspects in being able to determine if the proposed model is supported by the data. The first is if the respondents can be categorized into the three appraisals which the model states should occur in Level A, namely: 1. Benign-Positive Appraisal, 2. Irrelevant Appraisal, or 3. Threat Appraisal. The second aspect deals with the correlation of the scales which are indicative of the responses of people while at Level A.

\section{Distribution of Responses}

While the three appraisals of Level A (Benign-Positive Appraisal, Irrelevant Appraisal, and Threat Appraisal) seem to be intuitively obvious, seemingly exhaustive of the possibilities, and generally accepted by psychologists, human behavioralist, educators, and other practitioners of human responses, the author was not able to find where other researchers have validated this construct. In order to analyze that these three responses are representative of the possibilities, and if the respondents can be categorized into these three appraisals, the author first read each appraisal to determine if it was obvious if a 
TABLE VIII

SCALES AND ASSOCIATED CRONBACH'S ALPHA

Scale

Alpha

Benign-Positive Appraisal

Enthusiasm .95

Pleasure .95

Job Satisfaction

.94

Technology self Gratification

Irrelevant Appraisal

Indifference

Threat Appraisal

Fear

.96

Anxiety

.97

Cognitive Appraisal

Self Esteem

.93

Subjective stress

.94

Mastery

.91

Interpersonal Trust

.90

somatic symptoms

.80

Performance Difficulty

.87 
TABLE VIII

SCALES AND ASSOCIATED CRONBACH'S ALPHA

(continued)

Harm/Loss Appraisal

Depression $\quad .95$

Resentment $\quad .91$

Company Satisfaction $\quad .91$

Acceptance $\quad .95$

Challenge

Challenge $\quad .95$

$\begin{array}{ll}\text { Enthusiasm } & .95\end{array}$

$\begin{array}{lr}\text { Pleasure } & .97\end{array}$ 
respondent had a proponderence of responses falling into one of the three appraisals. Approximately 80 percent of the respondents fit nicely into one of the three appraisals. For the remaining 20 percent two methods were used to determine if the respondent "fit." First a numeric average score was determined for each of the respondents being investigated, and if an obviously high average occurred for one of the appraisals coupled with correspondingly low means for the other two appraisals, then the respondent was assigned to that category. For those respondents for which it was still not obvious if they fit into an appraisal category, a final test was used involving student's $t$ distribution. A 90 percent confidence interval was computed for each of the three appraisals based upon those responses which previously had been determined to fit into one of the three categories. The remaining responses were then compared to the confidence intervals to see if they fit into only one category. There were only two responses which did not fall into one of the three categories. The results of this analysis is given in Table IX, and demonstrates that which previously has been intuitively assumed has been numerically demonstrated for the subject computer professionels.

This distribution indicates that a large majority of the responding computer professionals regarded the advent 
TABLE IX

LEVEL A DISTRIBUTION OF APPRAISALS

\begin{tabular}{|c|c|c|c|c|c|c|c|c|c|}
\hline \multirow{2}{*}{\multicolumn{2}{|c|}{ Company }} & \multirow{2}{*}{\multicolumn{2}{|c|}{$\begin{array}{l}\text { Benign- } \\
\text { Positive } \\
\text { Appraisal }\end{array}$}} & \multirow{2}{*}{\multicolumn{2}{|c|}{$\begin{array}{l}\text { Irrelevant } \\
\text { Appraisal }\end{array}$}} & \multirow{2}{*}{\multicolumn{2}{|c|}{$\begin{array}{l}\text { Threat } \\
\text { Appraisal }\end{array}$}} & \multirow{2}{*}{\multicolumn{2}{|c|}{ No Fit }} \\
\hline & & & & & & & & & \\
\hline No. & Level & No. & $q$ & No. & $\%$ & No. & 8 & No. & $q$ \\
\hline 1 & A & 15 & $71 \%$ & 2 & $10 \%$ & 4 & $19 \%$ & 0 & $0 \%$ \\
\hline 2 & B & 19 & $51 \%$ & 6 & $16 \%$ & 11 & $30 \%$ & 1 & 38 \\
\hline 3 & $B$ & 11 & 528 & 3 & $14 \%$ & 6 & $29 \%$ & 1 & $5 \%$ \\
\hline 4 & $c$ & 32 & $65 \%$ & 7 & $14 \%$ & 10 & $21 \%$ & 0 & 08 \\
\hline 5 & $\mathrm{C}$ & 18 & $58 \%$ & 5 & $16 \%$ & 8 & $26 \%$ & 0 & $0 \%$ \\
\hline 6 & $\mathrm{C}$ & 26 & $70 \%$ & 1 & 38 & 10 & $27 \%$ & 0 & 08 \\
\hline \multicolumn{2}{|c|}{ TOTAL } & 121 & $62 \%$ & 24 & $12 \%$ & 49 & $25 \%$ & 2 & $1 \%$ \\
\hline
\end{tabular}

Total Number of Usable Responses $=121+24+49+2=196$ 
of the PC with a Benign-Positive Appraisal, and that almost two-thirds of them looked forward to the introduction of the PC into their workplace. It is noteworthy that the range of responses to the Benign-Positive Appraisal ranged from 51 percent to 71 percent, which always yields a majority of the computer professionals in each of the six companies viewing the $P C$ as desirable regardless of which level of penetration the PC has made at their particular companies. There does not seem to be any discernible pattern as to whether the level of PC penetration has tainted people's perceptions and rememberances of the ir feelings at the time when PCs were first being contemplated for introduction into their organization.

It is further noteworthy that a relatively small percentage (about 1 out of 8 ) of computer professionals felt that the impact of the PC would be irrelevant to their situation. Obviously, few of the computer professionals viewed the advent of the PC as having little impact on them. They are one class of worker for whom change has been a way of life, and they have introduced many changes for other workers, and have seen the pace at which change has occurred in the computer field. Thus, this relatively low number having irrelevant appraisals of the coming of the PC to their workplace is indicative of their previous experiences and knowledge. 
Finally, there is a sizable minority of one-fourth of the computer professionals who appraise the coming of the PC into their workplace as possibly having a negative impact on them. This does not mean that they are necessarily afraid of the PC itself, but are uncertain as to whether the impact of the PC on the organization may result in loss or harm to them in the way of prestige, position, status, rank, salary, job security, or other factors. While 25 percent is a decent sized minority, it is not as large a portion as some may have felt based upon hearing computer professionals discuss, while in informal group settings, the potential for misuse and abuse of computer resources and misuse of PC output from poorly constructed end user developed reports. The author heard many such discussions and a great deal of concern expressed by computer professionals in several companies when the advent and introduction of the PC was eminent in their workplace. Perhaps this was legitimate concern as to how to best manage a resource which was viewed as having benign or positive impact, and was not a reflection of their own fears and phobias as the author suspected in many cases. It is worth mentioning again that there is a lack of a definite pattern for the six participating companies as to the current level of PC penetration having a noteworthy influence on the proportions of the computer professionals 
experiencing the three appraisals. As Table IX shows, the only company which was still at Level A had 71 percent of the computer professionals with a Benign-positive Appraisal, and company 6 which is at Level $C$ has 70 percent of the computer professionals with the same appraisal. Similarly, the company at Level A has 19 percent with the Threat Appraisal, while company 4 which is at Level $C$ has 21 percent of the computer professionals with the same appraisal. The various percentages fit within that which would be expected from random samples being taken from various groups of similarly backgrounded people.

This is consistent with the findings of Lazarus and Folkman (1985) who studied not only reactions to change, but also the coping mechanisms which are employed by people to react and deal with the change. In their studies they surveyed two groups of people who were undergoing similar threat situations. One group they surveyed at three different time points: 1 , before the threat situation occurred but was pending (our Level A), 2. while the people were undergoing the stress associated with the change occurring (our Level $B$ ), and 3 , after the threat event had passed (our Level C). The other group of people were surveyed only after the change had occurred. Both groups were asked in the survey to identify their emotions at all three time periods, as well as the type of coping mechanism used during that time period. Lazarus and Folkman could 
find no statistical difference in the appraisals made by similar groups of people, facing similar threat events, which would indicate that those surveyed after a threat event had passed, had any different recollection of what their emotions or coping mechanisms were, from that of those who were surveyed while the threat event was unfolding.

\section{Correlations of Responses}

At the beginning of this section it was stated that there are two keys aspects of being able to determine if the proposed model is supported by the data. The second aspect deals with the correlations of the scales which are indicative of the responses one can expect from computer professionals who are having either a Benign-Positive, Irrelevant, or Threat Appraisal to the pending introduction of PCs into their workplace. In order to support the model, one would expect in the A Level to see high, positive correlations between the scales of Enthusiasm, Pleasure, Job Satisfaction and Technical Gratification, which correspond to a Benign-Positive Appraisal. Also, for the Threat Appraisal, one would expect to see high, positive correlations between the scales of Anxiety and Fear. One would expect, for the Irrelevant Appraisal, to see little correlation between the Indifference scale and the other scales associated with either the Benign-Positive 
Appraisal or the Threat Appraisal, since it is difficult to perceive something as being either threatening or beneficial while at the same time feeling it is irrelevant. Finally, one would expect to see hiqh negative correlations between the Benian-Positive Appraisal scales and the Threat Appraisal scales, since it is difficult to perceive something as being threatening to one's well being at the same time as perceiving it as being beneficial to one's we 11 being.

A statistical analysis was performed and the correlations between scales computed. The computations were done using an IBM PC and the software package ITAN (Gerbing and Hunter, 1988).

As can be seen in Table $x$, the lowest correlation amona the Beniqn-Positive Appraisal Scales was +.68, and the correlation between the Threat Appraisal Scales was +.98. In qeneral, the Indifference Appraisal scale exhibited siqnificant, but modest, negative correlations with all the other scales. Therefore, the correlation matrix in Table $x$ supports the proposed model.

Thus, analysis postulate one is accepted. P1: When faced with a change event the subject computer professionals go through a triad of appraisals and make either an Irrelevant Appraisal, Threat Appraisal, or a Beniqn-Positive Appraisal. 
TABLE X

SCALE CORRELATES FOR LEVEL A

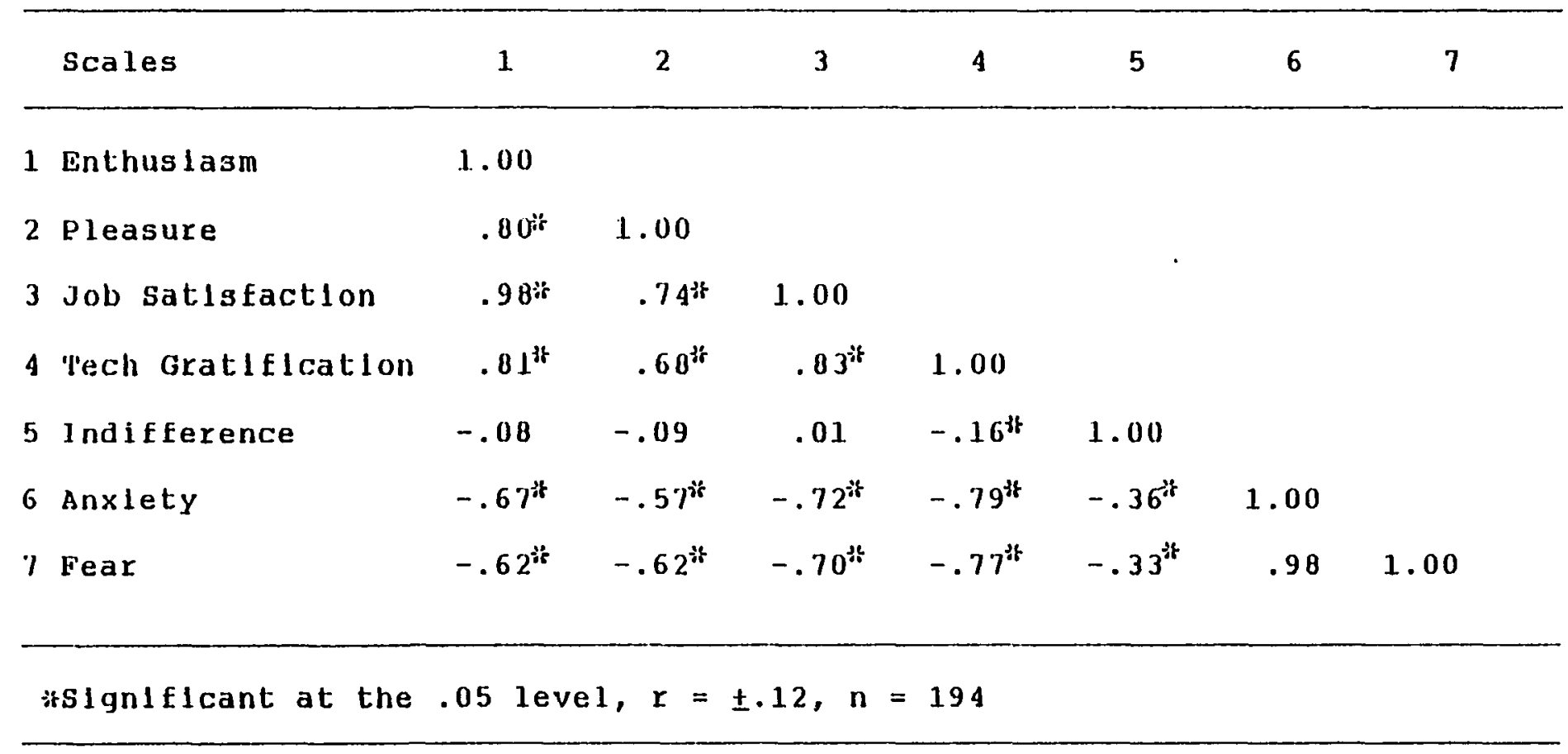


The results of Table $x$, combined with the results of Table IX, lead us to substantiate analysis postulates two and three. P2: With the Irrelevant Appraisal the subject computer professionals have indifferent feelings/emotions. P3: With the Benign-Positive Appraisal the subject computer professionals have pleasurable and comfortable feelings/emotions.

When the correlations are reviewed with respect to groupings by level of penetration of PCs in the organization we get similar relationships between the various scales, thus once again demonstrating that the passage of time does not materially effect the validity of the survey. Tables XI, XII, and XIII show the resulting correlates for companies at Level A, B, or C. One needs to be cautious when interpreting the results of this type of subset analysis because some of the subsets can have significantly smaller samples involved. Nevertheless, the correlations still have the same grouping of relationships as is indicated by the proposed model. Specifically, scales for Benign-Positive and Threat Appraisals still have high positive correlations within themselves. In particular, high positive correlations (statistically significant) were found among the Benign-positive Appraisal scales, and between the Threat Appraisal scales. The correlations between these two sets were moderately negative and statistically significant. 
TABLE XI

SCALE CORRELATES FOR LEVEL, $A$, FOR

COMPANIES STILL AT LEVEL A ( COMPANY ONE)

\begin{tabular}{|c|c|c|c|c|c|c|c|}
\hline Scales & 1 & 2 & 3 & 4 & 5 & 6 & 7 \\
\hline 1 Enthusiasm & 1.00 & & & & & & \\
\hline 2 Pleasure & $.91^{*}$ & 1.00 & & & & & \\
\hline 3 Job Satisfaction & $.98^{*}$ & $.85^{i f}$ & 1.00 & & & & \\
\hline 4 Tech Gratiflcation & $.78^{* t}$ & $.76^{\text {it }}$ & $.81^{\text {if }}$ & 1.00 & & & \\
\hline 5 Indifference & -.05 & .06 & .05 & -.05 & 1.00 & & \\
\hline 6 Anxlety & $-.45^{*}$ & $-.49^{*}$ & $-.60^{3 t}$ & $-.68 i$ & $-.53 *$ & 1.00 & \\
\hline 7 Fear & -.40 & $-.47 *$ & $-.57 \%$ & $-.63 *$ & $-.55^{*}$ & $.99^{\text {it }}$ & 1.00 \\
\hline
\end{tabular}

H Significant at the .05 level, $r= \pm .43, n=21$ 
TABLE XI I

SCALE CORRELATES FOR LEVEL A, FOR

COMPANIES STILL AT LEVEI, B

(COMPANIES TWO \& THREE)

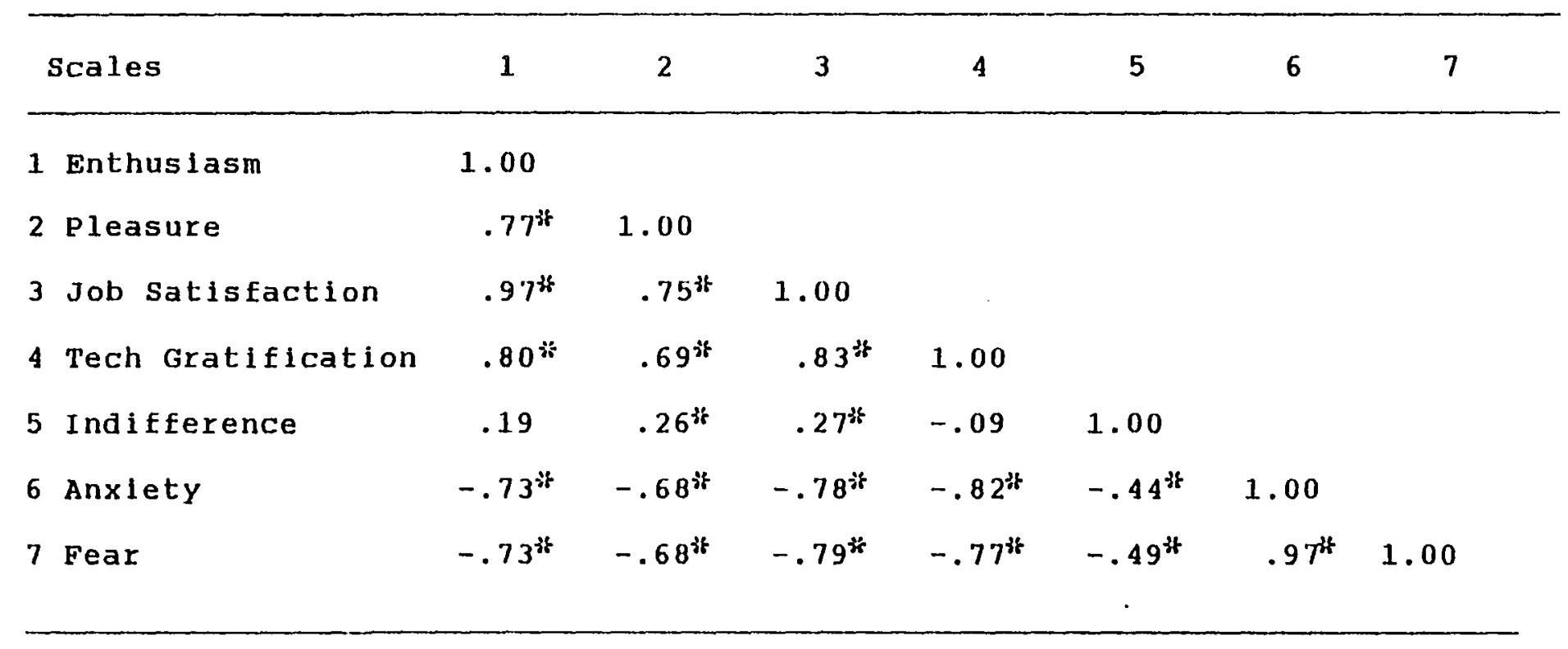

*Significant at the .05 level, $r= \pm .26, n=56$ 
TABLE XIII

SCALE CORRELATES FOR LEVEL A, FOR

COMPANIES AT LEVEL C (COMPANIES

FOUR, FIVE\&SIX)

\begin{tabular}{|c|c|c|c|c|c|c|c|}
\hline Scales & 1 & 2 & 3 & 4 & 5 & 6 & 7 \\
\hline 1 Enthusiasm & 1.00 & & & & & & \\
\hline 2 Pleasure & $.80^{i k}$ & 1.00 & & & & & \\
\hline 3 Job Satisfaction & $.99^{\text {it }}$ & $.73^{*}$ & 1.00 & & & & \\
\hline 4 Tech Gratification & $.82 *$ & $.67^{*}$ & $.84^{3 *}$ & 1.00 & & & \\
\hline 5 Indifference & -.14 & -.15 & -.07 & -.16 & 1.00 & & \\
\hline 6 Anxiety & $-.67 *$ & $-.53^{i k}$ & $-.70^{*}$ & $-.78^{36}$ & $-.38^{\text {it }}$ & 1.00 & \\
\hline 7 Fear & $-.68^{i k}$ & $-.61^{i f}$ & $-.68^{i t}$ & $-.77^{\text {if }}$ & $-.33^{46}$ & $.98^{3 t}$ & 1.00 \\
\hline
\end{tabular}


The Indifference Appraisal scale exhibited slight, negative, statistically significant correlation with the Threat Appraisal scales. The correlations of the Beniqn-Positive Appraisal scales and the Indifference Appraisal scale varied across company levels; near zero for Level A, somewhat positive for Level B, and negative for Level C.

\section{LEVEL B ANALYSIS}

Level $B$ of the model represents those individuals who have experienced a Threat Appraisal, and are undergoing a Coqnitive Adpraisal as to the potential impact of the change. The psychological responses which they are undergoing have to do with such variables as the eminence, duration, and uncertainty of the change. For those people experiencing a Threat Appraisal typical responses include such scales as a lessing of Self Esteem, increased Subjective stress, a lowering of a belief in their own Mastery, a lessing of Interpersonal Trust, increased Somatic Symptoms, and Performance Difficulty. As has been mentioned earlier, these scales have all been selected from previous work performed by other researchers on people undergoing threats to their well being. Thus, one would expect, if the proposed model is supported by the data, that those computer professionals who indicated on the questionnaire that they experienced a Threat Appraisal 
during Level $A$, then while in Level $B$ and undergoing the Cognitive Appraisal they would have high levels of correlation between those scales indicating a threat.

Table XIV shows the correlations for Level B.

All correlations among these scales are positive and statistically significant. Except for somatic symptoms, all of the correlations were high, with the correlations being moderate for somatic symptoms. Omitting for the moment Somatic symptoms, it can be easily stated that the other five scales show substantial intercorrelations, and thus substantiate the model at the $B$ Level. One can only conjecture as to why the correlation of somatic symptoms with the other scales is more modest, but perhaps it is because the threat of PCs is not of sufficient intensity to the computer professional to cause overt health problems. Nevertheless, Somatic symptoms still exhibited moderate correlation ranging from +.46 to +.55 , indicating that there still is a relationship between this scale and the other scales associated with the Threat Appraisal. Thus, the fourth analysis postulate is supported. P4: With the Threat Appraisal the subject computer professionals go through a cognitive process which produces psychological responses resulting from stress, such as loss of self esteem, anxiety, fear, and performance difficulty. 
IABLE XIV

SCALE CORRELATES FOR LEVEL B

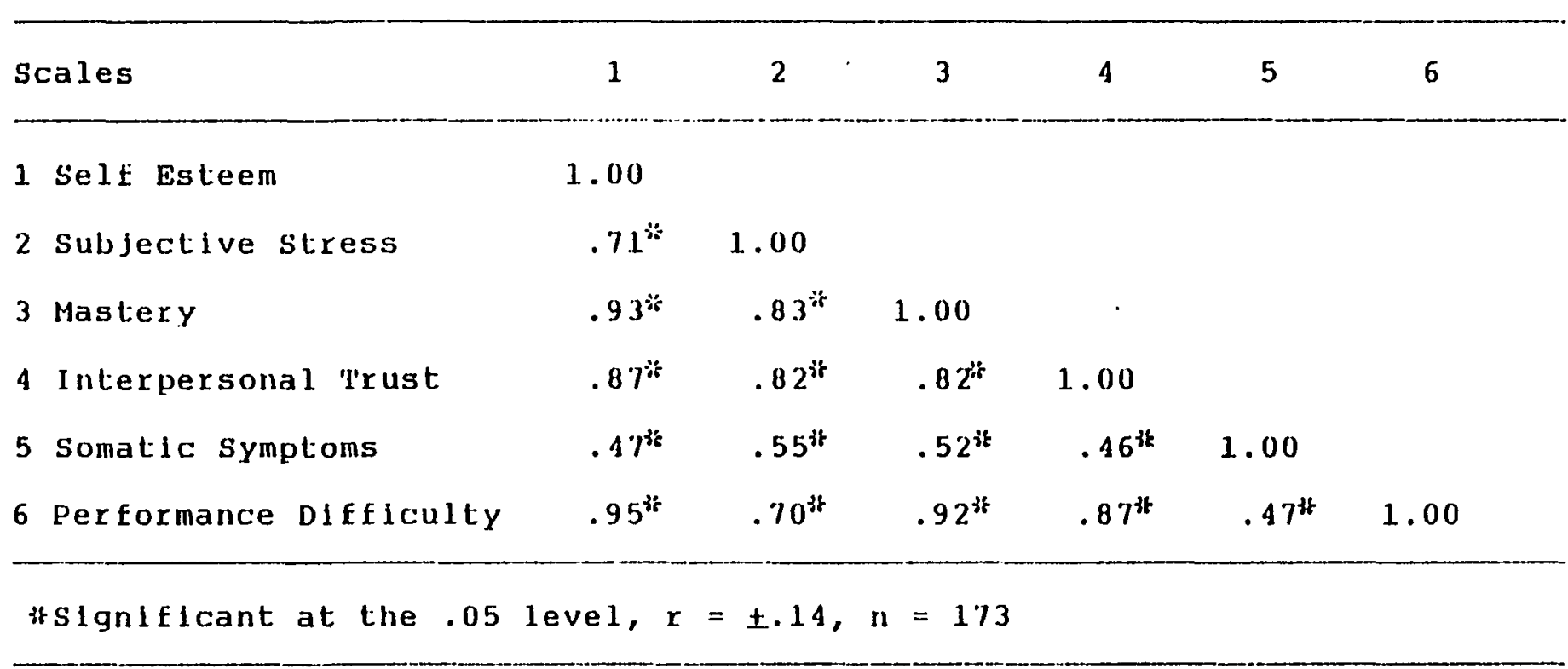


LEVEL C ANALYSIS

It remains to be seen if for Level $\mathrm{C}$ high correlations exist between the scales which the proposed model indicates.

For the category of alienation there should be high correlations between Depression and Resentment. For the category of acceptance there should be high correlations between Company Satisfaction and Acceptance of PCs. For the category of challenge there should be high correlations between the scales of Challenge, Enthusiasm, and Pleasure. Table XV shows the correlates for Level $C$.

The correlates correspond to those predicted for the proposed model. All correlations were statistically significant. Depression and Resentment demonstrated high correlation with each other and moderate to high negative correlation with all other scales. The correlations among the remaing five scales were positive. Company Satisfaction and PC Acceptance, which are scales for measuring Acceptance, have high, positive correlation with each other, and moderate, positive correlation with the scales which measure the Challenge Appraisal. Challenge and Enthusiasm, which are scales for measuring the Challenge Appraisal, have high, positive correlation with each other; while the remaining scale in the Challenge Appraisal, of Pleasure, has high, positive correlation with 
TABLE XV

SCALE CORRELATES FOR LEVEL C

\begin{tabular}{|c|c|c|c|c|c|c|c|c|}
\hline & Scales & 1 & 2 & 3 & 4 & 5 & 6 & 7 \\
\hline & 1 Depression & 1.00 & & & & & & \\
\hline ienat & 2 Resentment & $.83^{*}$ & 1.00 & & & & & \\
\hline & $\sqrt{3}$ Company satisfaction & $-.53 *$ & $-.69 *$ & 1.00 & & & & \\
\hline cceptanc & 4 PC Acceptance & $-.81 *$ & $-.71 \%$ & $.79 \%$ & 1.00 & & & \\
\hline & 5 Challenge & $-.67 \%$ & $-.58 \%$ & $.34 \%$ & $.57 *$ & 1.00 & & \\
\hline 1 enge $\{6$ & 6 Enthusiasm & $-.52 *$ & $-.55 *$ & $.42 \%$ & $.45 *$ & $.78 *$ & 1.00 & \\
\hline & 7 Pleasure & $-.43 *$ & $-.54 *$ & $.34 *$ & $.26 *$ & $.57 *$ & .78 & 1.00 \\
\hline
\end{tabular}

;rSignificant at the .05 level, $r= \pm .18, n=117$ 
Enthusiasm, and moderate, positive correlation with Challenge. Pleasure has lower (but still within the moderate to low range) positive correlations with PC Acceptance and Company Satisfaction.

Thus, the fifth analysis postulate is supported. P5: With the Threat Appraisal, after the change event has transpired, the subject computer professionals will have a Harm/Loss Appraisal or a Challenge Appraisal.

\section{CORRELATIONS CONSISTENT WITH THE MODEL}

Thus, it has been shown that hiqh scale reliability exists, the cluster qroupings of questions fall into categories indicated by the model, and for those categories high correlations exist among the scales. Thus, the various aspects of the model which were to be analyzed for computer professionals has been found to be consistent with the model, and the model appears to be an appropriate tool to use, in the target environment, for describing computer professionnals' appraisals and psychological responses as they faced the technological change associated with the introduction of PCs. The author believes the model would be valid for other types of changes in the workplace, and for other groups of people, but this needs to be substantiated by further research. 
DEMOGRAPHIC DATA

The demographic data was collected according to seven categories, namely by: gender, access to PC at home, access to PC at work, level of education, age, work experience in the computer field, and salary level. This demographic data will be presented for the three appraisals which the computer professionals made at the A Level when PCs are first being considered for introduction into the organization, namely: 1. Benign/Positive, 2. Irrelevant, and 3. Threat. An analysis will be made on the data to determine if there is statistical significance to the differences which occur in the numbers of individuals appearing in different categories. These will be done using inferential statistics for categorical data. A very general test for performing inferential statistics on frequencies of data is the chi square test of independence (Nunnally 1975). That is, it is used to test the null hypothesis that the numbers of individuals appearing in different categories are no different from what would be expected by chance alone.

\section{Appraisal Responses by Gender}

Table XVI shows the results of the survey broken out by gender, for each of the three appraisals: 1. Benign-Positive, 2. Irrelevant, and 3. Threat. 
TABLE XVI

APPRAISAL, RESPONSES BY GENDE:R

\begin{tabular}{|c|c|c|c|c|c|c|c|}
\hline \multirow[b]{2}{*}{ Gender } & \multicolumn{4}{|c|}{ Frequency } & \multicolumn{3}{|c|}{ Percent } \\
\hline & 1 & 2 & 3 & $1,2,3$ & 1 & 2 & 3 \\
\hline Male & 79 & 20 & 41 & 1.40 & 578 & $1.4 \%$ & 298 \\
\hline Female & 41 & 5 & 8 & 54 & $75 \%$ & $9 \%$ & $16 \%$ \\
\hline lotal & 120 & 25 & 49 & 194 & $62 \%$ & 128 & $25 \%$ \\
\hline $\begin{array}{l}\text { degrees of } \\
\text { chi square } \\
\text { Reject Ho: }\end{array}$ & $\begin{array}{l}\text { Ereed } \\
=6.3 \\
\text { Appra }\end{array}$ & $\begin{aligned} &= 2 \\
& \operatorname{chi} \\
& 1 \mathrm{re}\end{aligned}$ & $\begin{array}{l}\text { uare } \\
\text { nses }\end{array}$ & $\begin{array}{l}t .051 \\
\text { nd geno }\end{array}$ & $\begin{array}{l}5.99 \\
\text { inde }\end{array}$ & Jent. & \\
\hline
\end{tabular}


The calculated value of chi square is 6.39 . The null hypothesis that appraisal responses and gender are independent is rejected at the .05 level. The research hypothesis that gender and appraisal responses are related is accepted.

Looking at Table XVI it appears that females feel that the PC presents less of a threat to them than do males.

Appraisal Responses by Access to PC at Home

Table XVII shows the results of the survey broken out by those people who have access to a PC at their home vs. those who do not have access to a PC at their home, for each of the three appraisals: 1. Benign-positive, 2 . Irrelevant, and 3. Threat.

A calculated chi square of 14.12 was obtained. The null hypothesis that availability of PC at home and appraisal response are independent is rejected at the .05 level. The research hypothesis that availability of PC at home and appraisal responses are related is accepted. It may be assumed that those people with a PC in their home feel that the PC is less of a threat to them. We can not determine from the available data whether familiarity with PCs in the home has lead to a lessing in the fear of impact of PCs on their job, or if those people who felt the least threatened on their jobs by the impending use of PCs were more inclined to acquire them for home use. 
TABLE XVII

APPRAISAL RESPONSES BY ACCESS TO PC AT HOME

\begin{tabular}{|c|c|c|c|c|c|c|c|}
\hline \multicolumn{5}{|c|}{ Erequency } & \multicolumn{3}{|c|}{ Percent } \\
\hline Access to PC & 1 & 2 & 3 & $1,2,3$ & 1 & 2 & 3 \\
\hline PC at Home & 77 & 13 & 15 & 105 & 748 & $12 \%$ & 148 \\
\hline No PC at Home & 43 & 12 & 34 & 89 & $48 \%$ & $14 \%$ & $38 \%$ \\
\hline TOTAL & 120 & 25 & 49 & 194 & $62 \%$ & $12 q$ & $25 \%$ \\
\hline
\end{tabular}

degrees of freedom $=2$

chi square $=14.12$, chi square at .05 level $=5.99$

Reject Ho: Availability of a PC at home and appraisal responses are independent. 
Appraisal Responses by Access to PC at Work

Table XVIII shows the results of the survey broken out by those people who have access to a PC at work vs. those who do not have access to a PC at work, for each of the three appraisals: 1. Benign-Positive, 2. Irrelevant, and 3 . Threat.

The calculated value of chi square was 5.57 . The null hypothesis that appraisal responses and gender are independent is accepted at the .05 level. The research hypothesis that gender and appraisal responses are related is rejected.

This would lead one to suspect that access to a PC in the workplace does not lead to either an increase or a decrease in the perception of the individual as to whether or not a PC constitutes a threat to them in the workplace. Nevertheless, this is interesting because we saw in Table XVII that access to a RC at home was associated with less of a threat perception by individuals. This leads one to speculate that those who felt the least threatened by PCs in the workplace were the ones who were more inclined to acquire PCs for their homes. It would thus appear that PCs are assigned randomly in the workplace without regard to whether one feels threatened or not by PCs, i.e., it is just as likely that someone who feels threatened in the workplace by PCs will be assigned access to a PC, as 
TABLE XVII I

APPRAISAL RESPONSES BY ACCESS 'I'O PC AT' WORK

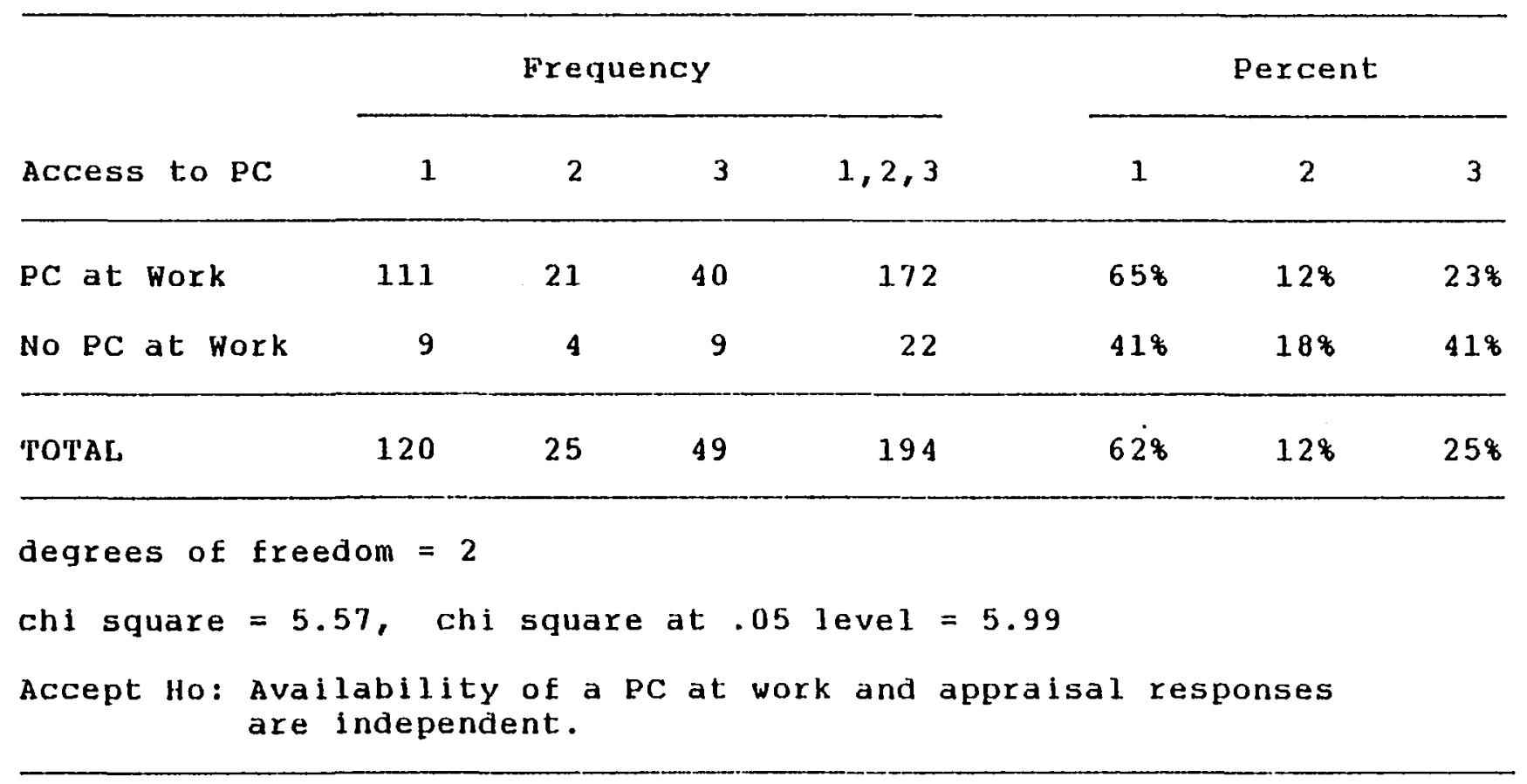


someone who does not feel threatened by PCs. This also leads one to speculate that management does not know, when assigning access to PCs in the workplace, whether or not the Individuals being so assigned feel threatened by PCs. However, it should be noted that only eleven percent of the respondents did not have access to a PC at work. Perhaps these people are in positions in which the use of a $P C$ is unimportant. Also, because only eleven percent did not have access to PCs in the workplace this gave a lopsided distribution with a relatively small number of people in this category. This coupled with the relative closeness of the chi square test with the calculated chi square of 5.57 versus the chi square at .05 level of 5.99 , leads to the possibility of a Type I error in which Ho is accepted when in reality the alternative is true.

\section{Appraisal Responses by Education Level}

Table XIX shows the results of the survey broken out by education level, for each of the three appraisals: 1 . Benign-Positive, 2. Irrelevant, and 3. Threat.

The calculated value of chi square is 13.51 . The null hypothesis that appraisal responses and education level are independent is rejected at the .05 level. The research hypothesis that education level and appraisal responses are related is accepted. 
TABI, E XIX

APPRAISAL, RESPONSES BY EDUCATION LEVEL

\begin{tabular}{|c|c|c|c|c|c|c|c|}
\hline \multirow[b]{2}{*}{ Education Level } & \multicolumn{4}{|c|}{ Frequency } & \multicolumn{3}{|c|}{ Percent } \\
\hline & 1. & 2 & 3 & $1,2,3$ & 1 & 2 & 3 \\
\hline Non Bachelors Degree & 36 & 12 & 23 & 71 & $51 \%$ & $17 \%$ & $32 \%$ \\
\hline Bachelors Degree & 44 & 10 & 21 & 75 & 598 & 138 & $28 \%$ \\
\hline Beyond Bachelors & 40 & 3 & 5 & 48 & 838 & 68 & $11 \%$ \\
\hline Iotal & 120 & 25 & 49 & 194 & 628 & $12 \%$ & $25 \%$ \\
\hline
\end{tabular}

degrees of freedom $=4$

chi square $=13.51$, chl square at the .05 level $=9.49$

Reject Ho: Education level and appraisal responses are independent. 
This is an interesting result which seems to indicate that the more highly educated an individual is, the less likely they are to feel threatened by the introduction of PCs into the workplace. One can only speculate whether this is because they are more highly educated and hence have a greater sense of self confidence that they can handle the situation, or if they feel more secure in their jobs because they know with their higher education and college degree(s) they can more readily find other jobs than someone without their educational background, or if there are some other possible explanations for this finding.

Appraisal Responses by Age

Table $x x$ shows the results of the survey broken out by age in years, for each of the three appraisals: 1. Benign-Positive, 2. Irrelevant, and 3. Threat.

The calculated value of chi square was 4.87 . The null hypothesis that appraisal responses and age are independent is accepted at the .05 level. The research hypothesis that age and appraisal responses are related is rejected.

This is significant, with implications that for computer professionals in the subject companies age makes no difference in whether or not they feel threatened in their jobs by the introduction of the PC. This goes counter to many people's belief that older people feel more 
TABLE XX

APPRAISAL RESPONSES BY AGE

\begin{tabular}{|c|c|c|c|c|c|c|c|}
\hline \multirow[b]{2}{*}{ Age (years) } & \multicolumn{4}{|c|}{ E'requency } & \multicolumn{3}{|c|}{ Percent } \\
\hline & 1 & 2 & 3 & $1,2,3$ & 1 & 2 & 3 \\
\hline 35 or Less & 54 & 11 & 30 & 95 & $57 \%$ & $12 \%$ & $31 \%$ \\
\hline 36 Thru 45 & 49 & 9 & 15 & 73 & $67 \%$ & $12 \%$ & $21 \%$ \\
\hline $46 \&$ Over & 17 & 5 & 4 & 26 & $65 \%$ & $1.9 \%$ & $15 \%$ \\
\hline Total & 120 & 25 & 49 & 194 & 628 & 128 & $25 q$ \\
\hline
\end{tabular}

degrees of freedom $=4$

chi square $=4.87$, chi square at .05 level $=9.49$

Accept Ho: Age of person and appraisal responses are independent 
threatened by computers. Perhaps popular belief is once again wrong, or perhaps because the subjects are computer professionals they are less likely to feel threatened by computers of any type, be they micro, mini, or maxi computers.

Appraisal Responses by Years of Experience

Table XXI shows the results of the survey broken out by years of work experience in the computer field, for each of the three appraisals: 1. Benign-Positive, 2 . Irrelevant, and 3. Threat.

The calculated value of chi square was 10.71 . The null hypothesis that appraisal responses and experience are independent is accepted at the .05 level. The research hypothesis that experience and appraisal responses are related is rejected.

This result indicates that years of familiarity with computers does not result in either a lessening or an increasing of the perception that PCs represent a threat to an individual computer professional in the workplace.

\section{Appraisal Responses by Salary Level}

Table XXII shows the results of the survey broken out by salary level, for each of the three appraisals: 1. Benign-Positive, 2. Irrelevant, and 3. Threat.

The calculated value of chi square is 11.53 . The null hypothesis that appraisal responses and salary level are 
I'ABLE XXI

APPRAISAL RESPONSES BY YEARS OF EXPERIENCE

\begin{tabular}{|c|c|c|c|c|c|c|c|}
\hline \multirow[b]{2}{*}{ Years of Experience } & \multicolumn{4}{|c|}{ Frequency } & \multicolumn{3}{|c|}{ Percent } \\
\hline & 1 & 2 & 3 & $1,2,3$ & 1 & 2 & 3 \\
\hline 5 Years or Less & 18 & 1 & 5 & 24 & $75 \%$ & 48 & $21 \%$ \\
\hline 6 Thru 10 & 37 & 11 & 22 & 70 & 538 & $16 \%$ & 318 \\
\hline 11 Thru 15 & 29 & 5 & 16 & 50 & $58 \%$ & $10 \%$ & $32 \%$ \\
\hline 16 or More & 36 & 8 & 6 & 50 & $72 \%$ & 168 & $12 \%$ \\
\hline Total & 120 & 25 & 49 & 194 & $62 \%$ & $12 \%$ & $25 \%$ \\
\hline
\end{tabular}

degrees of freedom $=6$

chi square $=10.71$, chi square at the .05 level $=12.59$

Accept Ho: Years of experience and appraisal responses are independent. 
TABLE XXI I

APPRAISAL RESPONSES BY SALARY LEVEL

\begin{tabular}{|c|c|c|c|c|c|c|c|c|}
\hline \multirow[b]{2}{*}{ Salary Level } & & \multicolumn{4}{|c|}{ Frequency } & \multicolumn{3}{|c|}{ Percent } \\
\hline & & 1 & 2 & 3 & $1,2,3$ & 1 & 2 & 3 \\
\hline$\$ 30,000 /$ Year & or Less & 17 & 3 & 16 & 36 & 478 & $8 \%$ & 458 \\
\hline$\$ 30,000$ Thru & $\$ 40,000$ & 47 & 13 & 20 & 80 & 598 & 168 & $25 \%$ \\
\hline$\$ 40,001 /$ Year & or More & 56 & 9 & 1.3 & 78 & 728 & 118 & $17 \%$ \\
\hline Total & & 120 & 25 & 49 & 194 & $62 \%$ & 128 & $25 q$ \\
\hline
\end{tabular}

degrees of freedom $=4$

chi square $=11.53$, chi square at the .05 level $=9.49$

Reject Ho: Salary level and appraisal responses are independent. 
independent is rejected at the .05 level. The research hypothesis that salary level and appraisal responses are related is accepted.

This particular set of demographic data was included in the questionnaire not so much to determine if higher paid people were less or more threatened by the introduction of PCs, but because it was assumed that companies were logical in their salary administration, and that higher pay correlated to the value the organization felt that the employee represented to it. Thus, the intention was to see if more valuable employees would feel less or more threatened by the introduction of PCs into the workplace. The above table seems to indicate that there is a difference in the feelings of being threatened. This. implies that the more valuable computer professionals feel less threatened by the introduction of the PC, and feel that it is a positive move.

Summary of Demographic Differences

Table XXIII shows the summary of demographic differences with respect to which demographic categories are independent (or dependent) with respect to the appraisal responses. It is noteworthy that four out of seven demographic categories appear to be related to the ir appraisal responses, namely: gender, access to PC at home, education level, and salary level. 
TABLE XXIII

DEMOGRAPHIC SUMMARY

\begin{tabular}{lcccc} 
& Chi Square & .05 Level & d.f. & $\begin{array}{c}\text { Accept } \\
\text { Ho:Independent }\end{array}$ \\
\hline Gender & 6.39 & 5.99 & 2 & No \\
PC Home & 14.12 & 5.99 & 2 & No \\
PC Work & 5.57 & 5.99 & 2 & Yes \\
Education & 13.51 & 9.49 & 4 & No \\
Age & 4.87 & 9.49 & 4 & Yes \\
Experience & 10.71 & 12.59 & 6 & Yes \\
Salary & 11.53 & 9.29 & 4 & No \\
\hline
\end{tabular}


One needs to keep in mind while reviewing the demographic data, that a very specific set of people were used in the quasi-experiment. Specifically, computer professionals, working in gas and electric utilities, who live and work in the Northwestern United States. While it is possible the demographic findings may be true for people in general, it is more likely that the results are peculiar to the specific environment and circumstances involved in the study. Generalities based upon this one set of data could be misleading and could lead to harmful results if used without sorethought and discretion. 
CHAPTER $V$

IMPLICATIONS

INTRODUCTION

The verified model is reviewed and the conditions of its validity are explained. There are implications as to how the model can be expanded into other environments, and implications for researchers and business practitioners alike.

REVIEW OF THE MODEL

\section{The Mode1}

A model was presented in Chapter II, which described the process of stages and psychological responses involved in individuals reacting to change in the workplace. The model was to be analyzed for computer professionals working in Northwestern Investor Owned Utilities (IOUs), who were experiencing the change associated with the introduction of PCs into the IoUs for whom they worked. The model is presented in Figure 4 . 


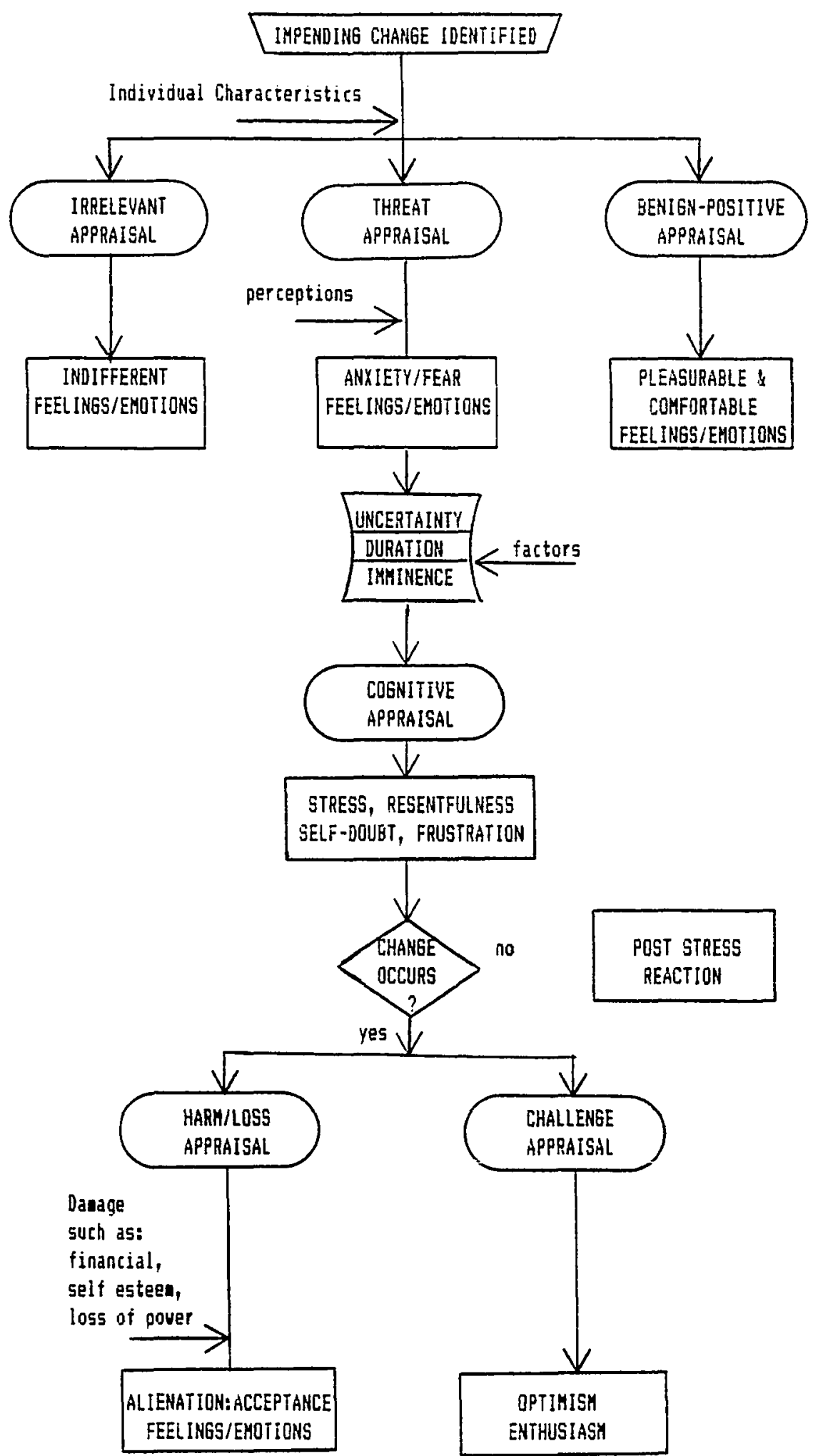

Fiqure t. The nooel. 
The process depicted by the model starts with the identification of a change event. The individuals facing the change event make one of a triad of appraisals of the situation, namely: 1. Irrelevant Appraisa1, 2. Benign-Positive Appraisal, or 3. Threat Appraisal. With the Irrelevant Appraisal they have indifferent feelings/emotions associated with the change event. With the Benign-Positive Appraisal they have pleasurable and comfortable feelings/emotions.

With the Threat Appraisal they go through a cognitive process involving individual characteristics, perceptions, and factors associated with the change, which result in emotions causing stress during the duration of the perceived threat. If the change event does not occur, then they return to their normal situations. If the change event does occur, then either they will have a Harm/Loss Appraisal or a Challenge Appraisal. Certain feelings/emotions are associated with the Harm/Loss Appraisal and Challenge Appraisal.

The model was analyzed for the above mentioned computer professionals as PCs were being introduced into six IOUs. These companies were at various stages of introduction of PCs into the organization, ranging from just starting plans on how to introduce PCs into the organization, to maturity in use of PCs in the organization. 
The analysis was performed using a quasi-experiment, with self-report surveys being completed by the subject computer professionals who were asked to rank their psychological responses at various times in the process of introduction of PCs into their companies. Scales were developed, and pilot tested on two other organizations, which would indicate if the computer professionals were experiencing the feelings/emotions indicated by the model. Modifications were made to the questionnaire based upon the pilot testing. The scales developed give a degree of measure and quantification toward being able to analyze relationships and explain behavior. The final instrument was administered to the six IoUs. Around 200 completed questionnaires were analyzed. Correlations were examined for scales which were duplicate predictors of certain appraisals, such as the Threat Appraisal had scales for Anxiety and Fear. Those scales which were duplicate predictors of specific appraisals had high, positive correlations, and certain appraisals which would evoke opposite scales (such as high Job satisfaction vs. high Anxiety) had high, negative correlations. The correlations observed were in the range of those which the model indicated would occur.

Further research is needed to validate the model by using such methods as Factor Analysis/Path Analysis. The behavior observed in this research can be explained and 
reviewed using the model. The research demonstrates correlations between the observed behavior and the model, but does not prove causality which is an extensive area for future research.

The correlation matrix for Level A (Table X) indicate that there are three high level factors, namely Irrelevant, Threat, and Benign-positive, even though there are seven scales. The seven scales relate to the high level factors with Enthusiasm, Pleasure, Job Satisfaction, and Technical Gratification being related to Benign-Positive; with Anxiety and Fear being related to Threat, and with Indifference being related to Irrelevant. Even though the Threat factor has subsequent appraisals and various outcomes of psychological responses, the overall factor is still the single element of Threat.

For those computer professionals making the Threat Appraisal, the subsequent correlation matrix shown in Table XII has correlates which correspond to those psychological responses associated with stress. This is the response indicated by the model for those who feel threatened by the eminent introduction of the PC. Table XIII has correlates which relate to the outcomes of alienation, acceptance, or challenge which are the final outcomes indicated by the model. 
Demographic Data Review

Additionally, demographic data was analyzed to determine if certain categories of individuals were more likely to experience certain appraisals. It was identified, for the subject computer professionals, that access to a PC in the workplace, age of the individual, and years of experience in the computer field were independent of the appraisals made by the individuals and hence independent of the feelings/emotions evoked.

In the case of gender it was indicated that female computer professionals felt less threatened by the introduction of PCs and were more likely to see them as being a positive change event.

Those computer professionals with access to a PC at home seem to be more likely to see the introduction of PCs into their workplace as a positive change event, and felt less threatened.

Those computer professionals with higher educations seem to be more likely to see the introduction of PCs into their workplace as a positive change event, and felt less threatened.

Those computer professionals with higher salary levels (and hence supposedly more valuable to their organizations) seem to be more likely to see the introduction of PCs as a positive change event, and felt less threatened. 
EXTENSION OF THE MODEL TO OTHER ENVIRONMENTS

The proposed model has been analyzed for computer professionals working in gas and electric, investor owned utilities (IOUs) in the Northwestern United States. Based on the author's experience in, and exposure to, the utility business across the United states and Canada, there is reason to believe the model would apply to computer professionals in all other IOUs in the United States and Canada.

The author has 29 years of experience in the computer field, having worked in the aerospace, electronics, manufacturing, insurance, engineering/construction, and real estate industries. Additionally, he has hired several hundred computer professionals from across the nation and from all types of organizations and has had the opportunity to observe that previous industry experience or geographic residence are not predictors as to whether someone will be a good performer as a computer professional in another industry or in another location. The conclusion of all this experience is that a good computer professional in one type of industry will be a good computer professional in another type of industry (the same applies to mediocre and poor performers as well), and that there are no discernible psychological patterns based on industry or geography. 
Based on this experience, the author believes there is not much difference in the psychological makeup of computer professionals in various industries or areas, and hence the model applies to computer professionals in all types of industries.

The author has seen many computer end users shift their career toward that of a systems analyst or programmer. Indeed, with the advent of the PC many computer end users are performing the duties of computer professionals. It has long been a common practice for many engineers to do their own systems analysis and programming on mainframe computers. Likewise, many a computer professional has become so well versed in the operations of their computer end user functions they support, that they have transferred to the end user departments and have essentially stopped performing the duties of a computer professional. Furthermore, in the case of some other computer professionals who transferred to end user departments it is difficult to determine if they are end users or computer professionals because they do both jobs interchangeably. Computer professionals often are very successful in end user positions. At one company for whom the author worked, a former programmer with a mathematics degree eventually became the controller, and another former programmer became the vice president of marketing. At that same company the vice president of finance told the author 
that the person who best understood how accounting worked in that company was one of the author's computer professionals. Based on this interchangeablility of computer professionals and end users, the author believes the model applies to all computer end users as well. Since almost everyone in today's organization uses computers, then this model applies to people involved in all aspects of organizations when adapting to computer induced change.

The author will speculate a step further and state that he believes that the model not only applies to computer induced change, but to all types of changes in the workplace. There is little reason to believe that computer induced change might trigger a different type of psychological response, than other types of changes in the workplace which might be perceived as being either benign-positive, irrelevant, or threatening. Indeed, the author's model was developed from combining the work and research of other investigators in the field of human research, which was not directed at only computer professionals' response to change, but was general in nature and involved many different types of people in many different types of situations.

It is recognized that further research needs to be done in order to confirm that the model does apply to many classes of workers in many different types of environments and industries. However, it is believed that the model is 
general in nature and can be used by managers and researchers alike for their various purposes.

\title{
IMPLICATIONS FOR RESEARCHERS
}

\author{
Researchers can use the model to determine that it \\ does have general application for more situations than the \\ one presented in this work. Upon further analysis, \\ researchers can start the process of further evaluation and \\ research to try and determine what causes various people to \\ feel threatened while others feel an impending change will \\ have positive or irrelevant effects. Researchers can also \\ analyze that when people do feel threatened by an event, \\ the model can be used to analyze what can be done to \\ minimize the extent of the threat which is perceived. \\ Furthermore, researchers can use the model to analyze what \\ it takes to get those people who feel threatened by a \\ change, to more readily move to the either the optimism or \\ enthusiasm of a Challenge Appraisal, rather than the \\ possible alienation emotions of a Harm/Loss Appraisal. \\ There is further room for research to determine if all \\ threatened employees who make a Harm/Loss Appraisal have a \\ dichotomy of events of either alienation or acceptance, or \\ actually experience the alienation emotions until they \\ finally adjust to acceptance. Maybe those employees who \\ are assessed as being alienated, are just those who take
}


longer to pass out of the alienation mode and into acceptance.

There are many implications for researchers once a new model as to how people move through the various psychological responses associated with change has been presented.

\section{IMPLICATIONS FOR BUSINESS PRACTITIONERS}

The author believes the most interesting area for implications is for the managers of people. Even though this model is of a general and theoretical nature, knowledgable managers can utilize it to help move their staff into the more desirable appraisals, or can identify which types of changes will cause the most dysfunctional behavior.

For example, the author is an experienced manager in the computer field, having managed computer departments in three different large companies over the past fifteen years. He felt he knew fairly well the psychic, hopes, fears, aspirations, and phobias of computer professionals as a whole, and at Ious in particular. Being an experienced manager he naturally had made a mental estimate as to what he thought the percentages would be for the triad of responses for Benign-Positive, Irrelevant, and Threat, as $65 \%, 5 \%$, and $30 \%$ respectively. The author was a little smug when the percentages from the research turned 
out to be $62 \%, 12 \%$, and $25 \%$ respectively (with $1 \%$ not fitting into any category). Even though the author was a little surprised by the higher percentage of people favoring the irrelevant appraisal, the research percentages were not very far from what had been mentally estimated before the research. The point is, many managers have a good feel for how their staffs will respond to different types of changes. If they recognize that a triad of initial responses exists to any type of change which is being proposed, then they can focus in on those changes which they feel wili have a high percentage of their stafe feeling a Threat Appraisal, and try and mitigate their appraisals before they are made. Thus, if a manager feels a high percentage of the staff will experience a Threat Appraisal by an impending change, then he or she can initiate a campaign, using one of the strategies shown in the spectrum in $F$ igure 1, to move more of the staff to have a more desirable appraisal when the change is introduced. For example, in the author's own case when PCs were being contemplated for introduction into the largest IOU in the Northwestern United States, for which he managed the Information Systems Department, and recognizing he estimated that $30 \%$ of his computer professionals (about 40 valuable employees) would have a Threat Appraisal when PCs were first being introduced, he would have utilized a strategy along the lines of the Normative-Reeducative 
school of thought (presented in Figure 1). Thus, there would have been sessions presented to the staff with the purpose of providing education about the benefits to be derived by computer professionals and the company from the PCs, and to try and modify and reeducate them in their norms and attitudes. Instead, the response was to provide technical training on the use of PCs (the typical response for Information systems Managers), and nothing was really done to help the $25 \%$ to $30 \%$ of the staff who were soon to undergo a Threat Appraisal. (In defense of the author this was eight years ago when he had more of a tendency to believe that most problems were of a technical nature, that logic and reason prevailed (typical Rational-Empirical school of thought shown in Figure 1 ), and there was little need for concern over the emotions of computer professionals.

Threat Appraisal - Uncertainty, Duration, Imminence

In addition to trying to head off problems by attempting to steer more people toward avoiding a Threat Appraisal, the model indizates that even if a Threat Appraisal occurs, then the factors leading to anxiety, self-doubt, fear, frustration, and resentfulness are the uncertainty, duration, and imminence of the threat. Recognizing these factors a manager can attempt to minimize the forces associated with these factors. 
As was stated in Chapter II, the uncertainty of the event involves both not knowing whether the event will occur and what the consequences might be. A manager could take steps to determine as soon as possible whether the event will take place or not, analyze what possible consequences might arise, and inform people immediately. Also, some thought should be given to trying to minimize what might be perceived as the unfavorable consequences of the event. For example, in the case of the introduction of PCs at the author's company, the Human Resources Department was discussing among themselves if the widespread use of PCs would create a situation in which every employee would do programming, and hence do away with the high paid technical classification of programmer. This premature speculate by a bunch of people who held power over careers, but knew very little at that point about PCs, leaked out to the rest of the organization in the form of rumors which increased part of the uncertainty about what the consequences of PCs would be. Using the model, a manager would recognize that such types of uncertainties need to be addressed, and informed decisions be made early which are as favorable to the employees as is practical.

The duration of the event involves how long the stress event will last if it does occur. The manager should take great efforts to see to it that the actual stress is short lived. In the case of the introduction of PCs into an 
organization, the introduction, training, procedures, practices, equipment, and any thing else needed for the successful use of PCs should occur as quickly as possible so that the actual time lapse, of the stressful event, occurs as quickly as possible, and the people effected do not undergo a long drawn out time period during which they feel the stress of the event. The same thing can be said for corporate mergers, reorganizations, introduction of new procedures, or any other type of change event.

The imminence of the event is the amount of time which elapses between when the possible change is identified and when the actual event occurs. That is, this is the time during which the employee waits for "the other shoe to drop." In the case of the introduction of PCs into an organization, the longer the "hows and whys" of the issue are debated by management, the longer the computer professionals feel the threat of living under the sword of Damocles and hence the greater the stress. Once a stress event has been identified, management should try to minimize the amount of time between the identification of the possible change and when the change actually takes place.

Challenge or Harm/Loss Appraisals

Even after all this effort, there will still be those employees who made the Threat Appraisal and the change 
event occurs, and will eventually make either a challenge or Harm/Loss Appraisal. An effort needs to be made by the manager to minimize the possibility of perception of harm or loss occurring. Great effort should be made to avoid the possibility of employees making a Harm/Loss Appraisal. Managers need to be creative in presenting threatening changes as really being opportunities to overcome challenges. In the case of corporate mergers, desirable employees should be given the chance to show that the company can't get along without them, and should be shown that the merger is an opportunity to demonstrate how needed they really are.

If there is no way to avoid a Harm/Loss Appraisal, with the result that an employee will experience alienation or acceptance, then the manager needs to steer the employee into an acceptance mode rather than let him or her stew in an alienation mode. In the case of corporate merger, where it is unavoidable that an employee be demoted, rather than let the employee just simmer in alienation, the manager needs to work with the individual to assure him or her that it was no reflection upon the employee's personal ability, a stronger company resulted from the merger, and that with this strength there is a good possibility that the employee will regain the lost position and even be able to climb higher in a faster manner than before. This or some similar approach, depending upon the individual, needs to 
be made in order to help the employee quickly move to an acceptance mode of emotions and feelings so that the employee can again be a productive and contributing member of the staff.

\section{LINKAGES TO OTHER CHANGE MODELS}

Schweiger, Ivancevich, and Power (1987) have 1 inked Elisabeth Kubler-Ross's (1969) model of the harm/Ioss associated with the death of a loved one in a lineal five stage model of denial, anger, bargaining, depression, and acceptance, to their own model as to effective actions to take to mitigate the harm/loss to an individual's job associated with a corporate merger. Both of these models deal with change, although only one deals with change in the workplace. Both of the above models may be Iinked to the model presented in this research. For the five stage model, it may be possible that alienated employees go through the five stages described by Kubler-Ross (1969) before they reach acceptance. Perhaps a stressful event in which they have a Harm/Loss Appraisal has a similar psychological response as the loss of a loved one. Also, Schweiger et al. (1987) details effective and ineffective actions which managers can take when employees feel that major losses in their work life are beyond their control. These same management responses fit nicely into the model this research has developed. 
The model on coping with change, developed and researched extensively by Lazarus and Folkman (1985), can be 1 inked quite nicely to the model verified by this research. In fact, part of this researcher's model was based upon the extensive work performed by Lazarus and Folkman. They have worked in concert with other researchers' and have published at least a half a dozen articles on research with different groups of individuals, in different environments, which the author has reviewed. All of their findings on individual's coping mechanisms, when dealing with change, would link nicely with this research model.

Likewise, the model verified by this research may be linked to other change models, proposed responses to change, proposals on how to manage change, or various other research aspects of change. This model can lead to rich opportunities to Iink change to many other researchers' efforts on analyzing change.

\section{THE MODEL DEPICTS A SYSTEM}

The model analyzed by this research constitutes a system. As a system it is possible to perform further research to understand the functioning of the system both from holistic and wholistic viewpoints. That is, it is possible to analyze the internal relationships of the system and understand how the system functions internally, 
and also to analyze the system within the context of its environment and how the system interacts with its environment. Thus, further research into the internal and external relationships and workings of the model can help develop methodologies for being able to interpret, measure, predict, analyze, and evaluate organizational change. The capabilities of systems science can be applied to the model to make it a powerful tool for the researcher and business practitioner. For example, among systems scientists there is a methodology called interpretive structural modeling (ISM) which can be applied to this model, which will allow analysis to be made of the relationships and effects of the model. The principles and applications of ISM have been amply described by such researchers as warfield (1976), Malone (1975), and Lendaris (1978). Warfield and his associates have even developed a computerized tool to facilitate the ISM methodology.

\section{IMPLICATIONS OF DEMOGRAPHIC DATA}

A review of Table XXIV in Chapter IV reveals that there were statistically significant differences in the responses to the reactions to the impending change brought about by the prospect of the introduction of PCs into the organization. In particular the significant differences occurred by gender, by those computer professionals who had a PC at home, by education level, and by salary level. 
There was not a significant difference for those who had access to a PC at work or not, by aqe, or by years of work experience.

The data given in Chapter IV indicates women felt less threatened by the introduction of PCs than men. Also, those who have computers at home appear to be less threatened by the introduction of PCs. Furthermore, those of a higher education level appear to be less threatened by PCs. Finally, those who have higher salary levels appear to be less threatened by PCs. An Information Systems Manager who is about to introduce PCs into an orqanization could have giver classes to comfort those with the highest tendency toward the Threat Appraisal, and could have invited only males, without a computer at home, with lower education levels, and lower pay levels, and would have had a high concentration of those computer professionals who needed such a class.

An interesting implication of the data also indicates that age was not a factor in someone having or not having $\exists$ threat appraisal. It has been generally assumed by the popular press that older people have a harder time adjusting to changes in the computer field. Yet this study shows that there is independence between the appraisals made by computer professionals in these organizations and the aqe factor. Perhaps the popular press has overplayed the aqe factor. Maybe a more important factor in 
acceptance of the computer is really whether someone is familiar with a touch keyboard or not. The author's own experience is that those people who are familiar with touch typing are less resistant to accepting computer terminals and PCs than those who are not touch typists. The author has seen very few secretaries who have been afraid of learning the wordprocessing capability of PCs, regardless of their age. On the other hand, the author has seen several managers and vice presidents (who are generally older) who were unfamiliar with keyboards, and who were very apprehensive about having PCs put in their office for fear their secretaries would show them up in the ability to learn to use PCs. However, managers and vice presidents who were touch typists seemed to be more eager to get their own PC and their only apprehension was how to get the budget to pay for it.

The finding that women computer professionals appear to be less threatened by the introduction of PCs into the organization than men is an interesting area for speculation and possible future research. Could it be that women in general are less threatened by new technology than men? Could it be that as long as the new technology has a keyboard, that women find it less threatening? As noted above the author has found secretaries more ready to accept PCs than vice presidents (who are almost always male). Or, could it be that the women computer professionals are of 
such a nature that they do not feel as threatened by new technology?

The author has observed for some time the industrious capabilities exhibited in the workplace by female computer professionals, and has formed his own opinion on the matter. Table XVI yields part of the first clue. It is observed that in the survey there were 140 male respondents and 54 female respondents. That yields a preponderance of over two and a half times as many men as women who are computer professionals. In our culture the areas of science and technology have long been dominated by males, with females only recently starting to enter into fields such as computers and medicine in significant numbers. The female computer professionals who the author has come in contact with have generally exhibited two traits which set them apart in his opinion. First, they seem to be more adventurous, less intimidated by conventional thinking, and willing to take on new challenges than the general population. These are probably traits which enabled them to be able to cope with male dominated classes in school, and male domination in their chosen occupation. second, they are generally very good team players in the workforce, and while they have personal ambition and desire for advancement, they outwardly exhibit less fear about the ir career and seem to be willing to "keep their nose to the 
grindstone" and are less upset with organizational disturbances which are going on around them. If these observed traits are generally correct, then it is understandable that female computer professionals would feel less threatened than their male counterparts by the introduction of PCs. The author bases his observations on his years of experience which included eleven years in an IOU managing a department of around three hundred people, which had over a hundred computer professionals, in which there were about thirty-five female computer professionals. There were around a hundred other females in the department who were not computer professionals.

\section{SUMMARY OF IMPLICATIONS}

This model has provided a tool with which the steps and stages of psychological reactions can be graphically represented, and a good beginning can be made to understand the relationships which occur during the change process. Much more work needs to be made to further analyze and validate the model for other groups of individuals in other environments, but there is nothing to indicate that the model is limited to the situation examined in the quasi-experiment provided in this research. It is believed that the model is general in nature and has wide application. Also, that the model can be linked to many other change models, tools, and apparatuses, which would 
make it an even more useful tool and broadens its application. Furthermore, the model depicts a system which can be analyzed using the methodologies of the systems scientist, and thus can be used to analyze, predict, measure, interpret, and evaluate organizational change. 
American Heart Association, Risk Factors and Coronary Disease, New York, 1968.

Argote, L., Goodman, P..S., and Schkade, D., "The Human side of Robotics: How Workers React to a Robot." Sloan Management Review, Vol. 24, Issue 3, 1983, pp. 31-41.

Argyris, C. Interpersonal competence and organizational Effectiveness, Homewood, Illinois: Richard D. Irwin, Inc., 1962 .

Brayfield, A., and Rothe, H., "An Index of Job Satisfaction," Journal of Applied Psychology, 1951, no. 35 , pp. 307-311.

Caplan, R. D., "Organizational Stress and Individual Strain: A Social Psychological study of Risk Factors in Coronary Heart Disease Among Administrators, Engineers, and Scientists." Ann Arbor: University of Michigan, Institute for Social Research, 1971.

Chapman, J. M., Reeder, L. G., et al. "Relationships of Stress, Tranquilizers and Serum Cholesterol Levels in a Sample Population Under study for Coronary Heart Disease." American Journal of Epidemiology." Vol. $83, \mathrm{pg} .537,1966$.

Chin, Robert, and Benne, Kenneth D., "General Strategies for Effecting Changes in Human Systems." from The Planning of Change, edited by Bennis, Benne, and Chin, Copyright, 1969 Holt, Rinehart and Winston, Inc.

Crowne, D. P., and Marlowe, D., The Approval Motive, New York: Wiley, 1964.

Doan, Shimon, and Tziner, Aharon, "Implementing Computer-Based Automation in the office: A study of Experienced Stress." Journal of organizational Behavior, Vol. 9, 1988 pp. 183-187.

Etzioni, Amitai, A Comparative Analysis of Complex organizations, New York: The Free Press, 1961. 
Folkman, S., Lazarus, R. S., Gruen, R. J., and Delongis, A., "Appraisal, Coping, Health Status, and Psychological symptoms." Journal of Personality and Social

Psychology, Vol. 50, No. 3, 1986, pp. 571-579.

Forcht, Karen A., Kulonda, Dennis J., and Moates, william H. Jr., "Emerging Roles of the MIS Professional: Technocrat or Change Agent?" Journal of Systems Management, v. 38, n.11, November, 1987, pp. 10-17.

French, J.R. R. Jr., and Caplan, R. D., "Organizational Stress and Individual strain." In A. J. Marrow (Ed.), The Failure of Success, New York: AMACOM, 1972 .

Gerbing, David W., and Hunter, John E., ITAN, Portland state University: Portland, Oregon, Auqust 29, 1988.

a

Goldberg, D. P., The Detection of Psychiatric Illness by Questionnaire, oxford: oxford University Press, 1972 .

Goldberg, D. P., "Manual for the General Health Questionnaire." Windsor, U.K.: National Foundation Eor Educational Research, 1978 .

Golembiewski, Robert R., "Social Desirability and Change in Organizations: Some Surprising Results and Conceptual Musings." Review of Business and Economic Research, Vol. 18, No. 3, Spring 1983, pp. 9-20.

Gutek, B. A., "Effects of 'Office of the Future' Technology on Users: Results of a Longitudinal Field Study." In G. Mensch \& J. Niehaus (Eds), Work, Organizations and Technological Change, New York: Plenum, 1982.

Ivancevich, John M., Schweiger, David M., and Power, Frank R., "Strategies for Managing Human Resources During Mergers and Acquisitions." Human Resource Planning. Vol. 10, No.1, 1987, pp. 19-35.

Johnson, T., and Graen, G. "Organizational Assimilation and Role Rejection." organizational Behavior and Human Performance, 1973, no. 10, pp. 72-87.

Kanter, Rozabeth Moss, The Change Masters: Innovations for productivity in the American Corporation, New York: Simon and Schuster, 1983. 
Kraut, A., "The study of Role Conflicts and Their Relationships to Job Satisfaction, Tension, and Performance." (Doctoral dissertation, University of Michigan, 1965), Dissertation Abstracts, 1965, no. 26, 7476 .

Kubler-Ross, Elisabeth, On Death and Dying, New York, Macmillian Press, 1969.

Lazarus, R. S., and Folkman, S., Stress, Appraisal, and Coping, New York: Springer, 1985.

Leinfuss, Emily, "Technical Support Shifts to Consultative Role." MIS Week, September 11, 1989, p. 29.

Lendaris, George, G., "Appendix B: Interpretive structural Modeling," The Use of Structural Modeling for Technology Assessment, Vol. 2. Portland state University, Systems Science, 1978.

Lendaris, George G., "On Systemness and the Problem Solver: Tutorial Comments." IEEE Transactions on SYSTEMS, MAN, AND CYBERNETICS, Volume SMC-14, no 4, pg 604, July/Auqust, 1986

Likert, R., The Human Organization: Its Management and Value, New York: McGraw-Hill Book Company, 1967.

Lipman, Ronald S., Karl Rickles, Lino Covi, Leonard R. Derogatis, and E. H. Uhlenhuth, "Factors of Symptom Distress: Doctor Ratings of Anxious Neurotic Outpatients." Archives of General Psychiatry, Vol. 21. pp 328-338, september, 1969 .

Majchrzak, Ann, and Cotton, John, "A Longitudinal study of Adjustment to Technological Change: From Mass to Computer-Automated Batch Production." Journal of Occupational Psychology (UK), Vol:61, Issue 1, March, 1988 .

Malone, D., "An Introduction to the Application of Interpretive Structural Modeling," Chapter 14, Baldwin, Ed., Portraits of Complexity, Batelle Memorial Institute, Columbus, Ohio, Monograph No. 9, 1975.

Martin, Robin, and wall, Toby D., "Attentional Demand and Cost Responsibility as stressors in Shopfloor Jobs." Academy of Management Journal, Vol. 32, No. 1, 1989, pp. $69-86$. 
McGregor, Douglas M., Leadership and Motivation, Cambridge, Massachusetts: The M.I.T. Press, 1968.

McLaughlin, Mark, "The Executive of the 2lst Century: A Change of Mind." New England Business, Vol: 11, Issue 4, April, 1989, pp. 42-53.

Morrison, David E., "Making Change User-Friendly: Managing the Impact of Technology on People." Informai: on Executive, Summer, 1988, pp. 36-39.

Nunnally, Jum C., Introduction to statistics for Psychology and Education, pp 285-290, McGraw-Hill Inc., 1975.

Parloff, M. B., Kelman, H. C.., and Frank, J. D., "Comfort, Effectiveness and Self-Awareness as Criteria for Improvement in Psychotherapy." American Journal of Psychiatry, no. 111, November, 1954, pp. 343-352.

Perlin, L.I., and Schooler, C. "The structure of Coping." Journal of Health and Social Behavior, Vol. 19, pp. $2-21,1978$.

Rizzo, J., House, R., and Lirtzman, S., "Role Conflict and Ambiguity in Complex organizations." Administrative Science Quarterly, 1970, no. 15, pp. 150-163.

Rosenberg, M., Society and the Adolescent Self-Image, Princeton, New Jersey, Princeton University Press, 1965 .

Rotter, J.B. "Interpersonal Trust, Trustworthiness, and Gullibility." American Psychologist, Vol. 35, pp. $1-7,1980$.

Scanlong, Peter R., "View From the Front Line of the Information systems Revolution." Directors \& Boards, v. 11, n.4, summer, 1987, pp. 34-35.

Schar, M. Reeder, L. G., and Dirken, J. M., "Stress and Cardiovascular Health: An International Cooperative Study - II, The Male Population of a Factory at Zurich." Sociology, Science and Medicine, Vol.7, 1973, pp. $585-603$.

Schweiger, David M., Ivancevich, John M., and Power, Frank R., "Executive Actions for Managing Human Resources Before and After Acquisition." Academy of Management EXECUTIVE, Vol. 1, No. 2, 1987, pp. 127-138. 
Toffler, Alvin, Future Shock, New York: Random House, 1970.

Warr, P. B., Cook, J. D., and Wall, T. D., "Scales for the Measurement of Some Work Attitudes and Aspects of Psychological Well Being." Journal of Occupational Psychology, 1979, no. 52, pp. 129-148.

Warr, P.B., Work, Unemployment and Mental Health, oxford: Oxford University Press, 1987.

Warfield, J.N., "Interpretive Structural Modeling," Chapter 14, Societal Systems, Hiley, 1976.

Winkler, Connie, "Battling for New Roles." Dataination, v. 32, n. 20 , October 15,1986 , pp. 82-88. 
APPENDIX A

ORIGINAL SET OF SCALES AND ITEMS FROM WHICH QUESTIONNAIRE WAS MADE 
APPENDIX A

\begin{abstract}
ORIGINAL SET OF SCALES \& ITEMS FROM WHICH QUESTIONNAIRE WAS MADE

Please answer these questions on a scale of from 1 to 5 with the following ranking: 1. Always true. 2. Often true. 3. Sometimes true. 4. Seldom True. 5. Never True.
\end{abstract}

BENIGN-POSITIVE APPRAISAL (Level A)

\title{
Enthusiasm Scale
}

$>1$. This week my job made me feel keen.

$>2$. This week my job made me feel lively.

> 3. This week my job made me feel enthusiastic.

4. This week my job made me feel stimulated.

5. This week my job made me feel excited.

6. This week my job made me feel invigorated.

7. This week my job made me feel energetic. Questions 1 to 3 from Martin \& Wall. (36)

$>$ This question was eliminated after analysis because of lack of contribution to the value of Cronbach's alpha. 


\section{Contentment scale}

1. This week my job made me feel calm.

$>2$. This week my job made me feel contented.

$>3$. This week my job made me feel relaxed.

$>$ 4. This week my job made me feel comfortable.

$>$ 5. This week my job made me feel pleasurable.

6. This week my job made me feel peaceful.

7. This week my job made me feel restful.

8. This week my job made me feel tranquil.

9. This week my job made me feel serene.

$$
\text { Questions } 1 \text { to } 3 \text { from by Martin \& Wall. }
$$

\section{Job Satisfaction Scale}

$>1$. This past week I felt frustrated with my job.*

$>2$. This past week I felt satisfied with my job.

3. This past week I felt interested with my job.

4. This past week I felt challenged with my job.

5, This past week I felt industrious with my job.

6. This past week I felt motivated with my job.

7. This past week I felt inspired with my job. Questions 1 to 4 EIs Martin \& Wall. (36)

* Signifies this question is to be reversed scored. 
Technology specific Self Gratification

1. I think a lot of good things will come to me because of the PCs.

2. I believe the PC will be good for the company and me.

> 3. I believe I will be able to readily learn to use PCs.

$>$ 4. This company needs to get moving soon on PCs.

5. I can haraly wait for my users to get. PCs.

6. I can hardy wait for my own PC.

IRRELEVANT APPRAISAL (Level A)

\section{Indifference scale}

1. The PC will not change my job significantly.

2. My job goes on the same, even though technology changes .

3. I do not get very excited about the prospect of PCs.

$>$ 4. PCs are just another form of computers.

5. I am indifferent when I think about PCs.

6. Five years from now computer professionals will still be doing the same basic things.

$>7$. I believe the $\mathrm{PC}$ will have an irrelevant effect on me. 
THREAT APPRAISAL (Level A)

\section{Fear Scale}

1. I feel threatened by PCs.

2. I feel my job will be threatened by PCs.

3. I fear a loss of status, position, or salary from use of PCs.

4. PCs are the single biggest threat my occupation faces.

> 5. PCs have the potential to dramatically change my job.

$>6$. The job I will be doing five years from now will be significantly different because of PCs.

7. I feel a great deal of uncertainty because of PCs.

\section{Anxiety scale}

1. A great deal of the time I have felt tense because of PCs.

2. A great deal of the time $I$ have felt frustrated because of PCs.

3. A great deal of the time I have felt anxious because of Pcs.

4. A great deal of the time I have felt concern because of PCs. 
5. A great deal of the time I have feit fearful because of PCs. Questions 1-3 from Martin \& Wall 1989. 
THREAT/COGNITIVE APPRAISAL (Level B)

\section{Self Esteem}

$>1$. I feel that I have a number of good qualities.*

2. I wish I had more respect for myself.

3. I feel I'm a person of worth, at least on an equal plane with others.*

4. I feel I do not have much to be proud of.

5. I take a positive attitude towards myself.*

6. I certainly feel useless at times.

>7. All in all, I am inclined to feel that $I$ am a failure.

> 8. I am able to do things as well as most other people.*

>9. At times I think I am no good at all.

10. On the whole, I am satisfied with myself.* From Rosenburg 1965.

\section{Subjective Stress scale - L. A. Heart Study}

1. In general, I am unusually tense or nervous.

2. There is a great amount of nervous strain connected with my daily activities, I am always under pressure.

3. At the end of day I am completely exhausted, mentally and physically. 
4. My daily activities are extremely trying and stressful.

From American Heart Association (1968).

\section{Mastery}

1. I have little control over the things that happen to me.

2. There is really no way I can solve some of the problems I have.

3. There is little I can do to change many of the important things in my life.

4. I often feel helpless in dealing with the problems of $l$ ife.

5. Sometimes I feel that I'm being pushed around in life.

$>6$. What happens to me in the future mostly depends on me. *

> 7. I can do just about anything I really set my mind to do.*

From Folkman, Lazarus, Gruen, \& DeLongis 1986. 
Interpersonal Trust

1. In dealing with strangers one is better off to be cautious until they provide evidence that they are trustworthy.

2. Most people can be counted on to do what they say they will do.*

$>3$. The Human Resources Department is a place where we all get unbiased treatment.*

4. It is safe to believe that in spite of what people say, most people are primarily interested in their own welfare.

$>5$. Most people would be horrified if they knew how much news that the public hears is distorted.

6. In these competitive times, one has to be alert or someone is likely to take advantage of you.

7. Most salespeople in this company are honest in describing their products.*

From Folkman, Lazarus, Gruen, \& DeLongis 1986.

\section{Somatic symptoms}

1. I get a soreness in my muscles.

$>2$. I feel my heart pounding or racing.

3. I get a weakness in parts of my body.

4. I get pains in my heart or chest.

5. I get pains in the lower part of my back. 
6. I have trouble getting to sleep or staying asleep. From Parloff et al. 1954.

\section{Performance Difficulty}

1. I am able to work under a great deal of pressure.*

2. I feel inferior to others.

> 3. I have to do things very slowly in order to be sure I am doing them well.

4. I have trouble concentrating.

5. I have difficulty remembering things.

6. I have difficulty in making decisions.

From Parloff et al. 1954. 
HARM/LOSS APPRAISAL (LeVEI C)

\section{Depression}

>1. A great deal of the time I have felt miserable because of PCs.

2. A great deal of the time I have felt depressed because of PCs.

3. A great deal of the time I have felt gloomy because of PCs.

4. A great deal of the time I have felt grim because of PCs.

$>$ 5. A great deal of the time I have felt grumpy because of PCs.

6. A great deal of the time I have felt discontented because of PCs.

>7. A great deal of the time people ask too much of me. (since we started using PCs)

> 8. A great deal of the time I feel blocked or stymied. (since we started using PCs)

9. A great deal of the time I feel others do not understand me. (since we started using PCs)

10. A great deal of the time I feel hopeless about the future. (since we started using PCs) Questions 1-3 from Martin \& Wall 1989. Questions 7-10 from Parloff, et al. 1954. 
5. I have reached the point of accepting PCs in the rorkplace.

>6. I feel comfortable with PCs.

>7. I am satisfied with the way PCs are being used in the company.

$>$ 8. Now that my users are using PCs, they are more satisfied with the computer department.

ChaLLENGE APPRAisal (Level C)

\section{Challenge}

1. I feel that the new technology will provide exciting challenges.

2. I am really challenged by the new technology we have.

3. I feel the challenge of the new technology will provide opportunities.

4. The new technologies we have are making this a more interesting place to work.

5. The new technologies are like a breath of fresh air and invigorate me.

$>6$. With the new technology my job is every bit as important as it has ever been. 


\section{Resentment}

1. I feel I get a raw deal out of life.

$>2$. Other people always seem to get the breaks.

3. When I look back on what's happened to me, I feel resentful.

4. I guess you could say I feel bitter about things.

5. I feel aggravated about what's happened to me. Questions 1-3 from Parlofe et al. 1954.

\section{Satisfaction with Company}

$>$ 1. Everything usually works out for the best.

2. All things considered, this company runs pretty well.

3. At this company, loyal employees are taken care of.

4. I like the organization I am in.

5. I get along pretty well with the supervision and management of this company.

6. I am satisfied vith this company.

\section{Acceptance}

1. Now that they are installed I believe that PCs have been good for the company.

2. PCs are not so bad.

3. I have come to like using PCs.

$>$ 4. My users are more satisfied now that they have PCs. 
$>7$. With the new technology I will be able to show how important I am to this organization.

$>$ 8. With the new technology this company will not be able to get along without me, or people like me.

\section{Enthusiasm}

>1. This week my job made me feel keen.

$>2$. This week my job made me feel lively.

> 3. This week my job made me feel enthusiastic.

4. This week my job made me feel stimulated.

5. This week my job made me feel excited.

6. This week my job made me feel invigorated.

7. This week my job made me feel energetic. Questions 1 to 3 from Martin \& Wall 1989. 


\section{Contentment}

1. This week my job made me feel calm.

$>2$. This week my job made me feel contented.

> 3. This week my job made me feel relaxed.

> 4. This week my job made me feel comfortable.

$>$ 5. This week my job made me feel pleasurable.

6. This week my job made me feel peaceful.

7. This week my job made me feel restful.

8. This week my job made me feel tranquil.

9. This week my job made me feel serene.

Questions 1 to 3 from Martin \& Wall 1989. 
APPENDIX B

PILOT QUESTIONNAIRE 
The purpose of this questionaire is to attempt to measure the responses of computer professionals to the introduction and use of personal computers (PCs) in the rorkplace. There will not be any attempt on the part of anyone to identify individuals or to analyze individual responses. This research is oriented roward identifying responses ot groups of people and to see if various classes of responses exist among zroups of computer professionals. ilso, to see how computer proiessionals nay have responded over time to PCs when : 1 . PCs were just being considered at an organization. 2. when PCs were just starting to be user at 3. organization. 3. When PCs have become an established tool at an organization.

The research is not oriented coward naking any type of jucgment as to how rell or how poorly PCs were introduced inco the organization, but is interested in validating a nodel or the stazes of psychological responses ahich people 30 through in the process of ?Cs being integrated into the sorkplace.

The data will be collected by company since some companies are at different stages of adaptation of 3 Cs into the workplace. Some demographic information is desired to see if there are any significant groupings of answers among different sets of people.

There are no wrong answers, only inconsistent answers which can cause "noise" in the research. Please answer the questions honestly and to the best of your ability and recollection (when recollection is reguired).

Once again it should be pointed out that individuals will not be identified, and no effort will be rade to identiry individual responses or to analjze individual responses. 
3ackground information: Please mark the spot indicated with the correct answer.

I am : male__ female

I have a PC at ny home : yes_ no

I have ready access to a PC ac the workplace : yes__ no _

Wy highest level of education is :

Hign School

Two years of less of college

Between two to four years of colleze

Completed Bachelors degree

Bachelors degree plus some graduate studies

Compleced Yasters degree

Completed Ph.D. degree

My age in years is :

25 or less

becieen 26 and 35

between 36 and 45

between 46 and 55

56 or over

My years of experience in the computer field is :

5 or less

between 6 and 10

berween 11 and 15

between 16 and 20

over 21 years

My salary level is :

$\$ 20,000 /$ year ( $\$ 1666 /$ monch) or less

between $\$ 20,001$ and $\$ 30,000 /$ year ( $\$ 1660$ \& $\$ 2500 /$ mo.)

berween $\$ 30,001$ and $\$ 40,000 /$ year ( $\$ 2501$ \& $\$ 3333 / \mathrm{mo}$. )

berieen $\$ 40,001$ and $\$ 50,000 /$ year ( $\$ 3334 \& \$ 4166 / m o$.

berween $\$ 50,001$ and $\$ 60,000 /$ year ( $\$ 4167 \& \$ 5000 /$ mo.)

sóu,001/year ( $\$ 5001 /$ mo.) or more 
Please answer these questions on a scale of from 1 to 5 which is explained below. The questions are asxed rithin the context of your workplace and the introduction of the new technology associaced with personal computers (PCs). In particular, the questionaire is aimed at determining your personal perspective of the potential, or accual impact, or PCs and the change associated with tais new technology.

Indicate answers with a scale of From 1 to 5 . With the Eollowing:

1. Almost Always True. 2. Often True. 3. Somerimes True.

4. Seldom True. 5. Never True.

Part d: These questions are aimed at the time period when your company Eirst started thinking about the use oi PCs. Recall your Eeeings and thoughts which you had when your company Eirst planned on using PCs. Circle the number which best represents your mencal atcitude during a tyoical week at that time.

1. This week my job made me feel keen.

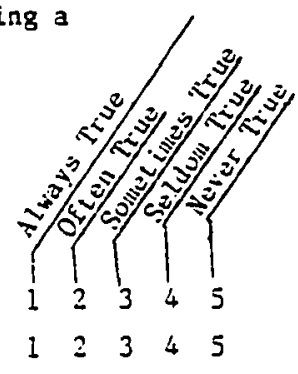

2. I feel threatened by PCs.

3. I think a lot of good things will come to me because of the PCs.

12345

4. A grear deal of the time I have feit tense because of PC.s.

$125 \quad 3 \quad 4 \quad 5$

5. This week my job made me feel calm.

$123 \quad 3 \quad 4 \quad 5$

6. The PC will not change my job signizicantly.

12345

7. This past week I felt frustrated by ay joo.

12345

8. This week my job made me feel lively.

12345

9. I feel my job will be threatened by PCs.

$123 \quad 3 \quad 4 \quad 5$

10. This past week I felt satistied with ny joo

$1 \quad 2 \quad 3 \quad 4 \quad 5$

11. A great deal of the time I have Eeit irustrated because of PCs.

12345

12. Yy job goes on the same, even though technology changes.

$123 \quad 3 \quad 4 \quad 5$

13. I believe the PC will be good for the company and me.

12345

14. This week ny job made me feel concenced.

12345 
15. This week my job made me Eeel relaxed.

12345

16. A greac deal of this time I have felc anxious because of PCs. $\begin{array}{lllll}1 & 2 & 4 & 5\end{array}$

17. I believe I will be able to readily learn to use PCs. $\quad 1 \quad 2 \quad 345$

18. I fear a loss of status, position, or salary from company use of PCs.

12345

19. I do not get very excited about the prospect of PCs. $\quad 1 \quad 2 \quad 345$

20. This past week I felt interested in ay job.

$\begin{array}{lllll}1 & 2 & 3 & 4 & 5\end{array}$

21. This week my job aade me feel enthusiastic.

$\begin{array}{llllll}1 & 2 & 3 & 4 & 5\end{array}$

22. PCs are just another form of computers.

$\begin{array}{lllll}1 & 2 & 3 & 4 & 5\end{array}$

23. This pase week I feIt challenged by tiv joo.

12345

24. This company needs to get moving soon on PCs.

$\begin{array}{lllll}1 & 2 & 3 & 4 & 5\end{array}$

25. PCs are the single biggest threat my occupation faces.

$\begin{array}{lllll}1 & 2 & 3 & 4 & 5\end{array}$

26. A zreat deal of the time I have felt concern because of PCs. $1 \begin{array}{lllll}2 & 3 & 4 & 5\end{array}$

27. This week ay job made me feel confortable.

$\begin{array}{lllll}1 & 2 & 3 & 4 & 5\end{array}$

28. This week my job nade me feel stimulated.

$\begin{array}{lllll}1 & 2 & 3 & 4 & 5\end{array}$

29. This week my job made me feel pleasurable.

$1 \quad 2 \quad 3 \quad 4 \quad 5$

30. PCs have the potential to dramatically change my joo. $\quad \begin{array}{llllll}1 & 2 & 3 & 4 & 5\end{array}$

31. I am indifferent when I think about PCs.

12345

32. I can hardly wait Eor ay users to get PCs.

$1 \quad 2 \quad 3 \quad 4 \quad 5$

33. This past week I felt industrious because of ay joo.

$\begin{array}{lllll}1 & 2 & 3 & 4 & 5\end{array}$

34. A great deal of the time I have felt fearful because of PCs. $\begin{array}{lllllll}1 & 2 & 3 & 4 & 5\end{array}$

35. This week my job aade me feel exciced.

$\begin{array}{lllll}1 & 2 & 3 & 4 & 5\end{array}$

36. This week my job made me feel invigorated.

$\begin{array}{lllll}1 & 2 & 3 & 4 & 5\end{array}$

37. This past week I felt motivated in my job.

125345

38. The job I will be doing five years from now will be significantly different because of PCs.

12345

39. This week my joo made me feel peaceful.

$125 \quad 3 \quad 4 \quad 5$

40. I can hardly wait for my own PC.

41. This past week I felt inspired by my job.

$\begin{array}{lllll}1 & 2 & 3 & 4 & 5\end{array}$

42. I feel a great deal of uncertainty because of PCs.

125345

43. This reek my job made we feel energetic.

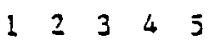

44. I believe the PC will have an irrelevant effect on me.

$\begin{array}{lllll}1 & 2 & 3 & 4 & 5\end{array}$

45. This week my job made me feel restful.

125345

40. This week ny job made se feel tranquil.

$125 \quad 3 \quad 4 \quad 5$

12345

47. This reek ay job made re feel serene.

$1 \quad 2 \quad 3 \quad 4 \quad 5$

48. Five years from now computer p.rfessionals will still be doing the same basic things.

12345

END OF PART A. 
Part B: These questions are aimed at the time period when the company was initially using PCs, both by your department and by various user departments. Recall your feelings and thougits which you had during a typical week when the company was initially using ?Cs. Circle the number which best represents your mental atcicude at that time.

1. I feel that I have a number of zood qualities.

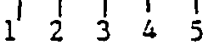

2. I have little control over the things that happen to me.

$123 \quad 3 \quad 4$ is

3. In general, I an unusually tense or nervous.

12345

4. In dealing with strangers one is betzer of $\tilde{z}$ to be cautious until they provide evidence that they are trustworthy.

12345

5. I am able to work under a grear deal of pressure.

12345

6. I get a soreness in my nuscles.

12345

7. There is really no way I can solve some of the problems I have.

8. I feel ay heart pounding or racing.

$\begin{array}{lllll}1 & 2 & 3 & 4 & 5\end{array}$

9. I wisi I had more respect for ayself.

$125 \quad 3 \quad 4 \quad 5$

12345

10. There is a great amount of nervous strain connected with ay daily activities, I am always under pressure.

12345

11. Most people can be counted on to do what they say they will do.

12. I feel inferior to others.

122345

13. I have to do things very slowly in order to be sure I an doing them well.

$1 \quad 2 \quad 3 \quad 4 \quad 5$

122345

14. I feel I'n a person of worth, at least on an equal plane with others.

12345

15. At the end of day I am completely exhausted, mentally and physically.

12345

16. There is little I can do to change zany of the important things in my life.

$\begin{array}{lllll}1 & 2 & 3 & 4 & 5\end{array}$

17. The Human Resources Department is a place where we all get unbiased treatment.

18. I get a weakness in parts of my jody.

$\begin{array}{lllll}1 & 2 & 3 & 4 & 5\end{array}$

19. My daily activities are extremely trging and stressful.

12345

12345 
PART C: These questions are ained at the current time period when PCs are commonly being used in the company. Express the thoughts and feeilings which you now have by circling the appropriate number by each question.

1. A great deal of the time I have felt miserable because of PCs.

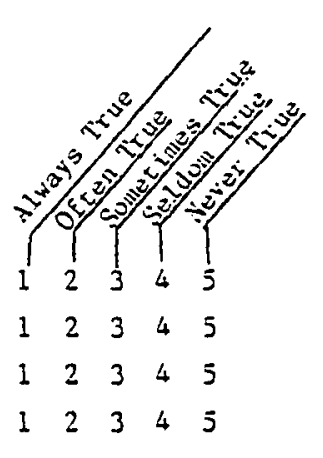

2. This week my job made me feel keen.

$\begin{array}{lllll}1 & 2 & 3 & 4 & 5\end{array}$

3. I teel I get a raw deal out of life.

$\begin{array}{lllll}1 & 2 & 3 & 4 & 5\end{array}$

4. Everything usually works our ior the best.

12345 good for the company.

12345

6. This week my job made ae ieei calm.

7. I feel that the new rechnology will provide exciting challenges.

12345

8. It greac deal of the time I have felt depressed because of PCs.

9. I am really challenged by the new tecinology we have.

10. This week ay job made re feel contented.

$123 \quad 3 \quad 4 \quad 5$

12345

$123 \quad 345$

11. PCs are noc so bad.

$\begin{array}{lllll}1 & 2 & 3 & 4 & 5\end{array}$

12. Other people always seem to get the breaks.

12345

12345

13. This week sy job made me feel lively.

12345

14. All things considered, this company zuns pretty well.

12345

15. At this company, loyal employees are taken care or.

$\begin{array}{lllll}1 & 2 & 3 & 4 & 5\end{array}$

16. This week my job rade me feel relaxed.

$\begin{array}{lllll}1 & 2 & 3 & 4 & 5\end{array}$

17. A great deal of the time I have felt gloomy because of PCs.

18. When I look back on whac's happened to me, I feel resentful.

19. I feel the challenge of the new technology will provide

$\begin{array}{lllll}1 & 2 & 3 & 4 & 5\end{array}$ opportunities for me.

12345

$\begin{array}{lllll}1 & 2 & 3 & 4 & 5\end{array}$

12345

20. I have come to like using $P C s$.

$\begin{array}{lllll}1 & 2 & 3 & 4 & 5\end{array}$

$125 \quad 3 \quad 45$

22. I like the organization $I$ am in.

$\begin{array}{lllll}1 & 2 & 3 & 4 & 5\end{array}$

23. A great deal of the time I have felt grim because or PCs.

24. The new recinology we have is making this a more interesting place to work.

12345

25. I guess you could say I Eeel bitter about things.

12345

26. This week ay job made me feel stimuiated.

12345 
27. My users are more satisfied now thar they have PCs.

$\begin{array}{lllll}1 & 2 & 3 & 4 & 5\end{array}$

28. This week my job made me feel comfirtable.

12345

29. I have reached the point of accepting PCs in the workplace. $\begin{array}{lllll}1 & 2 & 3 & 4\end{array}$

30. This week my job made me feel pleasurable. $\quad \begin{array}{lllll} & 2 & 4 & 5\end{array}$

31. This week my joo made me feel exciced. $1 \begin{array}{lllll}2 & 3 & 4\end{array}$

32. A zreat deal of the time I have felt grumpy because of PCs. 122345

33. I feel aggravated about whac's happened to me. 12345

34. I get along pretry weil with the supervision and management of this company.

12345

35. The new rechnologies are like a breach of Eresh air and invigoraze me.

$1 \quad 2 \quad 3 \quad 4 \quad 5$

36. A great deal of the time I have feit discontented because of PCs.

37. I feel comfortable with PCs.

38. I am satisfied with this company.

39. With the new rechnolozy mp job is every bic as important as it has ever been.

$\begin{array}{lllll}1 & 2 & 3 & 4 & 5\end{array}$

12345

12345

40. This week my job made ne Eeel invigorated.

$\begin{array}{lllll}7 & 2 & 3 & 4 & 5\end{array}$

$1 \quad 2 \quad 3 \quad 4 \quad 5$

$1 \quad 2 \quad 3 \quad 4 \quad 5$

41. This week ay joi made an feel peacerul.

42. A great deal of the time people ask too auci of me since we started using PCs.

$123 \quad 345$

43. With the new technology I will be able to show how important I am to this organization.

$123 \quad 345$

44. I am satisiried with the way PCs are being used in the company.

45. This week my job made me feel restiul.

46. This week iny job made re feel energeric.

47. A great deal of the time I feel blocked or stymied since we started using PCs.

48. Now that ny users are using PCs, they are more satisfied with our department.

$123 \quad 4 \quad 5$

12345

12345

12345

12345

49. With the new technology this company will not be able to get along without me, or people like ne.

$\begin{array}{lllll}1 & 2 & 3 & 4 & 5\end{array}$

50. This week ay job made ne feel tranquil.

12345

51. A great deal of the time I feei others jo not understand me since we scarced using PCs.

12345

52. This week ay joo made te feel serene.

12345

33. A great deal of the time I Eeel hopeless about the Euture since we started using PCs. 
COMENTS ?AGE (OPTIONAL)

If gou have any comments about the questionaire, or the questions themselves, which you believe might heip the researcher put cogether a jetcer (or more clearly stated) instrument for measuring attitudes/perceptions about PCs, please use this page to wake your coments. 
Note: For the company which was only at Level A, parts $B$ and $C$ of the questionnaire were omitted since those parts would have not applied to that company. Also, minor wording changes were made in the questionnaire to reflect the fact that parts $B$ and $C$ were omitted. Likewise for the two companies which were only at Level $B$, part $C$ of the questionnaire was omitted since it did not apply to those companies. Once again, it was necessary to make minor wording changes to reflect the fact that part $C$ was omitted. 
APPENDIX C

REVISED ITEMS FOR FINAL QUESTIONNAIRE 
APQENDIX C

REVISED ITEMS FOR FINAL QUESTIONNAIRE

Indicate answers with a scale of from 1 to 5 . With the following: 1. Always True. 2. Often True.

3. Sometimes True. 4. Seldom True. 5. Never True.

BENIGN-POSITIVE APPRAISAL (Leve1 A)

\section{Enthusiasm}

1. This week my job made me feel stimulated.

2. This week my job made me feel excited.

3. This week my job made me feel invigorated.

4. This week my job made me feel energetic.

\section{Contentment}

1. This week my job made me feel calm.

2. This week my job made me feel peaceful.

3. This week my job made me feel restful.

4. This week my job made me feel tranquil.

5. This week my job made me feel serene. 
Job Satisfaction

1. This past week I felt interested in my job.

2. This past week I felt challenged by my job.

3. This past week I felt industrious because of my job.

-: 4. This past week I Eelt motivated in my job.

5. This past week I felt inspired by my job.

\section{Technology Specific Self Gratification}

1. I think a lot of good things will come to me because of the PCs.

2. I believe the PC will be good for the company and me.

3. I can hardly wait for my users to get PCs.

4. I can hardly wait for my own PC.

\section{IRRELEVANT APPRAISAL (LeveI A)}

1. The PC will not change my job significantly.

2. My job goes on the same, even though technology changes.

3. I do not get very excited about the prospect of PCs.

4. I am indifferent when I think about PCs.

5. Five years from now computer professionals will still be doing the same basic things. 
THREAT APPRAISAL (Level A)

\section{Fear scale}

1. I feel threatened by PCs.

2. I feel my job will be threatened by PCs.

3. I fear a loss of status, position, or salary from company use of PCs.

4. PCs are the single biggest threat my occupation Eaces.

5. I feel a great deal of uncertainty because of PCs.

6. I feel my job will be endangered by PCs.

\section{Anxiety scale}

1. A great deal of the time I have felt tense because of PCs.

2. A great deal of the time I have felt frustrated because of PCs.

3. A great deal of the time I have felt anxious because of Pcs.

4. A great deal of the time I have felt concern because of PCs.

5. A great deal of the time I have felt fearful because of PCs. 
THREAT/COGNITIVE APPRAISAL (LeVEI B)

\section{SelE Esteem}

1. I wish I had more respect for myself.

2. I feel I'm a person of worth, at least on an equal plane with others.*

3. I feel I do not have much to be proud of.

4. I certainly feel useless at times.

5. On the whole, I am satisfied with myself.*

\section{Subjective Stress Scale - I. A. Heart Association}

1. My daily activities cause an unusual amount of tenseness or nervousness.

2. There is a great amount of nervous strain connected with my daily activities, I am always under pressure.

3. At the end of day I am completely exhausted, mentally and physically.

4. My daily activities are extremely trying and stressful.

5. A great deal of pressure and stress are part of my daily activities.

* Means this item is reverse scored 
Mastery

1. I have little control over the things that happen to $\mathrm{m} \subseteq$.

2. There is realiy no way I can solve some of the problems I have.

3. There is little I can do to change many of the important things in my life.

4. I often feel helpless in dealing with the problems of life.

5. Sometimes I feel that I'm being pushed around in life.

\section{Interpersonal Trust}

1. In dealing with strangers one is better off to be cautious until they provide evidence that they are trustworthy.

2. Most people can be counted on to do what they say they will do.*

3. It is safe to believe that in spite of what people say, most people are primarily interested in their own welfare.

4. In these competitive times, one has to be alert or someone is likely to take advantage of you.

5. Most salespeople at this company are honest in describing their products.* 
Somatic symptoms

1. I get a soreness in my muscles.

2. I get a weakness in parts of my body.

3. I get pains in my heart or chest.

4. I get pains in the lower part of my back.

5. I have trouble getting to sleep or staying asleep.

\section{Performance Difficulty}

I I am able to work under a great deal of pressure.*

2. I feel inferior to others.

3. I have trouble concentrating.

4. I have difficulty remembering things.

5. I have difficulty in making decisions.

\section{HARM/LOSS ARPRAISAL (LeVEI C)}

\section{Depression}

1. A great deal of the time I have felt gloomy because of PCs.

2. A great deal of the time I have felt grim because of PCs.

3. A great deal of the time I have felt discontented because of RCs. 
4. A great deal of the time I feel hopeless about the future since we started using PCs.

\section{Resentment}

1. I feel I get a raw deal out of life.

2. When I look back on what's happened to me, I feel resentful.

3. I guess you could say I feel bitter about things.

4. I feel aggravated about what's happened to me.

\section{Satisfaction with Company}

1. All things considered, this company runs pretty well.

2. At this company, loyal employees are taken care of.

3. I like the organization I am in.

4. I am satisfied with this company.

\section{Acceptance}

1. Now that they are installed I believe that PCs have been good for the company.

2. PCs are not so bad.

3. I have come to like using PCs.

4. I have reached the point of accepting PCs in the workplace. 


\section{CHALLENGE APPRAISAL (Level C)}

\section{Challenge}

1. I feel that the new technology will provide exciting challenges.

2. I am really challenged by the new technology we have.

3. I feel the challenge of the new technology will provide opportunities for me.

4. The new technology we have is making this a more interesting place to work.

5. The new technologies are like a breath of fresh air and invigorate me.

\section{Enthusiasm}

1. This week my job made me feel stimulated.

2. This week my job made me feel excited.

3. This week my job made me feel invigorated.

4. This week my job made me feel energetic.

\section{Contentment}

1. This week my job made me feel calm.

2. This week my job made me feel peaceful.

3. This week my job made me feel restfiz. 
4. This week my job made me feel tranguil.

5. This week my job made me feel serene. 
APPENDIX $X^{-1}$

REVISED ITEMS FOR FINAL QUESTIONNAIRE

CROSS REFERENCED WITH THE NUMBERS

FOR THE ITEMS ON THE

RILOT INSTRUMENT 
Numbering of question is the same number as it vas on the pilot instzument with new, additional questions being uithout numbers.

Chanqes to questions and ney questions are underlined for emphasis.

LEVEL_A

BENIGN-POSITIVE APPRAISAL

Enchusiasm scale

CROSS REFERENCE

FINAL INSTRUMENT

4. This week my job aace ne Eeel simulared.

5. This deek my joo made me Eeel excited.

5. This deek my job aade me Eeel invicoraced.

7 . This week my joo made ne seel enezceric.

contentment scale

1. This week my job made me feel calm.

6. This week my job made me Eeel deaceiul.

7. This week my job rade me Eeel resciul.

8. This week my job made me Eeel tranquil.

9. This week my job made me feel serene.

Jop_satisfaction scale

3. This past week I Eelt interested in ay job.

4. This past week I felt challenged by ny job.

5. This dast veek I Eelt industrious because of my job.

6. This past week I Eelt motivated in ay fob.

7. This jast week I Eelt insoired by ny job.

Technology specteic self Gratificatin scale

1. I thlnk a lot of aood things will come to me because of the PCs.

2. I believe the PC U11 be good for the company and me.

5. I can hardly vait for my users to get PCs.

6 . I can hardly valt for my own PC. 
LEVET B

THREAT/COGNITIVE APPRAISAL

Self Esteen Scale

2. I wish I had more zespect for myself.

3. I Eeel I'm a Derzon of worth, at least on an equal plane with others.*

4. I Eeel I do not have much to be proud of.

6. I certainly teel useless at times.

10. On the yhole, I am satisfied vie. zyselE.*

supjective stregs Scade_- L. A. Heart_issociation

1. My_daliy activifies gauge an unusual amount of́tenseness or nervousness.

2. There is a areat amount of nervous strain connected with my daily activities, I am always under oressure.

3. At the end of day I am completely exhausted, mentaliy and physically.

4. My daily activities are extremely trying and stressiul. A greac deal of pressuze and sezess aze gazt of my daily activities.

Magstery scale

1. I have little control over the hrinas that hadoen to me.

2. There is really no way I can solve solie of the problems I have.

3. There is little I can do to chance many of the imoortant thinas in my life.

4. I often feel heloless in dealing dith the problems of life.

5. Sometimes I feel that t'm being pushed around in life.

\section{Interpersonal Trust scale}

1. In dealing with strangers one is better off to be cautlous until they provide evidence that they are trustworthy.

2. Most people can be counted on to do what they say they yill do.*

4. It is safe to believe that in spite of uhat people say, most people are primarlly interested in their own welfare.

6. In these competitive times, one has to be alert or someone is likely to take advantage of you.

7. Most salespeople at this company are honest in describing their oroducts.*

* This item to be reversed scored 


\section{IRRELEVANT APPRAISAL}

Indifference Scale.

1. The PC will not change my job sianificantly.

2. My job goes on the same, even though technology chanqes.

3. I do not aet very excited about the prospect of PCs. I3

5. I am indifferent when I think about PCs. 19

6. Five years from now computer professionals will still be doing the 34 same basic things.

\section{THREAT APRRAISAL}

Fear Scale

1. I Eeel threatened by PCs.

2. I feel my job will be threatened by PCs.

3. I fear a loss of status, position, or salary from use of pCs.

4. PCs are a biq threat to my occupation.

7. I feel a great deal of uncertainty because of PCs. I Eeel my job will be endangered by PCs.

Anxiety Scale

1. A qreat deal of the time I have felt tense because of PCs.

2. A areat deal of the time I have felt Erustrated because of PCs.

3. A great deal of the time $I$ have Eelt anxious because of pcs.

4. A qreat deal of the time I have felt concern because of PCs.

5. A great deal of the time I have felt fearful because of PCs. . 
Somaric svmptoms scale

1. I get a soreness in my muscles.

3. I det a veakness in Darts of my body.

4. I get pains in my heart or chest.

5. I get pains in the lower part of my back.

6 . I have trouble dettina to sleep or staying asleep.

RefEormance Difficcilty scale

1. I an able to vork under a great deal of oressuze.*

2. I feel inferior to others at my vorkolace.

4. I have tzouble concentzatina.

5. I have dificiculicy rememoering thinos.

5. I have difficul=v in making decisions. 
LEVEL C

\section{HARM/LOSS APQRAISAL}

Depression Scale

3. A areat deal of the time I have felt aloomy because of PCs. 9

4. A areat deal of the time I have felt arim because of PCs. 14

6. A qreat deal of the time $I$ have felt discontented because of pcs. 22

9. A areat deal of the time I feel hopeless about the future since we 31 started usina PCs.

Resentment Scale

1. I feel I qet a ray deal out of life.

3. When I look back on what's happened to me, I feel zesenteul.

4. I auess you could say I feel bitter about things.

5. I feel aqaravated about what's happened to me.

Satistiaction vith Company scale

2. All things considered, this comoanv zuns pretty weil.

3. At this company, loyal employees are taken care of.

4. I like the organization I am in.

6. I am satisfied with this company.

Acceptance Scale

1. Now that they are installed I believe that PCs have been good for the company.

2. PCs are not so bad.

3. I have come to like using PCs.

5. I have reached the point of accepting PCs in the workplace.

\section{CHALLENGE APPRAISAL}

Challenge Scale

1. I feel that the new technology will provide exciting challenaes.

2. I am really challenged by the new technoloay we have.

3. I Eeel the challenae of the new technology vill provide opportunities.

4. The new technologies we have are making this a more interesting 15 place to vork.

5. The new rechnologies are like a breath of fresh air and invigorate 21 me. 
Enthus iasm Scale

4. This week my job made me feel stimulated.

5. This week my job made me feel excited.

6. This week my jod made me feel invicorated.

7. This week my job made me feel energetic.

Contentment scale

1. This week my job made me feel calm.

6. This week my job made me feel Deace 1 ul.

7. This week my job made me feel restful.

8. This week my joo made me feel tranquil.

9. This week my job made me feel serene. 
APPENDIX E

FINAL QUESTIONNAIRE 
The purpose of this questionaize is to attempt to measure the responses of computer professionals to the introduction and use of personal computers (PCs) in the rorkplace. There wil: not be any attempt on the part of entone to identify individuals or to analyze individual responses. This research is oriented toward identifying responses of groups of people and to see if various classes of responses exist anong zroups of computer professionais. Also, to see how computer professionals may have responded over time to PCs when : 1. PCs were just being consicered at an organization. 2. When PCs :ere just startiag to be used at an stzanization. 3. When ?Cs have becone an established 5001 at an organizacion.

The research is not orienced soward making eny type of judgment as to how rell or how poorly PCs were incroduced into the organization, but is interested in validating a nodel of the stages of psyciological responses inich people go through in the procass of PCs beiag integated into the workplace.

The data will be coliected by sompany since some companies are at different stages of adaptation of $\mathrm{CC}_{5}$ into the workplace. Some demographic information is desired to see if theze are any significant zroupings of answers among different sets of people.

There are no wrong answers, only inconsistent answers which can cause "noise" in the research. Please ensier the juestions honestly and to the best of your ability and recollection (when recollection is required).

Once again it should be pointed out that individuais will not be identified, and no effort will be sace to identiEy individual responses or to analyze individual responses. 
Background information: Please mark the spot indicated with the correct answer.

I am : male__ female

I have a PC at rny home : yes__ no

I have ready access to a PC at the workplace : yes_ no

My highest level of education is :

High School

Two years or less of college

Between two to four years of college

Complezed Bachelors degree

Bachelors degree plus some graduate studies

Completed Yasters degree

Compleced Ph.D. degree

Wy aye in years is :

25 or less

between 26 and 35

becween 36 and 45

between 46 and 55

56 or over

My years of experience in the compucer field is :

5 or less

between 6 and 10

between 11 and 15

berween 16 and 20

over 21 years

My salary level is :

$\$ 20,000 /$ year ( $\$ 1666 /$ month) or less

becween $\$ 20,001$ and $\$ 30,000 /$ Year ( $\$ 1600 t \&$ \& $\$ 2500 /$ mo.)

becween $\$ 30,001$ and $\$ 40,000 /$ year ( $\$ 2501 \& \$ 3333 / \mathrm{mo}$.)

between $\$ 40,001$ and $\$ 50,000 /$ year ( $\$ 3334 \& \$ 4160 / m o$.

becween 550,001 and $\$ 60,000 /$ year ( $\$ 4167 \& 5500 / \mathrm{mo}$ )

$\$ 60,001 /$ year ( $\$ 5001 / \mathrm{mo}$.) or nore 
Please answe: these questions on a scale of from 1 to 5 which is explained below. The questions are asked within the context of your workplace and the introduction of the new technology associated with personal computers ( $P C s$ ). In particular, the questionaire is aimed at determining your personal perspective of the potential, or actual impact, of PCs and the change associated with this new technology.

Indicate answers with a scaie of from 1 to 5 . W th the Eollowing:

1. Almost diways True. 2. Often True. 3. Sometimes True.

4. Seldom True. 5. Wever True.

Part A: These questions are aimed at the tine period when your company first started thinking about the use of PCs. Recall your teelings and thoughts which you had when your company first planned on using PCs. Circle the number which best represents your mental actitude during $a$ rypical week at that time.

1. I feel threatened by PCs.

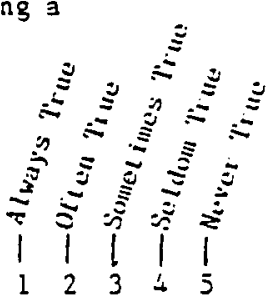

2. I think a lot of good things will come to me because of the PCs.

12345

3. A great deal of the time I have felt tense because of PCs.

$123 \div 5$

4. This week my job made ne teel caln.

$123 \div 5$

5. The PC will not change ay job significantly.

$\begin{array}{lllll}1 & 2 & 3 & 4 & 5\end{array}$

6. I feel my job will be threatened by PCs.

12345

7. A great deal of the time I have felt frustrated because

8 of PCs.

12345

9. My job goes on the same, even though technology changes.

12345

10: I believe the PC will be good for the company and re.

12345

11. A great deal of the time I have felt anxious because of PCs. 12345

12. I fear a loss of stacus, position, or salary from company use of PCs.

12345

13. I do not get very exciced about the prospect of PCs.

$123+5$

14. This past week I jelt interested in my job.

i $23-\vdots$ 
15. This past week I felt challenged by my job.

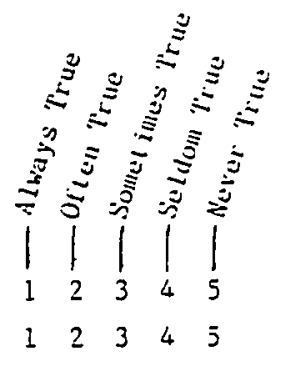

16. PCs are the single biggest threat ny occupation faces.

2345

17. A great deal of the time I have Eelt concern because of PCs. $\begin{array}{lllllll}1 & 2 & 3 & 4 & 3\end{array}$

18. This week my job made me feel stimulated. 12345

19. I an indifierent when I think about PCs. $\quad 1 \quad 2 \quad 3 \quad 4 \quad 5$

20. I can hardly wait Eor my users to zet PCs. $\quad 1 \quad 2 \quad 3 \quad 4 \quad 5$

21. This past week I felt industrious because of my job. $\quad 1 \quad 2 \quad 3 \quad 4 \quad 5$

22. A zrear deal of the time I have felt fearful because of PCs. $\begin{array}{lllll}1 & 2 & 4 & 5\end{array}$

23. This week ny job made me ieel excited. 123345

24. This week my job made ne feel invigorated. $\quad 1 \quad 2 \quad 3 \quad 4 \quad 5$

25. This past week I feIt nocivated in ny job. 12345

26. This week my joo zade re feel peacer̃ul. $\quad 1 \quad 2 \quad 345$

2i. I can hardly wait for ay own ?C. 12345

28. This past week I felt inspired by my job. 112345

29. I feel a great deal of uncertainty because of PCs. 12345

30. This week ay job wade the feel energeric. 12345

31. This week my job made me feel rescful. $\quad 1 \quad 2 \quad 345$

32. I feel my job will be endangered by PCs. 112345

33. This week my job made me Eeel serene. $123 \quad 3 \quad 45$

34. Five years from now compucer profiessionals will still be doing the same basic things.

$\begin{array}{lllll}1 & 2 & 3 & 4 & 5\end{array}$

35. This week my job made me feel tranquil.

I 2345

END OF PART A. 
Part 3: These questions are ained at the time period when the company was initially using ?Cs, both by your department and by various user departments. Recall your feelings and thoughts which you had during a tipical week when the company was initially using PCs. Circle she aumber which best represents your mental attitude at that time.

1. I have little control over the things that happen to me.

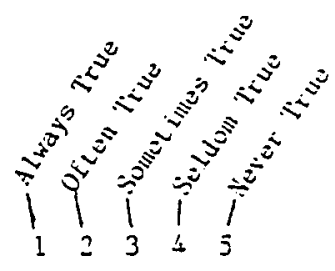

2. Yy daily activities cause an unusual amount of tenseness and nervousness

12345

3. In dealing with strangers one is better off to be cautious until they provide evidence that they are trustworthy.

4. I an able to work under a great deal of pressure.

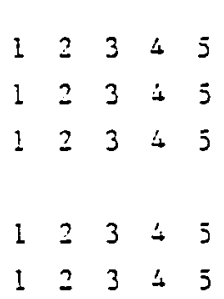

5. I get a soreness in my muscles.

6. There is really no way I can solve some of the problems I have.

7. I wish I had more respect Eor ayseiż.

12345

8. There is a zreat amount of nervous strain connected with $=\mathrm{y}$ daily activicies, I am always under pressure.

12345

9. Yost people can be counted on to do what they say they will do.

12345

10. I feel inferior to others at ay workplace.

$\begin{array}{lllll}1 & 2 & 3 & 4 & 5\end{array}$

11. I feel I'in a person of worth, at least on an equal plane with ochers.

$1 \quad 2 \quad 345$

12. It the end of day I am completely exhausted, gentally and physically.

12345

13. There is little I can do to change many of the important things in my life.

12345

14. I get a weakness in parts of my body.

12345

15. My daily activities are extremely trying and stressful.

12345

16. It is safe to believe that in spite of what people say, zost people are primarily interested in their own welfare.

17. I feel I do not have auch to be proud of.

$123 \div 5$

18. I get pains in my heart or chest.

$123+5$

19. I oiten Eeel helpless in dealing with the problems of liEe.

20. I have trouble concentracing.

? 2345

21. Sometimes I feel that I'a being pusined around in liEk.

$1 \div 3 \div 5$

$\therefore: \vdots-\vdots$ 
22. I get pains in the lower part of my back.

23. I have difficulcy remembering things.

24. I certainiy feel useless at times.

25. I have difficulty in making decisions.

26. In these competitive ímes, one has to be alert or someone is likely to take advantage of you.

27. I have crouble getting to sleep or scaying asleep.

23. Most salespeople at this company are nonest in describing their products.

29. On the whole, I am satisitied with ayselE.

30. I great deal of pressure and stress are part of ay daily activities.

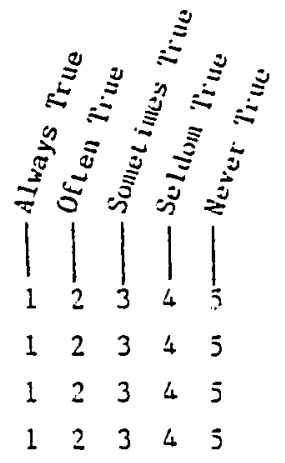

12345

12345

12345

12345

12345

END OF PART B. 
FART C: These questions are aimed ac the present time when PCs are commoni: being used in the company. Express the thoughts and Eeelings which you now have this week by circling she appropriace number by eaci question.

1. I Eeel I get a raw deal put of iife.

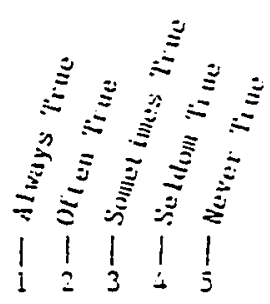

2. Now that they are inst3iled I believe that ?Cs have been good for the company.

3. This week ay job aade ze teei cai-

$123 \div 5$

$\rightarrow$ I jeel that the new tectinology dil: provide exciting challenges.

i. $2 \div 5$

5. I am really challenged jy the new zecinoiogy we have.

$123 \div 5$

o. PCs are rot so bad.

7. Ail things considered, this comoan: tuns preszy weil.

$123 \div 5$

$123 \div 5$

$125+5$

j. it this conpany, loyai emoioyees aze zaken care of́.

$123 \div 5$

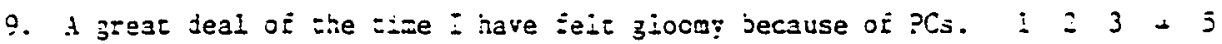

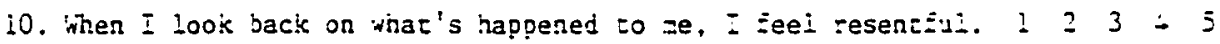

11. I teei the chailenge of the new technology ilil provide opportunities Eor we.

$123 \div 5$

i2. I have come to iike using ?Cs.

$1 \geq 3 \div 5$

13. I like the organization I em in.

$123 \div 5$

14. A great deal of the tife I have Eeit gril jecause of ?Cs.

$: 23+5$

15. The new tecinology we have is zaking tinis a more inceresting place to work.

16. I guess you could say I Eeel bizzer about zhings.

17. This week ay job made ze Eeel stimulated.

$123 \div 5$

$1=3 \div 5$

$\geq 23 \div 5$

18. I have reached the point of accepting ?Cs in the workplace.

$123+5$

19. This week jy job jade ze feel exc:=ed.

$123+5$

20. I Eeel aggravated abouc what's happened =0 ze.

$123+5$

21. The new tecinologies are like a breach of Ejesh jir and invigorate ae.

$123 \div 5$

22. I great deai of the time I have Ee: discontenced because of PCs.

23. I an satisitied with this company.

3. This week ay joo aade ge jeel invigoraced.

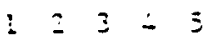

$i=3+\vdots$

$1: 3-\vdots$ 
25. This week $m y$ joi made me feel peaceful.

26. This week my job made me feel restful.

27. This week my job made me feel energeric.

29. This week my job made me feel tranquil.

2C. A great deal of the time I feel orhers do not understand me since we started using PCs.

30. This week my job made me feel serene.

31. A great deal of the time I feel hopeless about the future since we starced using PCs.

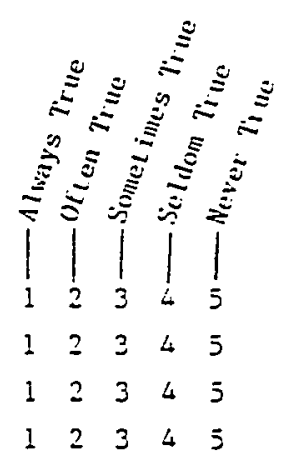

12345

12345

12345

END OF PART C: 
COMEITE FAUE (OFTTONAL)

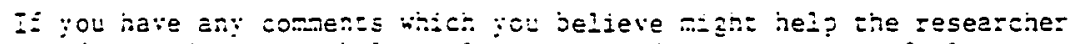
beziez understanc the psychoiogical zesponses (i.e. emotions, feelings, etc.) itich the acreat oz personal computezs has brough about, piease use this jege to make your coiments. lou car soment about gour owit personal jeelings c: aake zeneraliza:icns about compuze: prokessionals as a ciass, or any other

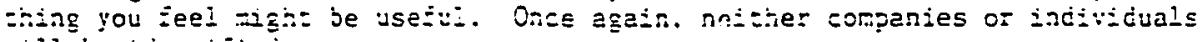
$\because: 2$ be identisiec. 